UIII norden

Biodiversity, carbon storage and
dynamics of old northern forests

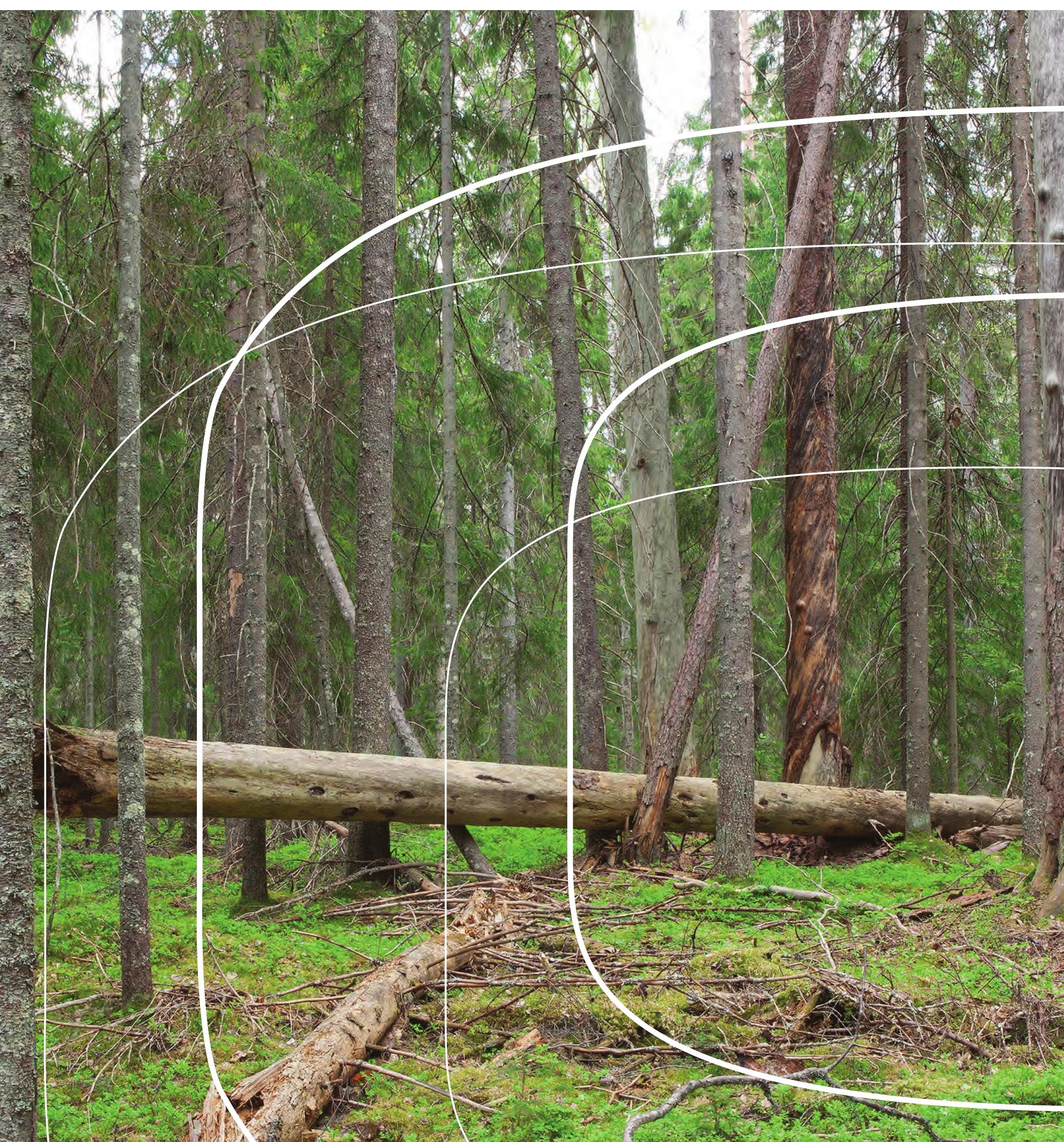



4 norden 



\section{Biodiversity, carbon storage and dynamics of old northern forests}

Erik Framstad, Heleen de Wit, Raisa Mäkipää, Markku Larjavaara, Lars Vesterdal and Erik Karltun 

Biodiversity, carbon storage and dynamics of old northern forests

Erik Framstad, Heleen de Wit, Raisa Mäkipää, Markku Larjavaara, Lars Vesterdal and Erik Karltun

ISBN 978-92-893-2510-3

http://dx.doi.org/10.6027/TN2013-507

TemaNord 2013:507

(c) Nordic Council of Ministers 2013

Layout: NMR

Cover photo: Erkki Oksanen, Metla

Print: Rosendahls-Schultz Grafisk

Copies: 130

Printed in Denmark

This publication has been published with financial support by the Nordic Council of Ministers. However, the contents of this publication do not necessarily reflect the views, policies or recommendations of the Nordic Council of Ministers.

\section{www.norden.org/en/publications}

\section{Nordic co-operation}

Nordic co-operation is one of the world's most extensive forms of regional collaboration, involving Denmark, Finland, Iceland, Norway, Sweden, and the Faroe Islands, Greenland, and Åland.

Nordic co-operation has firm traditions in politics, the economy, and culture. It plays an important role in European and international collaboration, and aims at creating a strong Nordic community in a strong Europe.

Nordic co-operation seeks to safeguard Nordic and regional interests and principles in the global community. Common Nordic values help the region solidify its position as one of the world's most innovative and competitive.

\section{Nordic Council of Ministers}

Ved Stranden 18

DK-1061 Copenhagen K

Phone (+45) 33960200

www.norden.org 


\section{Content}

Preface

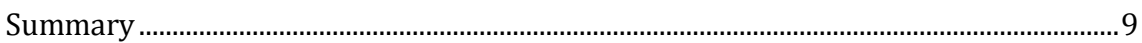

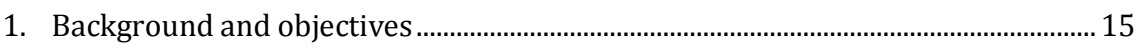

1.1 Background and knowledge gaps.................................................................. 15

1.2 Objectives ............................................................................................................. 18

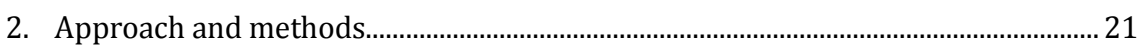

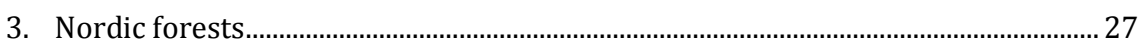

3.1 Natural dynamics of Nordic forests ........................................................... 27

3.2 Past and present human impacts on Nordic forests....................................... 33

3.3 Ecological factors and variation in forest types............................................... 39

4. Main determinants of forest biodiversity ................................................................. 45

4.1 Intact forest ecosystems and critical properties for biodiversity................. 46

4.2 Forest types or habitats of particular conservation value............................55

5. Forest carbon pools and fluxes.................................................................................. 57

5.1 Definitions of ecosystem carbon accumulation................................................57

5.2 Methods for studying forest carbon accumulation ........................................58

5.3 Driving factors of forest biomass growth ....................................................... 61

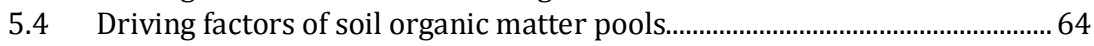

5.5 The role of northern forests in the global carbon cycle..................................6 68

5.6 Effects of forest management on forest carbon sequestration ...................... 71

5.7 Old forests - carbon sources or carbon sinks?................................................ 76

6. Old forest conservation: relevance for biodiversity and climate change

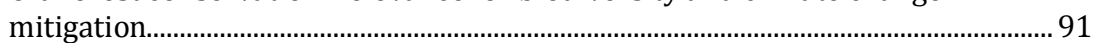

6.1 Forest carbon stocks and sequestration .......................................................... 91

6.2 Forest biodiversity and the carbon cycle......................................................... 96

6.3 Albedo and other biophysical climate impacts of forest management ...........98

6.4 Gaps in knowledge .......................................................................................100

6.5 Implications for forest policy and management.............................................102

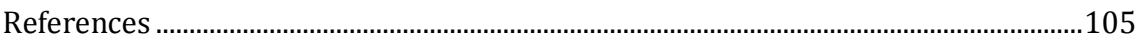

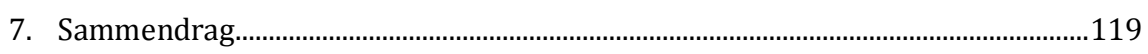

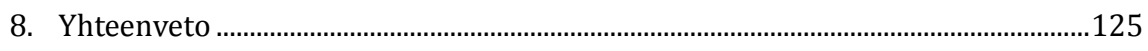

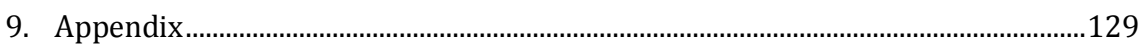

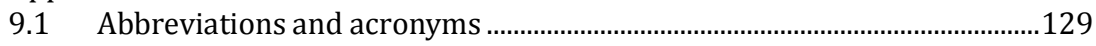

9.2 Tree species and their scientific names..........................................................129 


\section{Preface}

Forests represent important ecosystems in the Nordic countries, for biodiversity, carbon sequestration, and amenity values like outdoor recreation. The significance of old forests for maintaining forest carbon stocks has recently come into stronger focus in the discussions of climate mitigation policies. This has made it important to assess what is known about the amount and variation of carbon stocks in old and managed forests under various environmental conditions. In this report we give a scientifically based overview of the role of old forests in the carbon cycle and how carbon uptake may represent co-benefits for the well-documented value of old forests for biodiversity. Our focus has been on the variation in forest carbon stocks and uptake of $\mathrm{CO}_{2}$. We have not considered the wider climate effects of forest management, e.g., related to changes in albedo or the use of forest biomass for energy or various products. Such total system and life cycle studies would go far beyond the scope and resources available for this assessment.

The responsibilities of the writing team have been divided as follows. Erik Framstad (NINA) has drafted the text for chapters 1-4 and 6, as well as being responsible for overall editing and project management. Heleen de Wit (NIVA) has drafted the text for chapter 5, except sections 5.3 and 5.6 which were drafted by Markku Larjavaara and Raisa Mäkipää (Metla), respectively. Lars Vesterdal (Skov og landskab, University of Copenhagen) and Erik Karltun (SLU) have contributed with input of studies, data, and text to various parts of the report.

The work involved in producing this report has been supported by the Terrestrial Ecosystems Group under the Nordic Council of Ministers. We appreciate valuable input from colleagues in NINA to chapters 3 and 4 in particular, and contributions of photos from various colleagues (see credits per photo). We also wish to thank The Norwegian Mapping Authority, the Finnish Forest Research Institute (Metla), the Swedish University of Agricultural Sciences (SLU), The Norwegian Forest and Landscape Institute, and the Forest and Landscape Centre of the University of Copenhagen for permissions to reproduce figures 3.2 and 5.2.

Oslo, October 2012

Erik Framstad 


\section{Summary}

Forests are key terrestrial ecosystems in the global climate system, representing major components of the carbon cycle. The Nordic countries have extensive forests with large and growing tree biomass that captures substantial amounts of the greenhouse gas carbon dioxide $\left(\mathrm{CO}_{2}\right)$. Nordic forests also play a key role for biodiversity, containing a wide range of complex ecosystems which are habitats for more than half of all known native species and almost half of all threatened species in Finland, Norway, and Sweden. Forests also provide important recreational opportunities for people in the Nordic countries and supply the basis for the economically important forest sector.

\section{Aims of the report}

In this report we give a scientifically based overview of the role of old forests in the carbon cycle and how carbon uptake may represent cobenefits for the well-documented value of old forests for biodiversity. The role of old forests as components of the carbon cycle is much less studied than its role for biodiversity. Here, we synthesize recent findings on the carbon balance of old forests in the Nordic countries. By "old forests" we understand forests considerably older than their harvestable age, containing many trees approaching their natural life span.

\section{Forest development and human influence}

Nordic forests have developed after the last ice age as climate warmed and new species immigrated. Humans have used forests for a wide range of resources up through the ages, influencing forest structure and ecosystem functions. The human transformation of Nordic forests has been particularly strong in the lowlands as populations increased during the last 300 years, and in the interior and the north as modern industrial forestry developed from the end of the 1800s. Since the 1950s, management of whole forest stands, with clear-cutting, planting, and intensive silviculture, has been extensively applied and has been very successful in producing large amounts of harvestable timber while also increasing the growing stock substantially. This kind of forest management has also changed the forest landscape profoundly. 


\section{Natural forest dynamics and biodiversity}

In recent years, we have developed greater understanding of natural dynamics in boreal and temperate forests, in particular on the importance of natural disturbances in shaping forest structure and ecosystem functions. Natural forest dynamics produce key resources and processes important for the maintenance of native forest biodiversity, in particular a rich supply of dead wood and old trees, as well as a varied landscape pattern of such resources, critical for the long-term survival of many forest species. In addition to the dead wood and old trees resulting from natural forest dynamics, forest biodiversity will also benefit from productive forests with a rich supply of temperate broadleaved trees or aspens, willows and rowans, as well as special forest types like swamp forests, forests on calcareous soil, or recently burnt forests. Several forest properties of high importance for biodiversity are monitored in national forest inventories, e.g., tree species and age, dead wood, and site productivity. However, it is difficult to link environmental gradients and site factors directly to biodiversity values, and additional surveys of habitats and nature types are often necessary to identify the biodiversity value of an area. There are few studies that explicitly link forest properties of value for biodiversity with those driving high carbon stocks or sequestration rates. In general, forest areas of high value for both biodiversity and carbon stocks will be associated with old forests and productive forest sites.

\section{Old forests and the carbon cycle}

Forests play a large role in the global carbon cycle and take up 30-40\% (2.1-2.6 Pg C yr-1) of annual fossil fuel emissions. Biomass is a larger carbon sink than soils and dead wood. In boreal and temperate forests, carbon stocks in soils represent $60-85 \%$ of total forest carbon stocks. Estimates of total annual forest carbon sequestration in Finland and Norway in the past two decades are 8 and $5.6 \mathrm{Tg} \mathrm{C} \mathrm{yr}^{-1}$, respectively, or 39 and $46 \mathrm{~g} \mathrm{C} \mathrm{m}^{-2} \mathrm{yr}^{-1}$. For Sweden, forest carbon accumulation was estimated to be $7.1 \mathrm{Tg} \mathrm{C} \mathrm{yr}^{-1}$, or $31 \mathrm{~g} \mathrm{C} \mathrm{m}^{-2} \mathrm{yr}^{-1}$ between 1920 and 2000 . The soil carbon sink was estimated to circa $19-28 \%$ of the total carbon sink. Preliminary assessments for Denmark also indicate an increase in forest carbon stocks during the last decades. Forests in Fennoscandia represent about $1 \%$ of the global forest carbon sink. There are insufficient data to assess the contribution of old forests to the total carbon sink in Fennoscandia.

Old forests were previously thought to be carbon neutral because maintenance (loss of carbon) would equal production (uptake of carbon) and thus evolve towards equilibrium with the atmosphere with increasing forest age. It has also been assumed that old forests would turn into sources of atmospheric carbon due to increased mortality of old trees damaged by external disturbances like fires, storms, or insects. However, evidence is accumulating that forests serve as carbon sinks far beyond normal harvest- 
ing age. A few eddy covariance studies of old ( $>200$ yrs) temperate forests in North America indicate ecosystem carbon accumulation rates of about $150-500 \mathrm{~g} \mathrm{C} \mathrm{m}^{-2} \mathrm{yr}^{-1}$. Repeated sampling of soil carbon in a temperate beech forest ( $250 \mathrm{yrs}$ ) and a boreal spruce forest ( $90 \mathrm{yrs}$ ), both unmanaged, indicates soil carbon accumulation rates of $60-160 \mathrm{~g} \mathrm{C} \mathrm{m}^{-2} \mathrm{yr}^{-1}$. Indirect evidence from several chronosequence studies indicates ecosystem carbon accumulation rates of about 4.5-170 $\mathrm{g} \mathrm{C} \mathrm{m}^{-2} \mathrm{yr}^{-1}$ for forests 120 to $>200$ years old, with the lowest values for the oldest forests. Comparisons of forest stands of different ages also indicate that older forests have higher carbon stocks than younger forests. Although changes in soil or total ecosystem carbon stocks are difficult to monitor, and the various methods have their problems, the consistent direction of the results of the various studies provide convincing evidence that old forests function as carbon sinks for a long time. The carbon stocks in biomass of old forests continue to increase with age, possibly for several hundred years, although the rate of biomass accumulation and thus the carbon sink will decrease with increasing age. Also, carbon stocks of forest soil and dead organic matter (especially coarse woody debris) appear to increase with stand age.

Changes in forest biomass carbon stocks in boreal and northern temperate forests are largely determined by tree species and age of forest stands, site productivity and disturbance history. Forest soil carbon stocks are driven by site productivity and soil type (primarily driving litter production but also influencing decomposition), litter quality, and local topography and disturbance history. The relationships between external drivers and soil carbon stocks are complex, and it is therefore difficult to describe clear patterns in the response of soil carbon stocks to such drivers. Generally, variation in soil carbon stocks with environmental drivers is most pronounced for the organic layer, less so for the mineral soil and total soil carbon stocks.

\section{Effects of harvesting on carbon stocks}

Modern forest management incorporates various management measures which influence carbon stocks and fluxes. The most fundamental effect comes with the removal of biomass from the forest, directly reducing the biomass carbon stocks. Harvesting produces considerable amounts of logging residue of various sizes. Most of it will be of small dimensions and decompose rather quickly over a decade or so, but stumps represent coarse woody debris with a slow decay rate (lasting up to a century). The carbon from logging debris and natural litter production will partly be incorporated into the soil organic matter, and partly be released to the atmosphere as $\mathrm{CO}_{2}$. It is less clear how soil carbon stocks respond to the harvesting event as such. After the first rush of logging residues, little additional litter will be produced in a clear-cut stand for some decades. During the first few decades, decomposition of litter and soil organic matter will exceed production of biomass and the overall carbon stock will decline. Some studies indicate that the amount 
of soil carbon may be reduced after harvesting for several decades. Such effects of harvesting on soil carbon stocks are affected by reduced production and input of litter and coarse woody debris rather than by increased decomposition rates. Total carbon stocks in managed forests will increase with longer rotation period, less thinning and harvesting of logging debris and stumps, and management of regeneration sites to ensure rapid restocking of forest stands, such as site preparation, planting of productive species or provenances, and fertilization.

\section{Knowledge gaps}

Many studies on forest carbon and its role in the global carbon cycle have been published over the last 10-15 years, but there are still important gaps in our knowledge. Although the dynamics of tree growth and biomass carbon stocks are reasonably well understood for forests a bit older than harvestable age, such dynamics in old forest, with trees approaching their natural life span, are poorly known. In particular we have inadequate knowledge of old forest tree mortality under natural dynamics and whether gap-filling dynamics will compensate biomass loss by natural mortality agents. Another important area requiring better knowledge is the variation in soil carbon stocks with stand age, site productivity, and other environmental factors, as well as the responses of soil carbon to disturbances like biomass harvesting. A key issue to resolve is whether soil carbon stocks will accumulate indefinitely or reach some steady state in a matter of decades or centuries, depending on the forest type and climatic conditions. We also need to improve our understanding of the linkages between biodiversity structure and ecosystem functions, particularly how these interact with the carbon and nitrogen cycles and the relationships between these biogeochemical cycles. A challenging issue beyond the natural sciences is whether and how the various goods of biodiversity, carbon sequestration, timber production, recreation and other amenity values of forests may be handled and arbitrated within a common framework of ecosystem services.

\section{Policy implications}

Although the climate effects of forest management are challenging to assess realistically due to complex interactions of changes in the carbon cycle and the biophysical climate forcing of forests, as well as poorly understood substitution effects of harvested forest biomass, we can still make some recommendations for forest management in a climate perspective. As forest ecosystems continue to accumulate carbon for a long time, protection of forest carbon stocks by increasing the amount of old forest is a credible policy option that will also benefit biodiversity conservation. In managed forests, prolonged harvesting cycles will also increase forest carbon stocks. Thinning of production forest and harvesting of logging residues and stumps will decrease forest carbon stocks, whereas intensive management to ensure rapid establishment of well- 
stocked regeneration areas will increase carbon stocks. It still remains, however, to develop more complete life cycle analyses to address the sink strength of old forests or prolonged harvest rotation compared to alternative management options and systems. Such life cycle analyses can then serve as input to combined analyses of the provisioning of ecosystem services in old forests in terms of carbon sequestration, biodiversity and various amenity values.

Our understanding of effects of forest management on biodiversity is reasonably good, although there is some disagreement on how sensitive species and ecosystem functions are to various forest management actions. Overall, forest biodiversity will benefit most from extensive areas of old forests under natural dynamics, with many old and large trees, a rich and varied supply of dead wood, and long stability of substrates and microclimate. In managed forests both prolonged rotation periods, continuous cover-harvesting, and retention of old trees, dead wood and buffer zones against wetlands will benefit substantial parts of native forest biodiversity.

In the real world where forests shall fulfil several, partly conflicting policy objectives, the challenge is how forest management may be differentiated for areas with different properties of value for biodiversity, carbon sequestration or timber production, to balance these policy objectives in the best possible way. To provide more realistic analyses and models to inform such policy choices we need better knowledge of both carbon stock changes and biodiversity and their variation with environmental properties like climate, terrain, site productivity and current and previous land use. 


\section{Background and objectives}

\subsection{Background and knowledge gaps}

\section{Forests are key components of the carbon cycle and for maintaining biodiversity}

Nordic forests represent important ecosystems for biodiversity, have a significant role in the climate system due to their large carbon stocks, are important areas of recreation and other amenity values, and are the basis for the economically and socially important forest industry. Prentice et al. (2001) concluded that globally boreal forests contain vast terrestrial carbon stocks, estimated at $395-559 \mathrm{Pg} \mathrm{C},{ }^{1}$ compared to tropical and temperate forests with respectively 428-553 and 159-292 Pg C (although other authors have given lower estimates for boreal forests, e.g., Sabine et al. (2004), Fang et al. (2006)).

The Nordic countries, Finland, Norway and Sweden in particular, have extensive forest areas with large and increasing tree biomass. For instance, the annual net tree biomass increment in Norwegian forests is equivalent to almost $50 \%$ of Norway's annual carbon emissions (Haugland et al. 2011), and the figures are comparable for Sweden (Skogsstyrelsen 2011). Hence, forests are significant contributors to the national carbon balances of the Nordic countries and can have a potential role in national climate mitigation policy. According to the Kyoto protocol, countries may opt to use the carbon sinks of managed forests to compensate for the agreed reductions in their greenhouse gas emissions. However, only part of the carbon sinks resulting from forest management may be credited (UNFCCC 2001, Pohjola et al. 2004). Old forests, where growing stocks are not under active human management, may be considered as "unmanaged" and therefore neglected in this context (Schulze et al. 2002). However, individual countries may decide how they define managed forests under the UN Framework Convention on Climate Change (Freibauer 2009), and all sustainable stewardship of forests may therefore be considered management, including forest conservation (UNFCCC 2006). Recently, old forests have been identified as more important for carbon sequestration than previously thought (Luyssaert et al. 2008) and hence more relevant for consideration in climate policy. 
Forests in the Nordic countries also play a key role for biodiversity, containing a wide range of complex ecosystems providing important ecosystem functions and habitats for a large number of species. For instance, forests in Finland, Norway and Sweden are habitats for about $60 \%$ of the native species and about $45-50 \%$ of the red-listed species (Gärdenfors et al. 2010, Kålås et al. 2010, Rassi et al. 2010). Much of this species diversity is associated with old forests under natural dynamics, and various forestry operations have been identified as the main pressure on forest biodiversity.

The importance of old forests for maintaining biodiversity has long been recognized. Recent indications that old forests have large carbon stocks and still function as active carbon sinks raise the issue of possible co-benefits of old forest protection. Conservation of old forests may serve several policy objectives, i.e., both protection of biodiversity as well as climate mitigation by conserving forest carbon stocks and avoiding emissions of $\mathrm{CO}_{2}$ to the atmosphere.

\section{Key knowledge gaps}

Through photosynthesis, growing trees incorporate $\mathrm{CO}_{2}$ from the atmosphere as carbon in their biomass, in trunks, branches and roots. The amount of carbon accumulated in tree biomass increases with tree age, but the rate of carbon accumulation is highest for young forests, usually at an age of 30-70 years (depending on site productivity) for most boreal forests in Fennoscandia. Thereafter, the biomass accumulation rate decreases but may continue for the biological life span of the trees, for some species lasting several hundred years. Forest inventory data from northern Finland indicate that coniferous species maintain their slow rate of volume growth up to the oldest measured stands ( $>200$ years) (Ilvessalo \& Ilvessalo 1975). Slowly decomposing dead organic matter is accumulated in the forest ecosystem with a lag time of a few decades. Based on current models of tree growth and soil carbon dynamics, the mean annual carbon accumulation rate (i.e., the mean over all years up to the current age) in boreal forest ecosystems is assumed to reach a maximum 30-50 years after the normal rotation period for boreal forests of medium productivity (Nilsen et al. 2008). Using similar model assumptions, Haugland et al. (2011) concluded that with an optimal cutting age for timber production of 90 years, forests would accumulate carbon up to an age of 140-150 years, where forests older than 150 years would release more $\mathrm{CO}_{2}$ than they accumulate, due to assumed increased mortality of old trees. However, in a meta-analysis of a large number of studies of net ecosystem productivity in temperate and boreal forests, Luyssaert et al. (2008) found that even very old forests may accumulate carbon and act as carbon sinks. Recent studies from Sweden also indicate that forest ecosystems may continue to accumulate carbon even when aboveground biomass production declines (Wardle et al. 2012). Hence, it is a reasonable hypothesis that old forests in Fen- 
noscandia accumulate carbon far longer than currently assumed. However, we do not know whether this is a consistent pattern, we do not know the rate or how such carbon accumulation may vary between forests types and growing conditions.

The function of old forests as carbon stocks and sinks seems to be potentially important as a component of comprehensive climate policies in the Nordic countries. However, we have inadequate knowledge of the actual carbon dynamics of the carbon stocks as forests age, and for soil carbon stocks in particular. By pooling knowledge on the dynamics of carbon stocks in forests and soils from all the Nordic countries it will be possible to build a more comprehensive picture of old forest carbon dynamics under various environmental conditions.

Discussions of forest management as a climate mitigation measure have so far been mainly concerned with increased harvesting of forest biomass as a replacement for fossil energy. It is then often assumed that forest biomass is a climate-neutral energy source, as new forests will grow to replace the harvested biomass and thereby rebuild the carbon stocks. However, it has been acknowledged for some time that increased harvesting of forest biomass will temporarily lead to lower carbon stocks in forests and higher $\mathrm{CO}_{2}$ emissions (e.g., Harmon et al. 1990, Marland \& Marland 1992, Schlamadinger \& Marland 1996). With permanently increased harvesting and the typical 70-120 year harvesting cycles of boreal forests, the time for rebuilding carbon stocks may be more than 100-300 years (Haugland et al. 2011, Holtsmark 2012, Schulze et al. 2012). The timeframe for climate mitigation policy is usually much shorter, i.e. from a few decades up to the end of the current century. The calculations of effects of harvesting on carbon stocks have several uncertainties associated with the actual accumulation rate of carbon as forests age, the decomposition rate of dead wood of various dimensions, the effects of harvesting on soil carbon stocks, and the variability of carbon dynamics with site conditions and climate. Several of these uncertainties could make the time for rebuilding carbon stocks far longer than assumed in current studies.

Boreal forest soils contain about $80 \%$ of total forest carbon stocks, generally somewhat less in temperate forests (Prentice et al. 2001), including live and dead roots, freshly produced litter and soil organic matter in various stages of decomposition and humification. Responses of these components to disturbances - natural or anthropogenic - will vary and depend on climate and site conditions. Despite several decades of research on forest soil carbon dynamics, considerable uncertainty exists about the responses of forest soil carbon stocks to disturbance and climate change.

Hence, the process of incorporating sustainable forest management in climate policy is currently limited by important gaps in our knowledge about the role of forests in the carbon cycle. These gaps may be summarized as follows: 
- The role of old forests in the carbon cycle: Most estimates of the carbon dynamics in forests are based on empirical models of forest growth, adapted to modern stand-based forest management where the time horizon rarely goes past that of the harvesting cycle (70-120 years). Investigations of the ability of old forests to store carbon have therefore been limited. Little is known of the dynamics of tree mortality and recruitment, soil carbon dynamics etc in old forests.

- The importance of carbon dynamics in soils and dead biomass: The dynamics of the large carbon stocks in forest soils and dead wood, and how they respond to disturbances like harvesting are poorly known in general. The relative importance of carbon stocks in soil and dead wood is likely to be particularly great in old forests, where the accumulation of aboveground biomass tends to slow down.

- Variation in carbon stocks and uptake under various site and climate conditions: Different site conditions affect production of biomass, its decomposition and the dynamics of carbon sequestration. Better knowledge of these factors is needed for spatially differentiated forest management to accommodate balanced biodiversity conservation, climate mitigation, and forest production.

- Effects of different harvesting regimes on carbon stocks: Forest management and harvesting regimes will affect carbon stocks and uptake, as well as biophysical forest properties. Hence, it is important to clarify the effects of different harvesting regimes (e.g., clear-cut systems vs continuous cover forestry) as well as other forest management measures which mediate the climate mitigating effects of forests.

In this report our emphasis will be on the first two of these issues, i.e., the roles of old forests and soils in the carbon cycle. The variation in carbon stocks with site factors will be addressed to the extent that relevant information is available, whereas the effects of forest management will be discussed in more general terms.

\subsection{Objectives}

The main purpose of this report is to give a scientifically based overview of the role of old forests in the carbon cycle and how this may represent a co-benefit for the well-documented importance of old forests for biodiversity. The role of old forests in a climate perspective, more specifically, as a sink for atmospheric carbon, is much less studied. Hence, we synthesize recent findings on the carbon storage in old forest for forest types that are found in the Nordic countries.

More specifically, the objectives of this report are:

- To give an overview of forests in the Nordic countries, their natural dynamics, human impacts and ecological variation 
- To describe the main determinants of forest biodiversity related to forests under natural dynamics

- To describe the main drivers of soil carbon accumulation

- To evaluate effects of forest management on forest carbon sequestration

- To present current knowledge on carbon storage and dynamics in old forests, including biomass, coarse woody debris and soils

- To give an overview of forest conservation measures and their relevance for biodiversity and climate mitigation

This is a highly relevant issue for all Nordic countries and will help in the design of relevant climate policies directed towards forest management and the use of forest-based bioenergy. Improved knowledge on the role of old forests in the climate system will also have considerable European and global relevance, as forest management is widely considered as part of climate mitigation policies.

Old pines in the Trillemarka Nature Reserve, Buskerud county, SE Norway

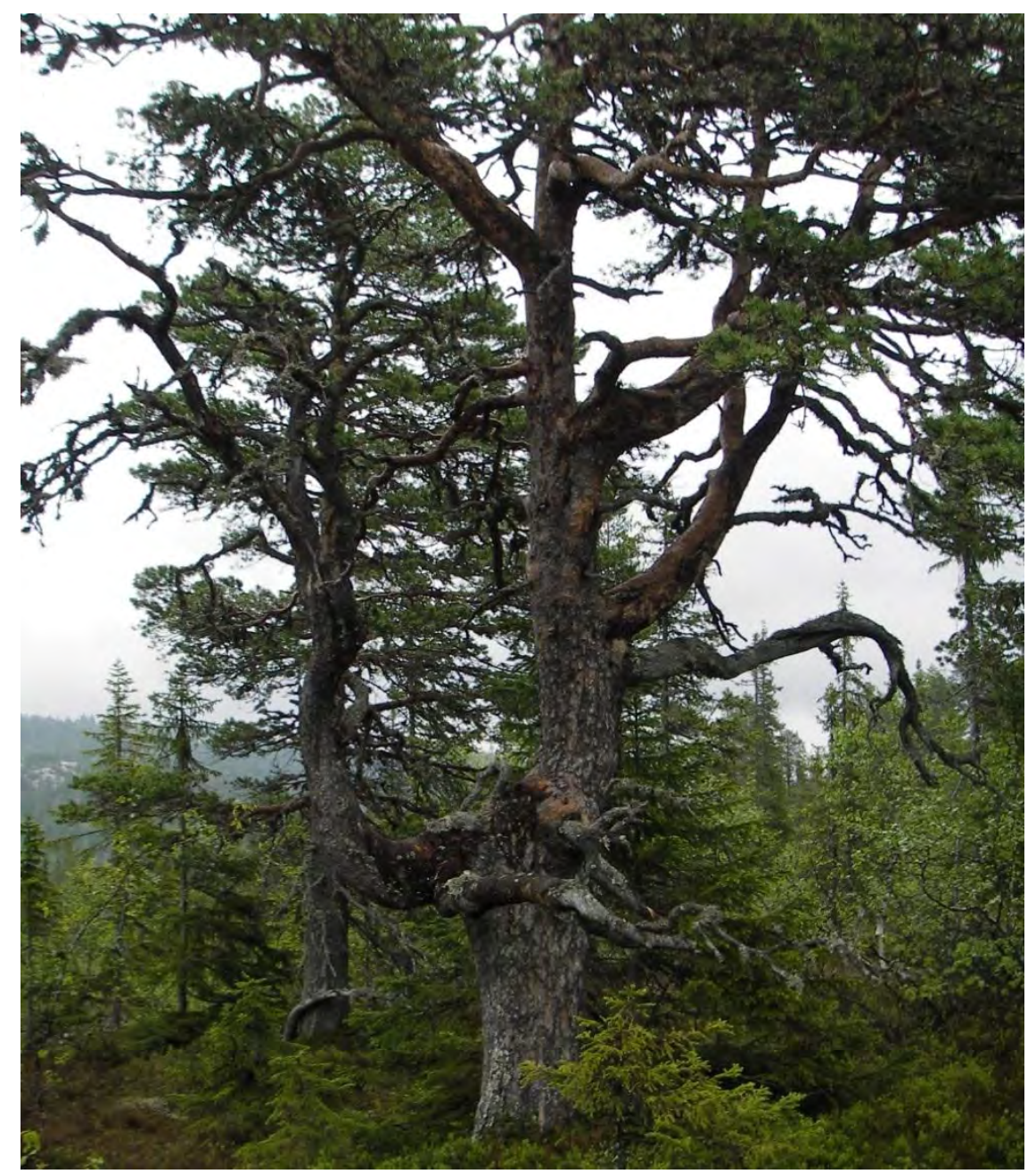

Photo: Erik Framstad, NINA. 


\section{Approach and methods}

In this report we are primarily concerned with boreal and northern temperate (or nemoral) forests in Denmark, Finland, Norway, and Sweden. It follows that we have to a great extent drawn on studies performed on such forests in these countries or in nearby areas in northern Europe, northwest Russia or the Baltic states. However, we have also included relevant studies from other boreal or temperate forest areas, such as North America. Some wider studies, synthesizing information from a range of forest types, have also been consulted to set the results from boreal and temperate forests into perspective.

Our approach in this report on carbon storage and fluxes in boreal and northern temperate forests is to review the results from existing published studies. We have not conducted any representative literature search. The relevant studies have been identified on the basis of the individual expertise and knowledge of the literature among the consortium members. Publications have mainly been drawn from the international scientific literature, but relevant studies published in national reports and other sources have also been included, particularly those from the countries covered by this report. In addition, the consortium members have drawn on their extensive experience on the topics covered. It has not been the ambition of this project, nor the resources available, to conduct any new analyses of data or modelling to extend or verify the results reported by the various studies referred to in this report.

For the purpose of this report we may use the term the Nordic countries as shorthand for Denmark, Finland, Norway, and Sweden when we refer to these countries collectively, although Greenland, Iceland, and the Faroe Islands are not covered by this report. We may also use the term Fennoscandia when we refer to Finland, Norway and Sweden as a collective geographic entity.

Although the term forest is apparently readily understood by most people, it may convey different meanings depending on tradition and circumstances. Here we keep to the common operational definition of forests as used internationally and nationally: A forest is a land area of at least 0.5 ha, with a tree crown cover of more than $10 \%$, where the trees should be able to reach a height of at least $5 \mathrm{~m}$ at maturity (Box 1). We otherwise do not distinguish in concept between the terms forest and woodland. In Fennoscandia, forest land is often subdivided into productive and unproductive forests.

In this report we will refer to the concepts of natural forest and old or old-growth forest, more or less linked to concepts of virgin or pristine for- 
ests (Box 2). As truly pristine or old-growth forest (i.e., with minimal past human influence) is very rare in all the Nordic countries, we will rather focus on old forests characterized by structural features typical of forests under natural dynamics (cf chapter 3.1). Such natural old forests may take several centuries to develop after natural or anthropogenic standreplacing disturbances. In several of the studies covered by this report, the age of and human impact on what is called old forest may vary considerably. Where authors (mainly from North America) have referred to their old forests as old-growth we have kept this terminology.

To enhance readability we will refer to common tree species by their common English names or the short versions of these (pine for Scots pine, spruce for Norway spruce etc). Unless otherwise stated, short names refer to the common northern European species. Full English and scientific names are given in Appendix 2. Abbreviations and acronyms are given in Appendix 1.

\section{Mixed boreonemoral forest in the Vemannsås Nature Reserve, Vestfold county,} SE Norway

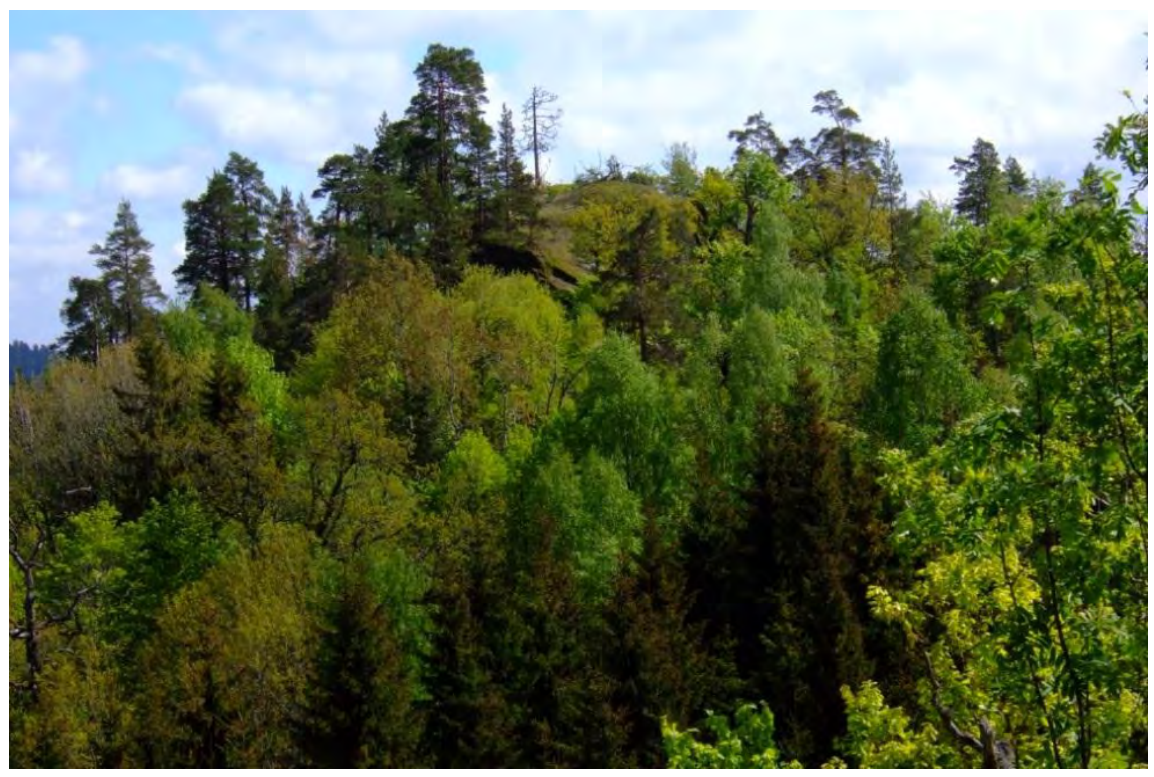

Photo: Anne Sverdrup-Thygeson, NINA. 


\section{Box 1: Forest definitions}

\section{FAO definitions (http://www.fao.org/forestry/fra/2005/terms/en/)}

Forest: Land with tree crown cover (or equivalent stocking level) of more than $10 \%$ and area of more than 0.5 hectares (ha). Trees should be able to reach a minimum height of 5 meters $(\mathrm{m})$ at maturity in situ. Young natural stands and all plantations established for forestry purposes which have yet to reach a crown density of $10 \%$ or tree height of $5 \mathrm{~m}$ are included, as are areas normally forming part of the forest area which are temporarily unstocked as a result of human intervention or natural causes but which are expected to revert to forest. The forest definition includes forest nurseries and seed orchards that constitute an integral part of the forest; forest roads, cleared tracts, firebreaks and other small open areas; forest in national parks, nature reserves and other protected areas such as those of specific scientific, historical, cultural or spiritual interest; windbreaks and shelterbelts of trees with an area of more than 0.5 ha and width of more than $20 \mathrm{~m}$; plantations primarily used for forestry purposes, including rubberwood plantations and cork oak stands. It excludes land predominantly used for agricultural practices.

Other wooded land: Land either with a crown cover (or equivalent stocking level) of $5-10 \%$ of trees able to reach a height of $5 \mathrm{~m}$ at maturity in situ; or a crown cover (or equivalent stocking level) of more than $10 \%$ of trees not able to reach a height of $5 \mathrm{~m}$ at maturity in situ (e.g. dwarf or stunted trees); or with shrub or bush cover of more than $10 \%$.

\section{CBD definitions (http://www.cbd.int/forest/definitions.shtml)}

Forest: Land area of more than 0.5 ha, with a tree canopy cover of more than $10 \%$, which is not primarily under agricultural or other specific non-forest land use. In the case of young forests or regions where tree growth is climatically suppressed, the trees should be capable of reaching a height of $5 \mathrm{~m} \mathrm{in} \mathrm{situ,} \mathrm{and} \mathrm{of}$ meeting the canopy cover requirement.

Primary forest: Forest that has never been logged and has developed following natural disturbances and under natural processes, regardless of its age. This includes forests that are used inconsequentially by indigenous and local communities living traditional lifestyles relevant for the conservation and sustainable use of biological diversity.

Secondary forest: Forest that has been logged and has recovered naturally or artificially. Not all secondary forests provide the same value to sustaining biological diversity, or goods and services, as did primary forest in the same location.

Old growth forest stands: Stands in primary or secondary forests that have developed the structures and species normally associated with old primary forest of that type have sufficiently accumulated to act as a forest ecosystem distinct from any younger age class. 


\section{UN Framework Convention on Climate Change (http://unfccc.int/resource/docs/2005/cmp1/eng/08a03.pdf\#page=3)}

Forest: a minimum area of land of 0.05-1.0 ha with tree crown cover (or equivalent stocking level) of more than $10-30 \%$ with trees with the potential to reach a minimum height of 2-5 $\mathrm{m}$ at maturity in situ. A forest may consist either of closed forest formations where trees of various storeys and undergrowth cover a high proportion of the ground or open forest. Young natural stands and all plantations which have yet to reach a crown density of $10-30 \%$ or tree height of $2-5$ $\mathrm{m}$ are included under forest, as are areas normally forming part of the forest area which are temporarily unstocked as a result of human intervention such as harvesting or natural causes but which are expected to revert to forest.

\section{National Forest Inventory definitions}

Denmark (Nord-Larsen et al. 2008)

Forest land: Land greater than 0.5 ha and wider than $20 \mathrm{~m}$, where trees higher than $5 \mathrm{~m}$ and canopy cover of more than $10 \%$, or trees able to reach these thresholds in situ; excluding land predominantly under agricultural or urban land use.

Other wooded land: Land not classified as "Forest", more than 0.5 ha and wider than $20 \mathrm{~m}$; with trees higher than $5 \mathrm{~m}$ and a canopy cover of $5-10 \%$, or trees able to reach these thresholds in situ; or with a combined cover of shrubs, bushes and trees above 10\%; excluding land predominantly under agricultural or urban land use.

\section{Finland (Metla 2011)}

Forestry land: All land not allocated for other land use, including forest land, poorly productive forest land, unproductive land and other forestry land

Forest land: Land with a capacity to produce at least $1 \mathrm{~m}^{3}$ of wood biomass (including bark) per ha annually.

Poorly productive land: Land with a capacity to produce $0.1-1 \mathrm{~m}^{3}$ of wood biomass (including bark) per ha annually.

Unproductive land: Land with a capacity to produce less than $0.1 \mathrm{~m}^{3}$ of wood biomass (including bark) per ha annually.

\section{Norway (Larsson \& Hylen 2007)}

Forest land: Land greater than 0.5 ha with crown cover of more than $10 \%$ and trees may reach at least $5 \mathrm{~m}$ height. Young stands established for forestry purposes but not yet with $10 \%$ crown cover or $5 \mathrm{~m}$ tree height are included, as are areas temporarily without tree vegetation due to human activity or forest fires.

Productive forest: Land with a capacity to produce at least $1 \mathrm{~m}^{3}$ of wood biomass (including bark) per ha annually.

Unproductive forest: Land with a capacity to produce $0.1-1 \mathrm{~m}^{3}$ of wood biomass (including bark) per ha annually. 


\section{Sweden (Skogsstyrelsen 2011: Appendix 2)}

Forest land: Land spanning more than 0.5 ha (NFI uses 0.02 ha as the smallest area) with a canopy cover of more than $10 \%$ for stands with a height at mature age of at least $5 \mathrm{~m}$.

Tree and shrub land: Land spanning more than 0.5 ha with at least $5 \mathrm{~m}$ high trees at maturity with a crown cover of $5-10 \%$, or with trees lower than $5 \mathrm{~m}$ or bushes at least $0.5 \mathrm{~m}$ high at maturity with a combined crown cover of at least $10 \%$.

Productive forest: Land with a capacity to produce at least $1 \mathrm{~m}^{3}$ of wood biomass (including bark) per ha annually.

Unproductive land (mountain coniferous forest, mountains, mires, rock ground): Land with a capacity to produce less than $1 \mathrm{~m}^{3}$ of wood biomass (including bark) per ha annually.

\section{Box 2: Natural, pristine, primeval, virgin, and old-growth forest}

The various concepts of natural, pristine, virgin or old-growth forest are closely related, implying forests that have characteristics indicating that such forests have an origin and development overwhelmingly governed by natural processes with minimal impact from human activities. Here we do not give a full discussion of these concepts, only a summary of the main distinctions applied to each concept. The concepts are more fully discussed by Rolstad et al. (2002), Wirth et al. (2009), Brumelis et al. (2011), and others.

\section{Virgin, pristine or primeval forests}

The terms virgin, pristine or primeval forest cover the same concept, namely, natural forests which have never been significantly influenced by humans, i.e., with an unbroken history of natural development (Peterken 1996). The Scandinavian term urskog covers the same meaning. The use of the term virgin forest in Europe has often been more liberal, also including forests which have been traditionally used by humans for grazing of livestock, wood gathering etc.

\section{Natural forests}

In Finland, Norway, and Sweden natural forests are generally considered as forest developed through natural regeneration on untouched forest land or on old, treecovered natural grazing land. The forest exhibits long continuity or consists of a first tree generation in areas of natural forest expansion. Natural forests may often have some influence of human activities but systematic forest management has not taken place. The ground in natural forests has not been affected by fertilization, ditching, ground preparation or similar actions. (Tanninen et al. 1994). Regeneration from local stock is an absolute requirement. A distinction can be made between primary natural forests which have had a forest cover for a long time, and secondary natural forests which may have originated on previously non-forested land. 
Previous considerations of forest naturalness have often been based on (1) structural aspects like tree species composition, age structure, canopy layers, amount and distribution of dead wood, (2) species composition, especially the presence of characteristic or indicative species such as sets of fungi or lichens, or (3) processes like natural disturbance regime and succession. Brumelis et al (2011) recommends that these should all be considered when assessing the natural character of a forest and they propose a qualitative ranking of naturalness based on all three dimensions.

\section{Old-growth and old forests}

The concept of old-growth forest has been much used, especially about old, natural forests in North-America. Still, a common and agreed definition does not seem to have been developed (Peterken 1996).

Most definitions of old-growth forests use multiple criteria, which fall into three groups: (1) structural and compositional features, (2) successional processes maintaining the old-growth stage, and (3) biogeochemical processes (Wirth et al. 2009). Structural features may be stand age, presence of large old trees, multi-layered canopy, presence of logs and a diverse tree community. Successional features are climax forest, gap-phase tree replacement, postcommercial timber rotation and a stand age exceeding the life span of species. Biogeochemical features are presences of all decay stages of logs, nutrient retention and increased understory productivity. Some of these criteria are only useful for some forest types, e.g., in tropical forests decay rates are so high that dead wood stocks are generally low. Others may lead to confusion of function and definition, such as criteria relating to productivity. The relationship between disturbance and occurrence of old-growth forests is fundamental.

A single, precise definition applicable to all forest types may not be possible. However, a pragmatic definition will include the following characteristics: Presence of relatively old trees, that is - large, old, late-successional tree species with ages close to their life-expectancy and a mean age that is half of the age of longlived, dominating trees (their longevity); structural and compositional features that witness self-replacement through gap-phase dynamics (Wirth et al. 2009). A compact definition of old-growth forests could thus be old, natural forests, i.e., forests significantly older than the normal harvestable age and with structural features characteristic of natural ecological processes and disturbances, with less concern about past human influences that currently have a marginal effect of forest ecosystem structure and function. Here, we will essentially have such a concept in mind when referring to old forests. 


\section{Nordic forests}

The purpose of this chapter is to give an overview of forests in the Nordic countries, as a framework for the discussion of the roles of forests as custodians of biodiversity as well as important components of the global carbon cycle. This includes a presentation of natural forests as dynamic ecosystems with important properties for biodiversity and carbon dynamics, as well as the effects of the varied human influences on the forest ecosystems up through the ages. Finally, we present some of the ways forests are classified in order to get a better overview of the variation in forest properties for more effective research and management.

\subsection{Natural dynamics of Nordic forests}

Virtually all organisms in the Nordic countries, including the tree species, have immigrated since the last glacial period about 11000 years ago (Andersen \& Borns 1997). Although some species may have survived in refuges during the last glaciation (e.g., Parducci et al. 2012), Nordic forest ecosystems and their associated species have become established since the last ice age. Since the end of the ice age various tree species have immigrated, as a consequence of dispersal opportunities, climate and soil development (Andersen \& Borns 1997, fig. 2-68). Birches and Scots pine were among the earliest. As the climate warmed, a range of temperate broadleaved deciduous tree species arrived between 8,000 and 5,000 years ago. Although Norway spruce may have established outposts already soon after deglaciation (Öberg \& Kullman 2011), it was the last species to reach dominance as a forest tree, between 6,000 years ago in eastern Finland and 2,000 years ago in Eastern Norway (Giesecke \& Bennett 2004, Seppä et al. 2009). It has not yet reached its full potential distribution in western Norway through natural dispersal.

The human influence on the Nordic forests has developed in parallel with the changing species structure, making it difficult to find examples of forests under natural dynamics with only a minimum of human influence. Nevertheless, based on studies of disturbance dynamics in remote forest sites with little apparent impact from modern human activities, characteristics of natural dynamics of boreal forests in Fennoscandia have recently been described (e.g., Angelstam \& Kuuluvainen 2004, Kuuluvainen 2009, Kuuluvainen \& Aakala 2011, Jonsson \& Siitonen 2012). Natural forest dynamics are driven by two primary processes: (1) natural disturbances caused by a range of factors (e.g., fires, storms, avalanches/rock slides, 
floods, insect attacks) operating at various spatial and temporal scales (Figure 3.1), and (2) succession from establishment of a new tree generation towards a more stable climax state or a new disturbance. Several recent studies indicate that large-scale, severe stand-replacing disturbances by fires or storms, resulting in an entirely new tree generation, must have been relatively rare, with a frequency of 200-500 years in the northern boreal zone (Kuuluvainen 2009 and references therein). Even most large-scale disturbances varied in severity across the landscape. They rarely killed all the original trees but often left behind a number of trees as components of the new forest developing after the disturbance. More frequent and less severe disturbances by fires, storms, avalanches, insect attacks, killing some age classes of trees but not all, may be termed cohort dynamics and result in multimodal age structures (cohorts) over smaller spatial scales. Yet smaller scale disturbances, caused by heart-rot, insect attacks, wind throws, snow breaks, may result in patch or gap dynamics where single trees (gaps) or small groups of trees (patches) die and the forest develops a more varied age structure (Kuuluvainen \& Aakala 2011). The variable role of fire as a disturbance agent is also emphasized by Ohlson et al. $(2009,2011)$ who showed that fires have varied considerably across Fennoscandia, having often been less extensive and frequent than previously considered (e.g., Zackrisson 1977). The frequency and effects of fires depended on both climate (few fires in oceanic climates) and the establishment of spruce as a dominant forest tree (resulting in far fewer fires than before) (although Hellberg et al. (2009) found that fire was an important disturbance agent in spruce forests in their study area).

\section{Forest fires generate suitable habitats for many treatened species. Burning a young spruce stand in Puolanka in central Finland}

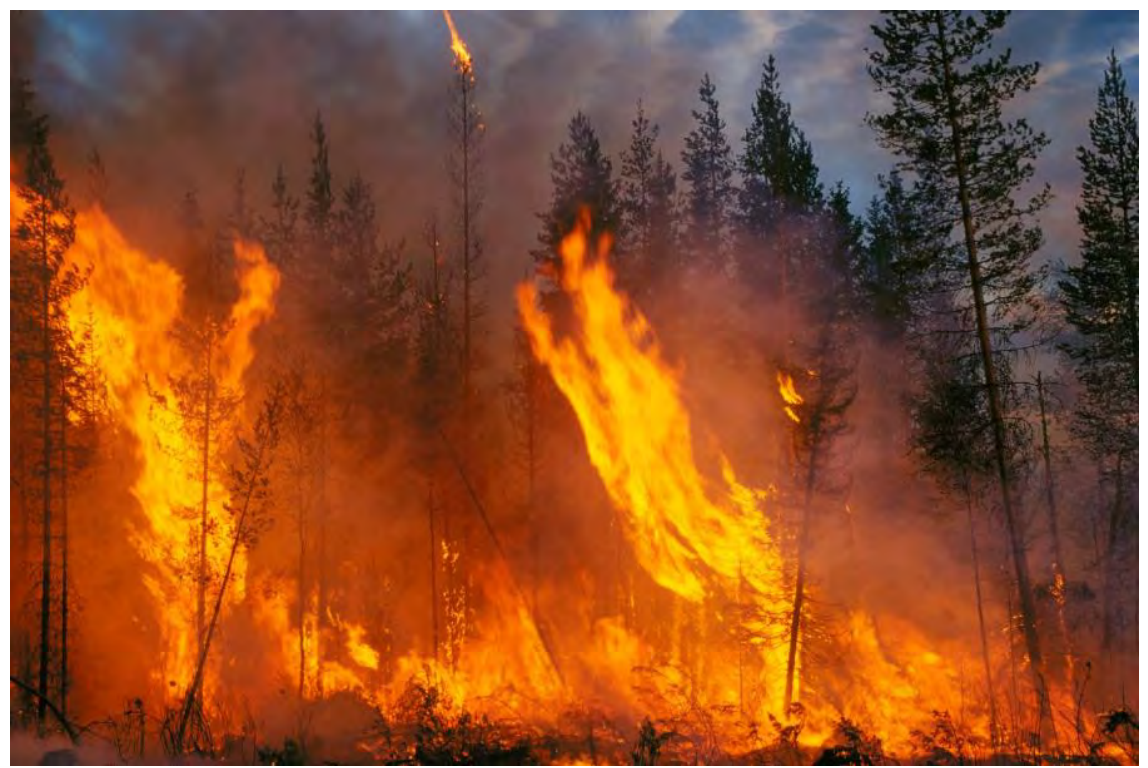

Photo: Erkki Oksanen/Metla. 
Figure 3.1. Disturbance factors at various spatial and temporal scales in boreal forests. The spatial scale will run from single trees to several stands or parts of catchment areas and the temporal from sub-annual to centuries

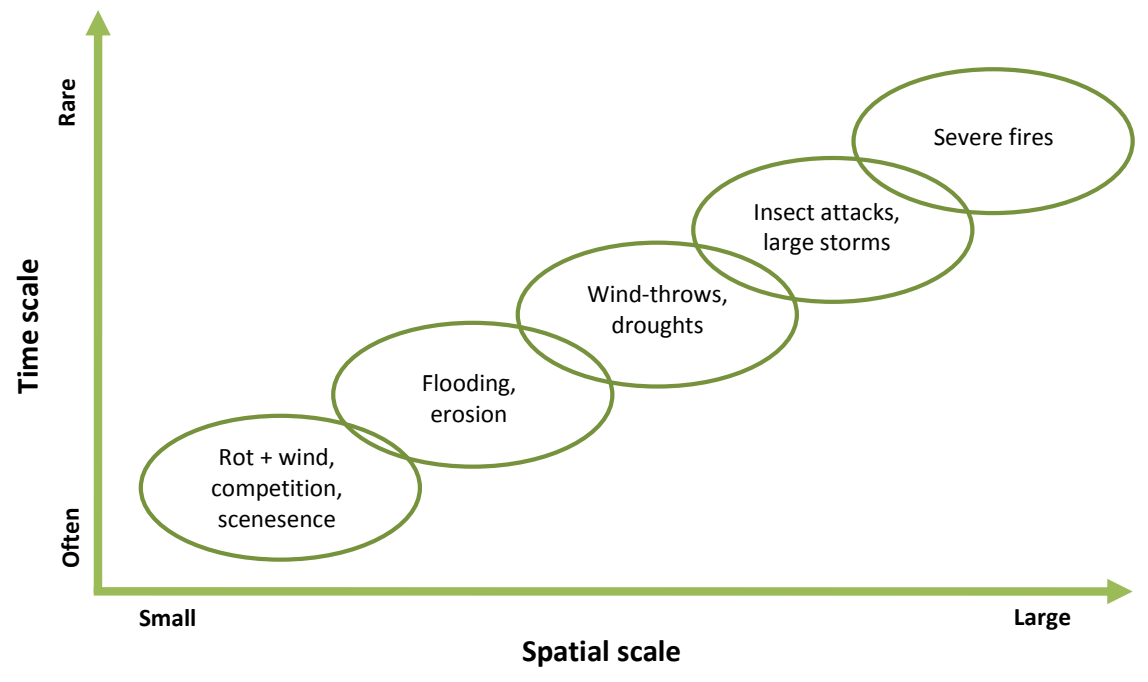

Modified from Jonsson \& Siitonen 2012.

Shorohova et al. (2011) summarized current understanding of natural disturbance regimes and the related dynamics determining the natural prevalence and development of old-growth boreal forests (Table 3.1). They concluded that in contrast to forests in western North America and western Siberia, boreal forests of northwest Europe tend to be dominated by less severe, non-stand-replacing fires and other disturbances, letting more varied and smaller scale disturbances shape forest development and structure, between the rather infrequent severe, stand-replacing fires. Forests are then mainly dominated by small-scale gap dynamics, with cohort dynamics where fires of medium severity occur, giving a complex and fine-grained forest structure. As the proportion of old-growth forests in a landscape is determined by the frequency and severity of recurrent stand-replacing disturbances (fires, storms, insect outbreaks), the low frequency between severe disturbances in boreal forests in Fennoscandia should imply that old-growth, multi-aged forests may originally have covered a considerable area and lasted for rather a long time. In western and northern Norway, the broken topography and moister climate should have made large, stand-replacing fires very rare, but local storm damage and avalanches would probably have been quite common.

Studies of natural forest dynamics in the Nordic countries have been concentrated to boreal forests (mainly of the northern and middle boreal zones), with little specific information on the natural dynamics of temperate forests (Peterken 1996). This is mainly due to the long-lasting and extensive human influence in temperate forests ( $\mathrm{cf}$ below), leaving virtually no suitable cases for studies of such dynamics, although some selected forest tracts with long forest continuity can be found, e.g., the 
Danish Draved forest (Bradshaw et al. 2005) and particularly Suserup forest (Hahn et al. 2007). Still, it seems reasonable to assume that similar disturbance regimes would have influenced temperate forests under natural dynamics, although probably with a higher relative frequency of patch and gap dynamics and quite different successional pathways (Peterken 1996, Andersson \& Löfgren 2000, Emborg et al. 2000, Bradshaw \& Hannon 2004). Like in the boreal forests, occasional natural fires were probably a significant renewal agent also in temperate forests, but windthrows, temporary flooding and grazing and browsing by large herbivores may have been just as important in shaping temperate forest structure. These disturbance factors probably resulted in forests with considerable continuity at the stand level, with trees in a variety of age classes, interspersed with small-scale open patches.

Table 3.1. Disturbance regimes and dominating dynamics in old-growth boreal forests. Adapted from Shorohova et al. (2011)

\begin{tabular}{llll}
\hline $\begin{array}{l}\text { Disturbance } \\
\text { severity }\end{array}$ & \multicolumn{3}{c}{ Disturbance return interval (yrs) } \\
\cline { 2 - 4 } & $<\mathbf{1 0 0}$ & $\mathbf{1 0 0 - 2 5 0}$ & $\mathbf{2 5 0}$ \\
\hline High & No old-growth & Even-aged old-growth & $\begin{array}{l}\text { Even-aged old-growth } \Leftrightarrow \\
\text { Cohort dynamics } \Leftrightarrow \text { Small- } \\
\text { scale gap dynamics }\end{array}$ \\
Ledium & Cohort dynamics & Cohort dynamics & $\begin{array}{l}\text { Cohort dynamics } \Leftrightarrow \text { Small- } \\
\text { scale gap dynamics }\end{array}$ \\
\hline
\end{tabular}

The temperate semi-natural Suserup Forest Reserve in Denmark

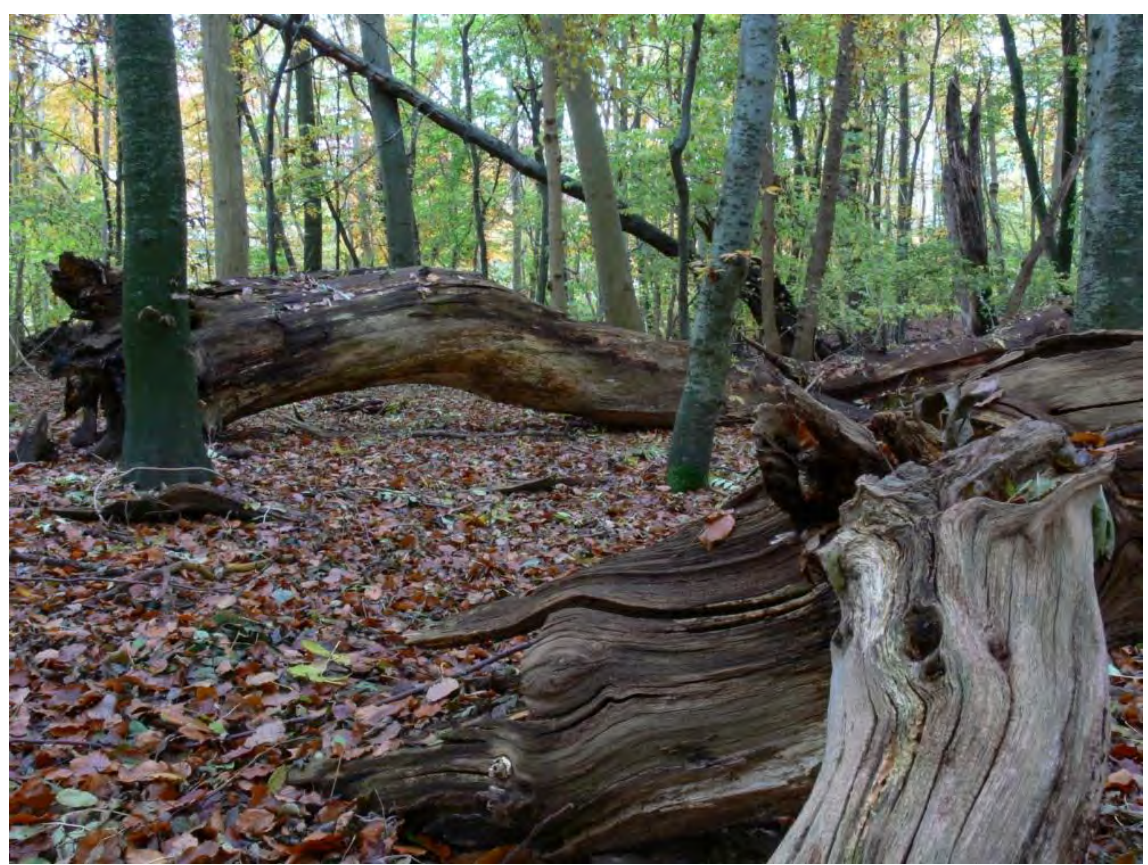

Photo: Morten Christensen. 
Although natural disturbance factors and their resulting forest dynamics will vary across the forest landscape with differences in terrain, climate and hydrology, with a low frequency of severe, stand-replacing disturbances, most forests under natural dynamics will be formed by a combination of less severe disturbance factors. This results in structurally complex forests with small-scale spatial variation and a landscape with continuous presence and high proportion of old, large trees, reaching their biological age of 200-400 years (Kuuluvainen 2009). A few modelling studies considering the effects of the various natural disturbance regimes on the forest age structure (Angelstam \& Andersson 1997, Pennanen 2002) as well as historical studies of selected old forest sites in northern Sweden (Östlund et al. 1997) indicate that biologically old forests (far older than the current harvestable age) may have constituted $40-50 \%$ of the forest landscape, varying from $20 \%$ under predominance of extremely severe fires to $80 \%$ under low-severity fire regimes. Such natural forest dynamics also result in a large, more or less continuous supply of dead wood in the form of logs and snags, covering a range of sizes, wood types, decay stages and mortality agents. Estimates of the total amount of dead wood in forests under natural dynamics vary from 20-120 m ${ }^{3}$ ha $^{-1}$ in boreal forests in Fennoscandia to $130-250 \mathrm{~m}^{3} \mathrm{ha}^{-1}$ for European temperate forests (Jonsson \& Siitonen 2012: table 12.4, Christensen et al. 2005: table 1). Siitonen (2001) specified that the amount of coarse woody debris (CWD) varies from $90-120 \mathrm{~m}^{3} \mathrm{ha}^{-1}$ in the southern and middle boreal zone, $50-80 \mathrm{~m}^{3} \mathrm{ha}^{-1}$ in the northern boreal zone, and to about $20 \mathrm{~m}^{3} \mathrm{ha}^{-1}$ in the northernmost timberline forests. Such variations in the natural supply of dead wood can also be expected on a local scale, with the highest production at more productive sites. Decay rates also vary with climatic factors, being faster in warm and moist than in cool and dry climates.

Considering that stand-replacing disturbances like severe fires seem to be less frequent in natural boreal forests than previously thought (Kuuluvainen 2009), it is relevant to consider how long-term absence of major disturbances will affect key ecosystem properties. Wardle et al. (2012) have recently synthesized their studies of ecosystem processes for a number of boreal forest lake islands in Northern Sweden, where time since the last major disturbance by fire varies from 60 to more than 5000 years. As time since the last major disturbance has progressed, islands have gone through a succession where key nutrients like nitrogen $(\mathrm{N})$ and phosphorus $(\mathrm{P})$ become less accessible for plant growth and primary production and decomposition rates decrease. This results in lower aboveground biomass production, but lower decomposition leads to higher belowground and overall carbon stocks. Total ecosystem carbon sequestration rates appear to be similar for younger and older islands, at about $4.5 \mathrm{~g} \mathrm{~m}^{-2} \mathrm{yr}^{-1}$, over several thousand years. Species richness for vascular plants and aboveground (but not belowground) invertebrates increases with time since disturbance. 
In wet and cool forests the process of successional paludification, i.e., the gradual accumulation of organic material in the form of peat and associated changes in soil properties, may result in similar reductions in aboveground productivity and strong accumulation of carbon in the ecosystem (e.g., Simard et al. 2007).

The results of Wardle et al. (2012) with respect to net primary production and carbon storage in old forest ecosystems are consistent with a meta-analysis of results from a number of temperate and boreal forest ecosystems performed by Luyssaert et al. (2008). They found that most of the studied ecosystems accumulate carbon for a long time beyond the normal harvestable age of the trees. Note that the forest ecosystems studied by Wardle et al. (2012) have avoided major disturbances for far longer than the ecosystems covered by Luyssaert et al. (2008).

In the context of this report, forests under natural dynamics may represent an interesting contrast to today's heavily managed forests with respect to implications for biodiversity as well as carbon dynamics:

- Natural boreal (and probably also temperate) forests in the Nordic countries tend to be formed by a combination of different disturbance factors, where stand-replacing major disturbances are rare for most forest types. Low to intermediate disturbances may be quite frequent but will vary with terrain and forest types.

- These dynamics result in a complex forest structure with a diversity of tree species and age classes over small spatial scales, with many old trees and much dead wood over a range of sizes and decay classes. At the landscape scale, open patches with few trees, more open, low-density forest as well as denser forest would result.

- The structural complexity, abundance of old trees, and amount and diversity of dead wood represent important resources for a wide range of species (particularly fungi and insects) closely associated with natural forests. High species richness and occurrence of redlisted species of all major species groups in the forest landscape will be depend on a variety of dense forest of high continuity, of more open, sun-exposed forest, and of patches of burnt ground or temporarily open areas.

- Forests without major disturbances for a long time tend to be characterized by lower plant productivity and slower decomposition, declining aboveground carbon sequestration but increased belowground and total carbon storage. 


\subsection{Past and present human impacts on Nordic forests}

Humans have dispersed into the recently ice-free lands of Scandinavia and Finland rather soon after the end of the last ice age. Human presence and the establishment of the forest thus developed in parallel. However, it was not until the introduction of agriculture and the keeping of livestock almost 6,000 years ago (Berglund 1991, Myhre \& Øye 2002) that humans started to have an impact beyond the effect of natural disturbance factors. The early impacts of agricultural activities were strongest in the southern lowlands and coastal areas of the nemoral and boreonemoral zones (cf Figure 3.2), where clearing of fertile land for cultivation, grazing of livestock and harvesting of fodder affected forest cover and species composition (Andersson \& Löfgren 2000, Bradshaw \& Hannon 2004). The use of fire as a management tool to improve grazing must also have been common around settlements. The impacts of agricultural activities were pronounced from about 4000 years ago. Along the western coasts of Norway, Sweden and Denmark the tree-less coastal heathlands were formed at this time. With increasing populations in the Nordic countries towards the Viking Era, peaking just before the Black Plague in 1350, the pressure on agricultural resources increased as well (Myhre \& Øye 2002). This included an expansion of the cultivated area as well as extensive use of resources for grazing and fodder from forests, mountains and mires. With the Black Plague, and several plagues following over the next few hundred years, the population was drastically reduced. For Norway it is estimated that the population level before the Black Plague (about 0.5 million) was not reached again until about 1700 (Lunden 2002). After the population collapse following the plagues, nature was to some extent able to reclaim areas previously exploited by humans. As populations increased rapidly from about 1700, the pressure on agricultural resources in the Nordic countries peaked at the end of the 1800s, with extensive use of available land for cultivation, grazing and fodder extraction. Slash-and-burn agriculture was particularly common in eastern and central Finland (less so in parts of Sweden and Norway) until the early 1800s. Forest grazing was common in Finland and Sweden until the early 1900s, and still continues in parts of Norway, but was prohibited in Denmark from about 1800 (Tanninen et al. 1994).

The ban on forest grazing in Denmark marked an important segregation of land uses. Around 1800, the forest area had decreased to $2 \%$ of the land cover due to population expansion and over-exploitation of natural resources. Remaining forest patches were open and without regeneration due to overgrazing by farm animals. Large farmland areas on poor soils in Jutland had been abandoned due to lack of productivity and had then developed into heathlands. The major reform to segregate land-uses as well as large-scale afforestation efforts to convert anthropogenic heathlands 
into conifer plantations gradually increased the forest area over the next 200 years to the approximate $15 \%$ forest cover of today.

Forests have also been used for the production of various non-food products from an early age, where the production of tar from pines, potash from deciduous trees, iron from mires, and the cooking of salt along the coast had a heavy impact on local forest resources from about 500 AD. Already in the Middles Ages timber and other forest products were exported from Norway to England (Myhre \& Øye 2002). The timber exports from Norway increased considerably with the introduction of new sawing techniques around 1500 . Over the next 100 years timber exports increased nearly 20 times, and by the end of the 1600s several sources complained about the depletion of timber resources (cf sources quoted by Rolstad et al. 2002). In the 1500s and 1600s a number of mines and iron works were established in various parts of Fennoscandia, all needing vast amounts of timber resources for mining activities and metal extraction, harvested from a wide area around mines or iron works, sometimes depleting local forest resources completely. In the early 1700s timber exports started from western Sweden, but it was not until the mid-1800s that the vast forest resources from the northern Baltic Sea region dominated timber exports from Fennoscandia. With the emergence of the pulp and paper industry in the latter half of the 1800s, forest harvesting increased in both extent and intensity as previously marginal wood resources became economically interesting.

\section{Forest grazing by cattle is still common in parts of Norway. Lunner, Oppland county, SE Norway}

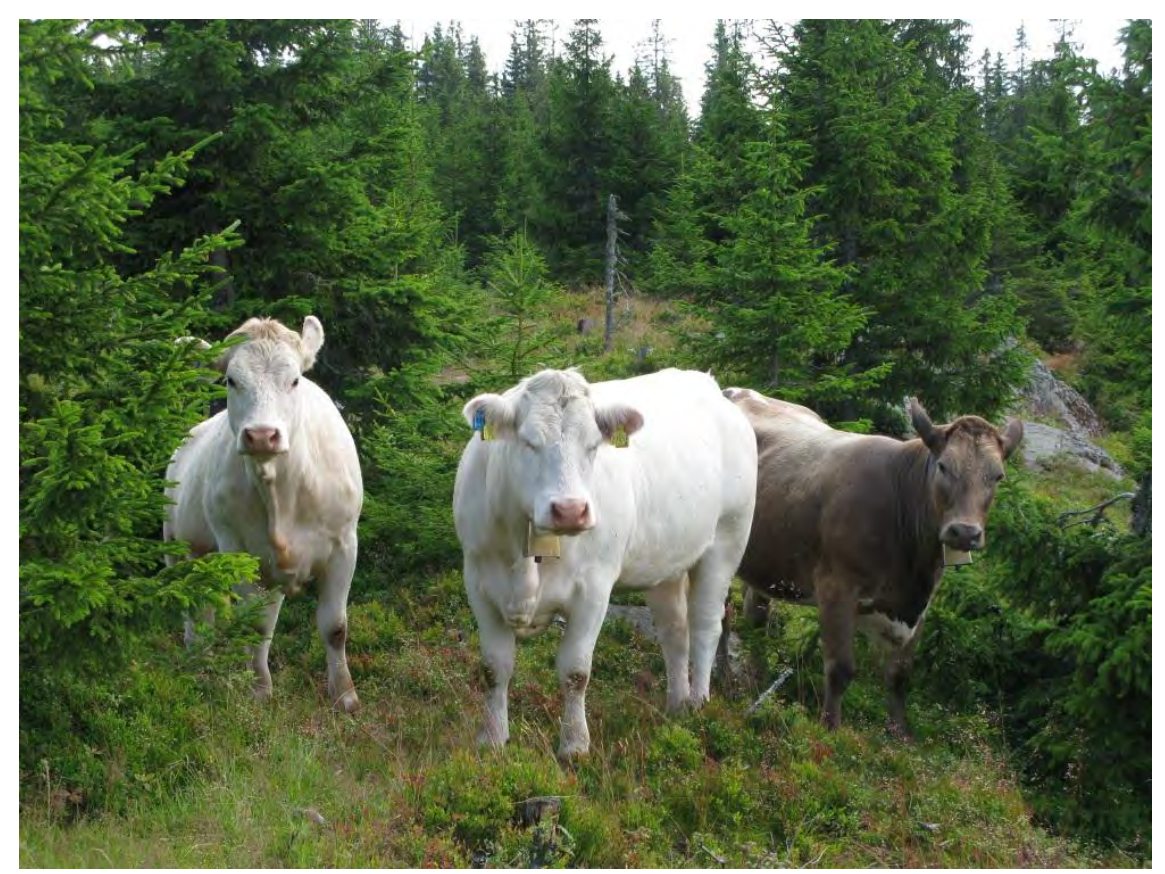

Photo: Egil Bendiksen, NINA. 
The human direct and indirect impacts over millennia have changed the tree species composition of forests, particularly in the boreonemoral and nemoral zones where species diverse deciduous or mixed forests were gradually replaced by forests dominated by beech and conifers in Denmark and conifers in Sweden (e.g., Bradshaw \& Holmqvist 1999, Björse \& Bradshaw 1998). The expansion of agricultural activities to feed an increasing population and inadequate consideration of forest resources probably resulted in the smallest forest area since the last ice age in the late 1700s in Denmark and about 100 years later in Finland, Norway and Sweden (Bradshaw 2004).

In spite of the accelerated forest harvesting of boreal forests during the late 1800 s, considerable forest areas in the north and interior were probably not very heavily influenced by active forestry around 1900 (Östlund 2004). Nevertheless, the total growing stock of Fennoscandian forests at this period may have been at its lowest since forests were established after the last ice age. This was due both to the reduction of the forest area in order to increase agricultural production, as well the extractive nature of the harvesting of the forest resources, where especially the largest and most valuable trees were harvested first without much effort invested in developing new growing stock.

Results from the earliest forest inventories in Finland, Norway and Sweden, as well as various studies of forest history (e.g., Östlund et al. 1997, Östlund 2004, Storaunet et al. 2005, Hellberg et al. 2009, Lie et al. 2011), give an impression of what these forests were like around 1900:

- The total growing stock was quite low, maybe as low as $20 \%$ of the original forest growing stock before the expansion of agriculture from the Bronze Age onwards and the increasing timber harvesting over the last 500 years. In Norway, the forest growing stock today is more than doubled since the early $1900 \mathrm{~s}^{2}$ and in Finland and Sweden the equivalent increase is about 70\% (Metla 2011) and 85\% (SLU 2011), respectively. However, locally, the growing stock may have been comparable to current levels (Lie et al. 2011).

- The forest structure was quite open, multi-layered, with an established canopy over most areas, and with a varied age structure and poorlydefined stand structure. 
- Most of the largest and presumably oldest trees were harvested by 1900 , with a significant reduction in the diameter of the largest trees (Andersson \& Östlund 2004). Nevertheless, old trees and some very large trees were rather common in parts of northern Sweden in the early 1900s (Östlund 2004), and the number of pines and spruces older than 160 years has declined since then, whereas old deciduous trees has not (Andersson \& Östlund 2004).

- There were probably fewer deciduous trees than in natural forests, at least for Norway and Sweden where forest inventories indicate an increase in the volume of deciduous trees since the early 1900s. However, in Finland the relative volumes of deciduous trees have been rather stable (Metla 2011). Locally the proportion of spruce may have been higher than today (Hellberg et al. 2009, Lie et al. 2011).

- The amount of dead wood was far lower than expected for natural forests, particularly near settlements where dry dead wood would be harvested for firewood. Local studies vary considerably in their estimates of dead wood, from less than $1 \mathrm{~m}^{3} \mathrm{ha}^{-1}$ (Lie et al. 2011) to 11-14 $\mathrm{m}^{3} \mathrm{ha}^{-1}$ (Östlund 2004). Forest inventories indicate that the volumes of dead wood have now increased to about $12 \mathrm{~m}^{3} \mathrm{ha}^{-1}$ in Norway, $8 \mathrm{~m}^{3} \mathrm{ha}^{-1}$ in Sweden and $6 \mathrm{~m}^{3} \mathrm{ha}^{-1}$ in Finland (Storaunet et al. 2011).

- Fires had been suppressed for the previous 100-200 years, but in parts of northern Sweden and eastern Finland several forest landscapes were still influenced by fires in 1900 (Östlund 2004, Wallenius 2011).

- The spatial pattern of the forest landscape was mainly defined by natural variation in growing conditions and natural disturbance factors, with small-scale variation within forest patches and gradual transitions between them.

Whereas traditional forestry was mainly focused on selective cutting of the most suitable trees for various purposes (initially, mainly large trees), a new stand-based management model for forestry was developed in the early 1900s and put into practice on a large scale in boreal forests after the second world war. The stand management model considers the forest as made up of individual stands, i.e., groups of trees within an area of more or less homogeneous growing conditions, of at least 0.2 ha. The individual stand should be homogeneous with respect to tree species and age, and it should be managed as a unit, with the same planting, silviculture and harvesting operations for the whole stand. Forest management should be optimized for rapid growth of the preferred tree species and wood qualities, including ground preparation (scarification, forest ploughing), ditching of wetlands, planting of the most productive tree species (including exotic species and varieties) or natural regeneration with selected trees, fertilization, control of pests and undesirable species, thinning and other pre-harvest man- 
agement, and final cutting of the whole stand. This management model was rapidly applied on a large scale, particularly in Finland and Sweden, somewhat less consistently in Norway, and in Denmark mainly in the coniferous forests. Since the 1990s some of these silvicultural measures have been more strictly regulated than in previous decades, e.g., use of pesticides, forest ploughing, ditching, and planting of exotic species. In Denmark, nature-based forest management has been introduced since 1990, with more use of natural regeneration, less ditching, and more use of native species, although planting of exotic welladapted species and provenances is also used.

The basic idea behind the stand-based management model is to promote rapid growth and a large harvestable stock of the preferred tree species. However, if consistently applied over the whole forest area, as originally envisaged, it would also lead to removal of non-preferred tree species, trees without adequate growth potential, trees older than the optimal cutting age (70-120 years in most boreal forests), and a strong reduction in the amount of dead wood (coarse woody debris in particular). Also, the structure of the forest landscape is more schematic, with high contrast between clear-cuts or young forest stands and stands of dense mature or over-mature forest.

Over the last few decades, two opposing processes have influenced forest management. One is a trend towards ever more effective forest management, especially of the most productive forests, and an intensification of harvesting, as seen in the increasing interest in whole-tree harvesting for bioenergy, including stump removal. The other involves incorporation of a range of environmental measures to ensure more sustainable forestry for biodiversity, recreation and other social goods, resulting in retention of some forest resources of importance for biodiversity, such as key biotopes, buffer zones along mires and water bodies, dead wood etc. In addition, forest areas of low productivity or otherwise marginal economic potential have to some extent not been managed or harvested. In Norway in particular, less than $50 \%$ of the annual increment in the growing stock is currently harvested. ${ }^{3}$ Compared to forest conditions of about 100 years ago, current boreal forests have far higher growing stocks. During recent decades, some key resources for biodiversity, such as dead wood, trees older than 120 years, and deciduous trees, have received special attention. However, growing stocks (and hence carbon stocks) are probably lower than under natural forest dynamics where old forest would tend to dominate (Kuuluvainen 2009). Also, forest structures and resources of particular significance for biodiversity, such as forest older than 160

${ }^{3}$ http://www.ssb.no/emner/10/04/20/skog/ 
years, large trees and amounts and diversity of dead wood are far lower than we would expect in forests under natural dynamics (e.g., Linder \& Östlund 1998, Siitonen et al. 2000).

A summary of forest land and growing stock in the Nordic countries today is given in Table 3.2 .

Table 3.2. Land area, forest area and growing stock in Denmark, Finland, Norway and Sweden

\begin{tabular}{|c|c|c|c|c|}
\hline & Denmark & Finland & Norway & Sweden \\
\hline \multicolumn{5}{|l|}{ Nordic Council of Ministers } \\
\hline Area $\left(\mathrm{km}^{2}\right)$ & 43,561 & 338,440 & 323,787 & 450,295 \\
\hline Forest area $\left(\mathrm{km}^{2}\right)$ & 5,294 & 228,190 & 123,840 & 225,430 \\
\hline \multicolumn{5}{|l|}{ FAO Global Forest Resource Assessment 2010} \\
\hline Area $\left(\mathrm{km}^{2}\right)$ & 43,100 & 338,420 & 323,800 & 450,290 \\
\hline Forest $\left(\mathrm{km}^{2}\right)$ & 5,440 & 221,570 & 100,650 & 282,030 \\
\hline Other wooded land $\left(\mathrm{km}^{2}\right)$ & 470 & 11,120 & 27,030 & 30,440 \\
\hline Other tree covered land $\left(\mathrm{km}^{2}\right)$ & 60 & 1,830 & 0 & 5,300 \\
\hline Total tree covered $\left(\mathrm{km}^{2}\right)$ & 5,970 & 234,520 & 127,680 & 317,770 \\
\hline Primary forest $\left(\mathrm{km}^{2}\right)$ & 250 & 0 & 2,230 & 26,090 \\
\hline Naturally regenerated forest $\left(\mathrm{km}^{2}\right)$ & 1,120 & 162,520 & 83,670 & 219,810 \\
\hline - of which exotic species (\%) & $31 \%$ & $0 \%$ & $0 \%$ & $0 \%$ \\
\hline Planted forest $\left(\mathrm{km}^{2}\right)$ & 4,070 & 59,040 & 14,750 & 36,130 \\
\hline - of which introduced species (\%) & $47 \%$ & ns & $18 \%$ & $18 \%$ \\
\hline Growing stock in forest (mill. $\mathrm{m}^{3}$ ) & 108 & 2189 & 987 & 3358 \\
\hline Growing stock in other wooded land (mill. $\mathrm{m}^{3}$ ) & 1 & 10 & 25 & 11 \\
\hline \multicolumn{5}{|l|}{ National forest statistics } \\
\hline Forest land $\left(\mathrm{km}^{2}\right)$ & 5,856 & 261,490 & 128,264 & 282,760 \\
\hline Productive forest land $\left(\mathrm{km}^{2}\right)$ & 5,783 & 203,050 & 83,399 & 232,220 \\
\hline Unproductive forest land $\left(\mathrm{km}^{2}\right)$ & 74 & 58,430 & 44,865 & 50,540 \\
\hline Forest growing stock (mill. $\mathrm{m}^{3}$ ) & 115 & 2,284 & 878 & 3,256 \\
\hline Annual stock increment (mill. $\mathrm{m}^{3}$ ) & na & 103.7 & 24.9 & 117.4 \\
\hline Annual stock removal (mill. m³) & 2.6 & 71.5 & 11.8 & 69.0 \\
\hline
\end{tabular}

Sources:

Nordic Council of Ministers: http://www.norden.org/no/fakta-om-norden/nordiske-land-

faeroeyene-groenland-og-aaland.

FAO Global Forest resource Assessment 2010: http://www.fao.org/forestry/fra/fra2010/en/

Denmark: Nord-Larsen et al. 2012: tab. 2.2, tab. 2.11, tab. 2.23; Note: Unproductive forest = permanently unstocked (forest roads etc); Annual stock increment not available; Annual stock removal = harvesting only.

Finland: Metla 2011: tab. 1.0; Note: Unproductive forest = Poorly productive forest land + Unproductive land + Forest roads etc; Annual stock removal = harvesting + other losses.

Norway: http://www.ssb.no/skog/; Note: Unproductive forest = productivity $<1 \mathrm{~m}^{3} \mathrm{ha}^{-1} \mathrm{yr}^{-1}$; Annual stock removal $=$ harvesting only.

Sweden: SLU 2011: tab. 1.1.2, tab. 2.1, tab. 3.1, tab. 5.1; Note: Unproductive forest = productivity $<1 \mathrm{~m}^{3} \mathrm{ha}^{-1} \mathrm{yr}^{-1}$; Annual stock removal = harvesting only. 
A modern clearcut with aggregated retention trees from Nordmarka, Oslo, SE Norway

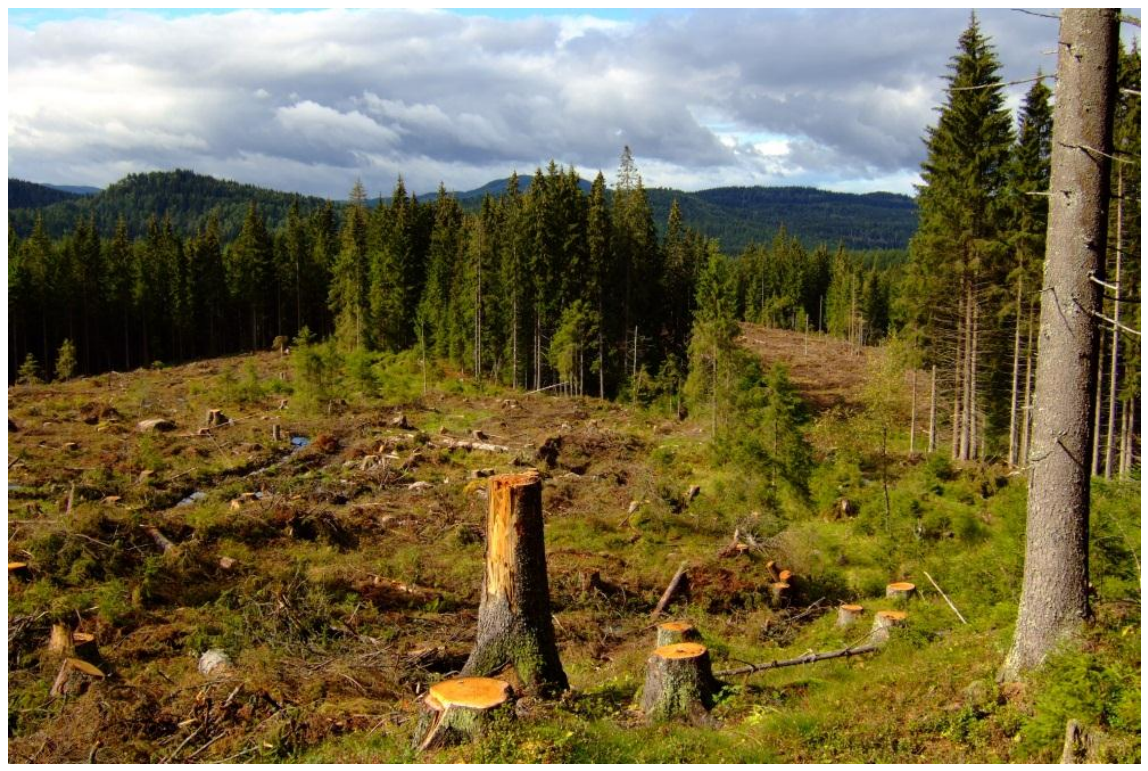

Photo: Anne Sverdrup-Thygeson, NINA.

\subsection{Ecological factors and variation in forest types}

The characteristic distributions of tree species and vegetation types of forests in the Nordic countries are mainly shaped by the natural variations in climate and site factors (primarily nutrient and water supply), the immigration of organisms since the last ice age, various natural disturbance regimes, as well as human resource use and management through the ages (cf the previous sections).

The climate, especially the overall temperature regime, has long been recognized as a major determinant of forest biodiversity, as represented by the vegetation zones from the nemoral in the southern lowlands of Fennoscandia to the alpine of the northern or mountainous parts (e.g. Ahti et al. 1968, Påhlsson 1994, Moen 1998; Figure 3.2). The temperature regime distinguishes the broadleaved deciduous temperate forests of the nemoral zone from the spruce, pine or birch-dominated boreal forests of the southern to northern boreal zones, with the mixed forests of the boreonemoral (hemiboreal) zone in between. An additional factor is the humidity gradient of high precipitation in the oceanic parts in the west and low precipitation in the continental parts in the east or in the interior, as reflected in Moen's vegetation sections (Moen 1998). The humidity gradient tends to influence ground vegetation composition rather than the major shifts in tree species composition. These climate 
factors are also reflected in the European biogeographic regions, ${ }^{4}$ as well as in the more objective and updated ecological stratification of Europe presented by Metzger et al. (2005).

Within the broad climate-based vegetation zones, local variation in nutrient and water supply is the main determinant of forest vegetation and site productivity. Hence, these are the underlying ecological factors for most classifications of forest types based on the ground vegetation (cf summary in Påhlsson 1994; see also Cajander 1949, Fremstad 1997, Hotanen et al. 2008, as well as the current Finnish forest typology), ${ }^{5}$ as illustrated in Figure 3.3 for some of the most common forest types in boreal forests. The main gradient in nutrient supply reflects a change from forest types dominated by lichens and dwarf shrubs on poor soils to increasing frequencies of grasses and herbs, with increasing species richness, as the nutrient supply increases. The other main gradient from dry to wet growing conditions is accompanied by changes in the ground vegetation from drought-tolerant, often low species to generally taller and denser vegetation (except for the wettest conditions). Forest types of poor or medium productivity tend to cover most of the forest area, with the richest forest types being rather uncommon.

Figure 3.2. Vegetation zones (left) and sections (right) reflecting gradients in annual temperatures and humidity. Indicated vegetation zones are (top to bottom): southern arctic, alpine, northern boreal, middle boreal, southern boreal, boreonemoral, nemoral. Indicated vegetation sections are (top to bottom): strongly oceanic, clearly oceanic, weakly oceanic, transition section, weakly continental

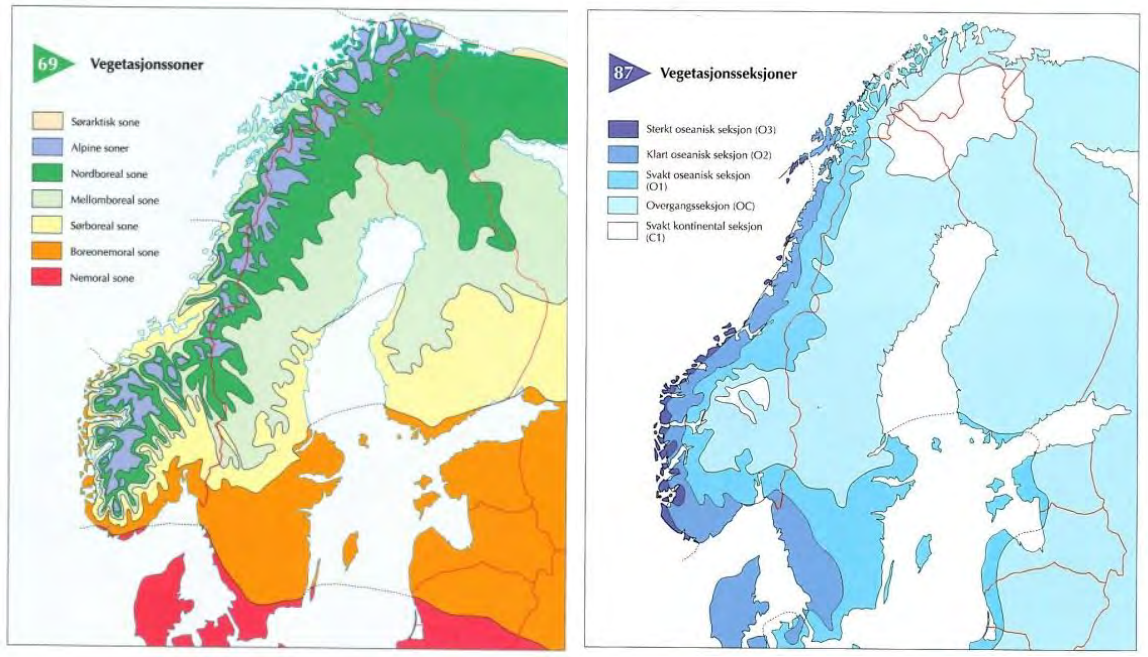

Moen 1998; reproduced by permission from the Norwegian Mapping Authority.

${ }^{4} \mathrm{http}: / /$ www.eea.europa.eu/data-and-maps/figures/european-biogeographical-regions-and-seas

${ }^{5}$ http://www.metla.fi/metinfo/kasvupaikkatyypit/skogstyperna/skogstyperna.swf 
In the boreonemoral and nemoral zones the human influence has been much stronger and more long-lasting than in the boreal zones (cf section 3.2 above), leading to stronger modification of the natural tree species distribution than in the boreal zone. Nevertheless, we can find similar responses in the forest types to gradients in nutrient supply, with dwarf shrubs and low herbs dominating the poor to medium types which often have oak or beech as dominating tree species, with hazel, birch, pine, aspen or other tree species as additional frequent species. On richer soils a richer ground flora will often be characteristic, with oak, hornbeam, elm, lime, ash, maple, and alder constituting key species of the tree layer. Under particularly poor and/or dry conditions pines may constitute the dominating tree species even in the nemoral zone. At the wet end of the moisture gradient, swamp forests with ash, common alder, birch and various willows tend to dominate in different sub-types.

Figure 3.3. The distribution of boreal forest types along gradients in nutrients and soil moisture

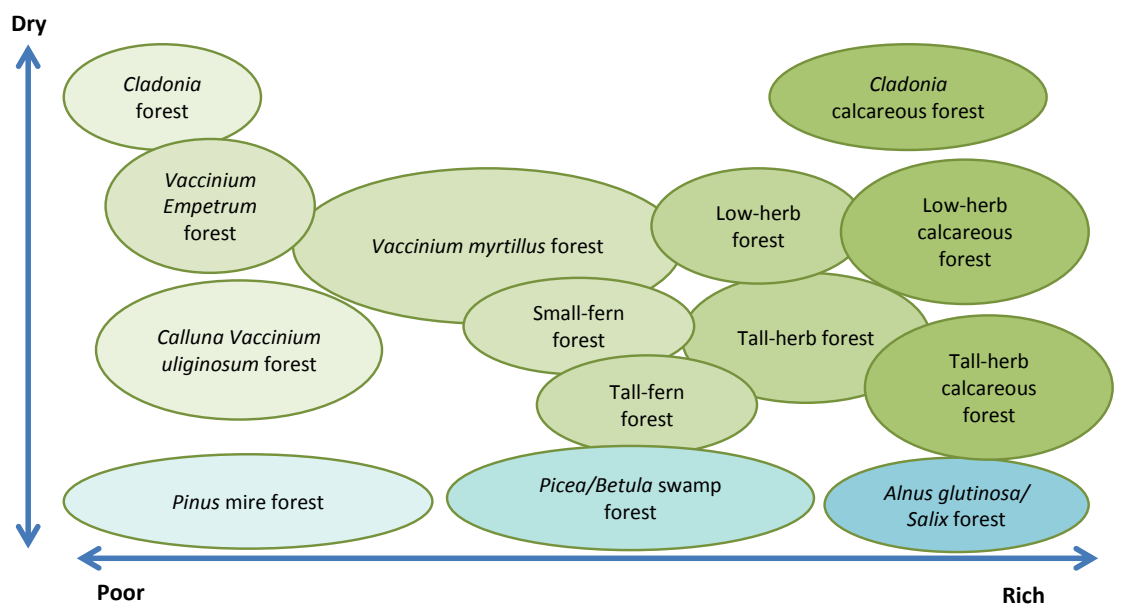

Adapted from Larsson \& Søgnen 2003, cf also Påhlsson 1994, fig. 2:1.

The national forest inventories mainly characterize natural forest variation by site quality (i.e., a scoring of the stand's potential production of tree volume) and tree species composition (mainly based on a few dominating tree species), cf Figure 3.4 (see also Figure 5.1B for an illustration of the variation in forest productivity). The Finnish, Norwegian and Swedish forest inventories also record information on forest types based on characteristics of the ground vegetation (Figure 3.3). The Danish forest inventory collects information on the main functional groups of the forest vegetation (NordLarsen et al. 2008). The forest inventories also present information on forest age (Figure 3.5). This is an important reflection of the effects of forest management on the age structure of the forests. A number of other measures of forest conditions are also recorded and presented in reports 
from the forest inventories, mainly related to the condition and changes in the growing stock, as well as various aspects of forest management.

Figure 3.4. Proportion of productive forest area distributed on major dominant tree species in Denmark, Finland, Norway, and Sweden. Boreal broadleaved species include birches, aspen, alders, willows. Temperate broadleaved species include beech, oaks, hornbeam, maples, limes and others. Mixed species stands were not reported for Norway. Mixed species stands for Finland are those where the dominating species constitutes $<75 \%$

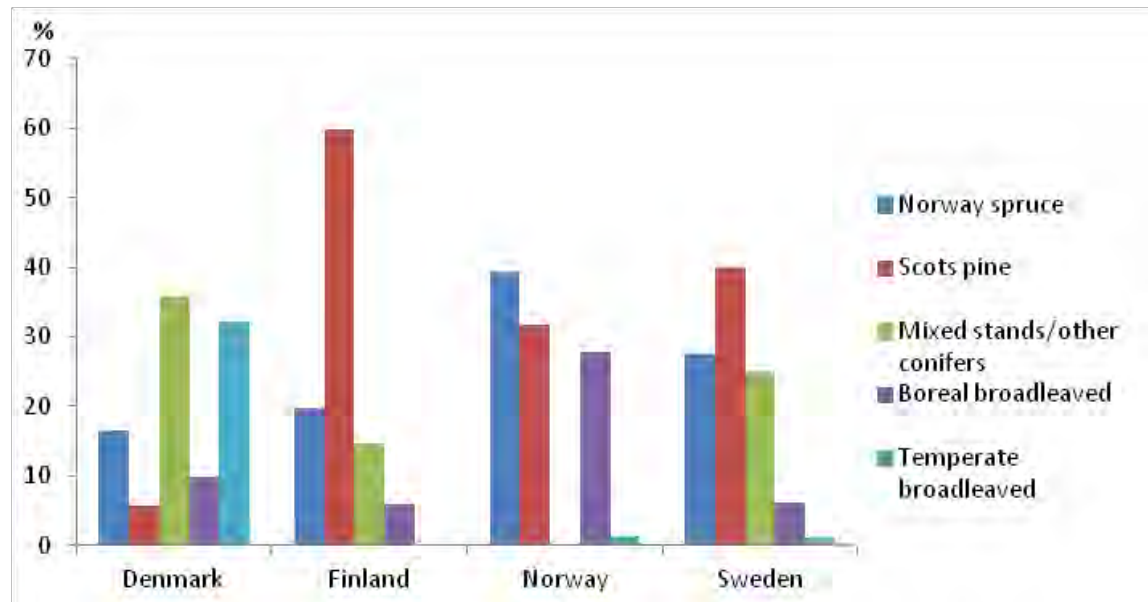

Sources: DK: Nord-Larsen et al. (2012), tables 2.2, 2.3, 4.1; FI: Metla (2011), table 1.12; NO: Larsson \& Hylen (2007), table 8; SE: SLU 2011, table 1.4.

Figure 3.5. Proportion of productive forest area distributed on age classes in Denmark, Finland, Norway, and Sweden

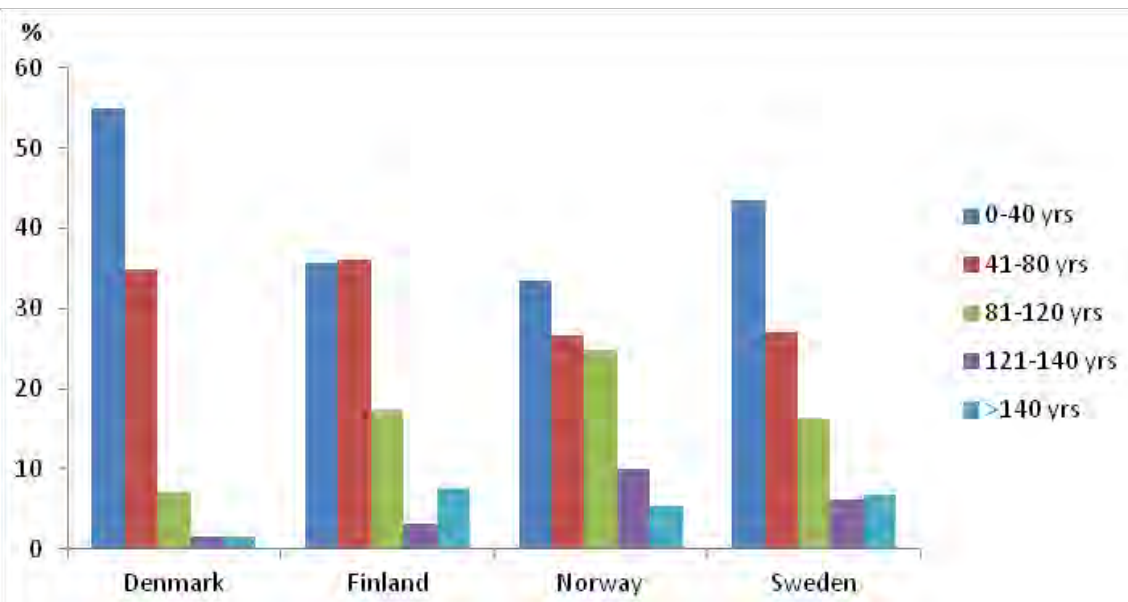

Sources: DK: Nord-Larsen et al. (2012), table 2.4; FI: Metla (2011), table 1.13; NO: Larsson \& Hylen (2007), table 4; SE: SLU 2011, table 1.5.

To the extent that national forest inventory data are used as a basis for assessing carbon stocks and fluxes, site quality and dominating tree species are the most relevant measures representing variation in forest productivity. Measures of tree sizes, as well as annual increment and 
loss of growing stock are also highly relevant for calculation of changes in carbon stocks. Other measures, such as ground vegetation, key biotopes, and the amount of dead wood, are more relevant for assessing forest biodiversity.

\section{Old-growth boreal forest in Vesijako Nature Reserve, southern Finland}

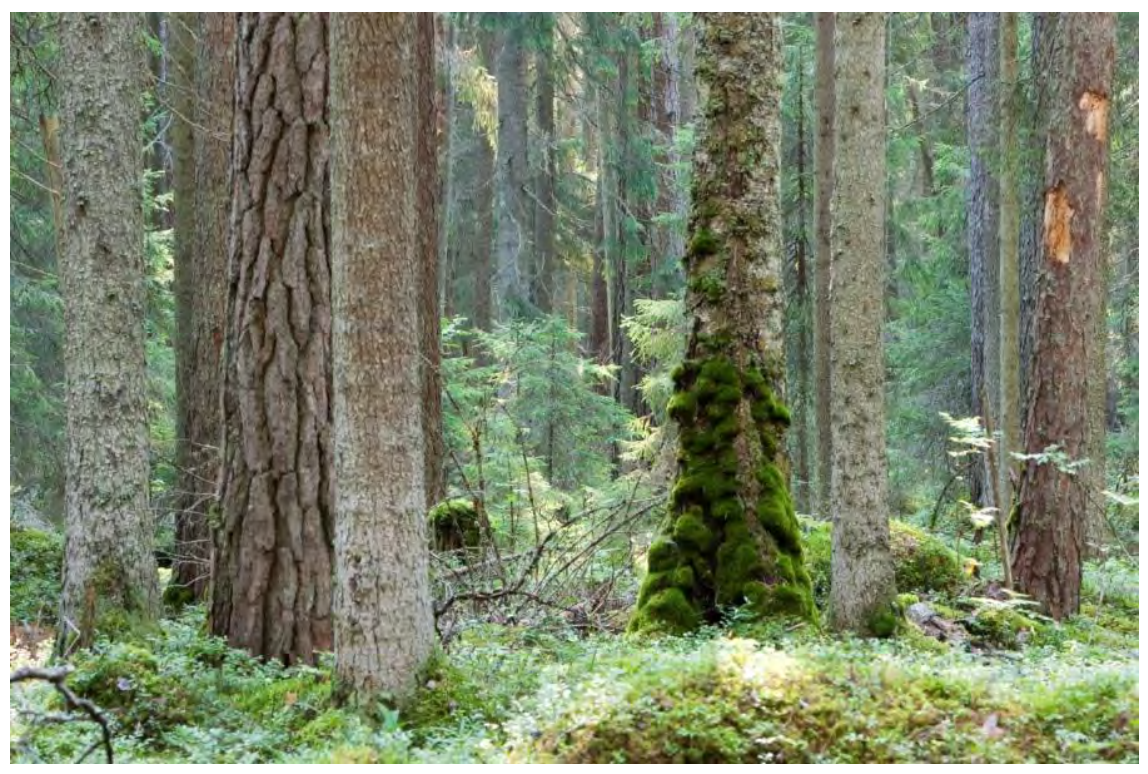

Photo: Erkki Oksanen/Metla. 


\section{Main determinants of forest biodiversity}

The Convention on Biological Diversity (CBD, Article 2) defines biodiversity as "the variability among living organisms from all sources including, inter alia, terrestrial, marine and other aquatic ecosystems and the ecological complexes of which they are part; this includes diversity within species, between species and of ecosystems." 6 Hence, biodiversity is a broad and complex concept whose attributes include composition, structure and function, at various organizational levels (Noss 1990). Depending on the biodiversity issues of interest, we may focus on specific biodiversity components representing relevant attributes and organizational levels. From a conservation perspective we may focus on threatened species or particular habitat types of conservation value. Being concerned with ecosystem functioning we may focus on biogeochemical cycles or food web linkages and dynamics.

In this chapter we will mainly take a conservation perspective on forest biodiversity and summarize how the conservation of intact forest biodiversity will depend on the maintenance of forest types and properties linked to natural forest dynamics. The biodiversity components of interest will then often be:

- Various types of intact forest ecosystems, with their characteristic structures, processes and species assemblages.

- Threatened species and their habitats, as well as threatened habitats or forest types in themselves.

- Species-rich forest types or habitats (hotspot habitats) or habitats with other conservation values.

Forest species have evolved within various natural forests and depend on specific ecosystem properties and processes linked to such natural forests. However, many forest species may have good viability also in forests without the full characteristics of natural forests, as long as they can find their key resources for survival and reproduction. Hence, we need to identify the critical properties that our current forests should

${ }^{6}$ http://www.cbd.int/convention/articles/?a=cbd-02 
contain if our aim is to maintain the original biodiversity associated with natural forests in the Nordic countries.

\subsection{Intact forest ecosystems and critical properties for biodiversity}

In chapter 3 we have described the development of natural forests and their properties in the Nordic countries, as well as the consequences of human use and management of these forests through the ages. We have seen that the managed forests of today deviate on a number of characteristics from natural forests, with respect to the underlying disturbance dynamics and turnover time between stand-replacing disturbance events, as well as in structural elements such as tree species composition, age classes, amount and quality of dead wood, and the very pattern of the landscape distribution of these structural elements.

To the extent that we have preserved sufficiently extensive forest areas under natural disturbance dynamics, it would be quite likely that we would also preserved the structural elements of particular significance for conserving the species dependent on natural forests, as well as all associated ecosystem processes. However, as has been well documented over the last few years, only very few and limited areas of natural boreal forests exist today in Fennoscandia (e.g., Aksenov et al. 1999, Hanski \& Walsh 2004, Axelsson et al. 2007, Kuuluvainen 2009). Of temperate broadleaved forests hardly any natural forests exist today (cf Andersson \& Löfgren 2000). Protected forest reserves and national parks would be an important potential resource for natural forests and associated biodiversity. However, various assessments have concluded that the network of protected forest areas is quite inadequate in Fennoscandia, with respect to total area, coverage of forest types and biogeographical distribution, as well as the degree of intactness (cf Ruuhijärvi et al. 2000, Angelstam \& Andersson 2001, Framstad et al. 2002, 2010). The lack of protection is particularly acute for forests of the southern boreal, boreonemoral and nemoral zones.

With the limited possibility of conserving natural forests at a sufficient level in protected areas, maintaining critical natural forest characteristics for biodiversity in the managed forest landscape is essential. Such critical characteristics will particularly be those properties which tend to be lacking in a forest landscape dominated by industrial, standmanaged forestry (Esseen et al. 1997, Siitonen 2001):

- Amount and diversity of dead wood, especially the continuity in supply of coarse woody debris in various stages of decay. The great significance of dead wood for forest biodiversity has recently been reviewed in detail by Stokland et al. (2012); see also Siitonen (2001). 
- Old and/or large trees of all species, but particularly old deciduous broadleaved trees like aspen, rowan, willows, and temperate deciduous species (Esseen et al. 1997). Old trees provide a range of micro-habitats for many species, including stable and varied bark structure and chemistry, a variety of dead woody substrates, and various cavities. Slow-growing old trees will have particular wood qualities of significance for several species.

- Forests recently disturbed by fire will have a variety of fire-induced dead wood as substrates and habitats for a selection of specialist species, as well as various burnt ground habitats (Granström 2001). Several specialized species either move in from distant, previously burnt sites or lie dormant between fire events for a given site. Fires also give rise to successions of deciduous trees ("lövbrännor") functioning as a temporary oasis for many species in the coniferous forest.

- Swamp forests and other wetlands will also provide a range of special habitats for vascular plants, bryophytes, lichens and insects. Such forests have often functioned as fire refugia for a long time and are characterized by continuous forest cover, as well as a moist microclimate. Both open and forested wetlands are important components of the mosaic boreal forest landscape, providing habitats for both specialized wetland species and species dependent on using a combination of habitats (Sjöberg \& Ericson 1997). Hörnberg et al. (1998) summarized studies from several swamp forests in boreal Sweden, showing high species diversity and many specialized species linked to the unique habitats of such forests.

Andersson \& Löfgren (2000) point to many of the same important properties for biodiversity in forests dominated by deciduous broadleaved trees in southern Sweden, but emphasis also properties formed by longterm traditional management, such as forests influenced by grazing/ browsing and mosaics between pastures and forests. Andersson \& Löfgren (2000) also give an indication of how long it may take for important structural elements to form and how long they may last in these kinds of forests (Table 4.1).

Table 4.1. Delivery times and duration of key resources for biodiversity in South Swedish forests

\begin{tabular}{lrr}
\hline Resource for biodiversity & Delivery time & Resource duration \\
\hline Burnt tree & 1 day (+ time to grow) & $10-50 \mathrm{yrs}$ \\
Dead wood - twigs, sticks & $3 \mathrm{yrs}$ & $3 \mathrm{yrs}$ \\
Old trivial deciduous forest & $80 \mathrm{yrs}$ & $100 \mathrm{yrs}$ \\
Dead wood - fresh coarse log & $250 \mathrm{yrs}$ & $100 \mathrm{yrs}$ \\
Dead wood - strongly decayed log & $>300 \mathrm{yrs}$ & $50 \mathrm{yrs}$ \\
Old oak & $>300 \mathrm{yrs}$ & $>300 \mathrm{yrs}$ \\
Hollow oak with $5 \mathrm{~m}^{3}$ mould & $>400 \mathrm{yrs}$ & $>100 \mathrm{yrs}$ \\
Oak pasture with continuity of giant oaks & $1,000 \mathrm{yrs}$ & $>1,000 \mathrm{yrs}$ (if managed) \\
\hline
\end{tabular}

Source: Andersson \& Löfgren 2000 
The development time and duration of important elements like old trees and coarse woody debris (CWD) in boreal forests may be quite long, due to the generally cool climate. For instance, Anderson \& Östlund (2004) and Östlund (2004) indicated a maximum lifespan of 800,400 , and 300 years for pine, spruce, and birch, respectively, and ageing starting at 300400 years for pine and 200 years for spruce. Shorohova et al. (2011) gave a natural longevity of 100-200 years for boreal deciduous trees (aspen, birches) and more than 200 years for spruce and pine. Storaunet \& Rolstad (2002) found that dead spruces could remain standing for up to 90 years, and downed spruce logs decomposed completely within about 100 years in their study sites in the southern boreal zone of SE Norway. Siitonen (2001) presented decay times for large spruce logs of 70 years for a site in southern Sweden and more than 200 years in northern Sweden. This indicates development times of at least 100 and 200 years for old boreal deciduous and coniferous trees, respectively, and a duration of another 100 to several hundred years. CWD may develop over 100 to several hundred years (probably longest for coarse pine logs) and last from less than 100 years for deciduous logs and up to a few hundred years for coarse pine logs, depending on wood quality and climate.

Concern for biodiversity in forest landscapes under industrial forestry has not only focused on the reduced supply of key habitat elements like dead wood, old trees and recently burnt areas, but also on the distribution of such elements in the forest landscape. A reduction in the overall abundance of such habitat elements will also lead to a fragmentation of their distribution, by reducing the size of each patch of habitat and increasing the isolation between patches (Andrén 1997, Kouki et al. 2001, Hanski \& Walsh 2004). The habitat reduction and fragmentation of old-growth boreal forests has been seen as the major threat to boreal forest biodiversity in Fennoscandia. The reason is that species confined to small habitat patches tend to have small populations and therefore run a higher risk of going extinct. However, habitat reduction and fragmentation are two different processes that are difficult to separate. Fragmentation effects would be apparent if the abundance of involved species decrease faster than the decrease in habitat abundance. The reduced habitat level where fragmentation increases the negative effect of habitat reduction will vary with species home range requirements and dispersal abilities and whether species will be able to use the landscape around the preferred habitat or not (Andrén 1997). Habitat specialists, poor dispersers, and species with large home range requirements will be most sensitive to fragmentation. 
Some red-listed species associated with dead wood. Clockwise from upper left: the lichen Letharia vulpina from Engerdal, Hedmark county, E Norway, the fungus Cystostereum murrayi from Marifjell Nature Reserve, Akershus county, $S E$ Norway, the fungus Artomyces pyxidatus from Østmarka, Akershus county, $S E$ Norway, larva of the beetle Cucujus cinnaberinus from Larvik, Vestfold county, SE Norway
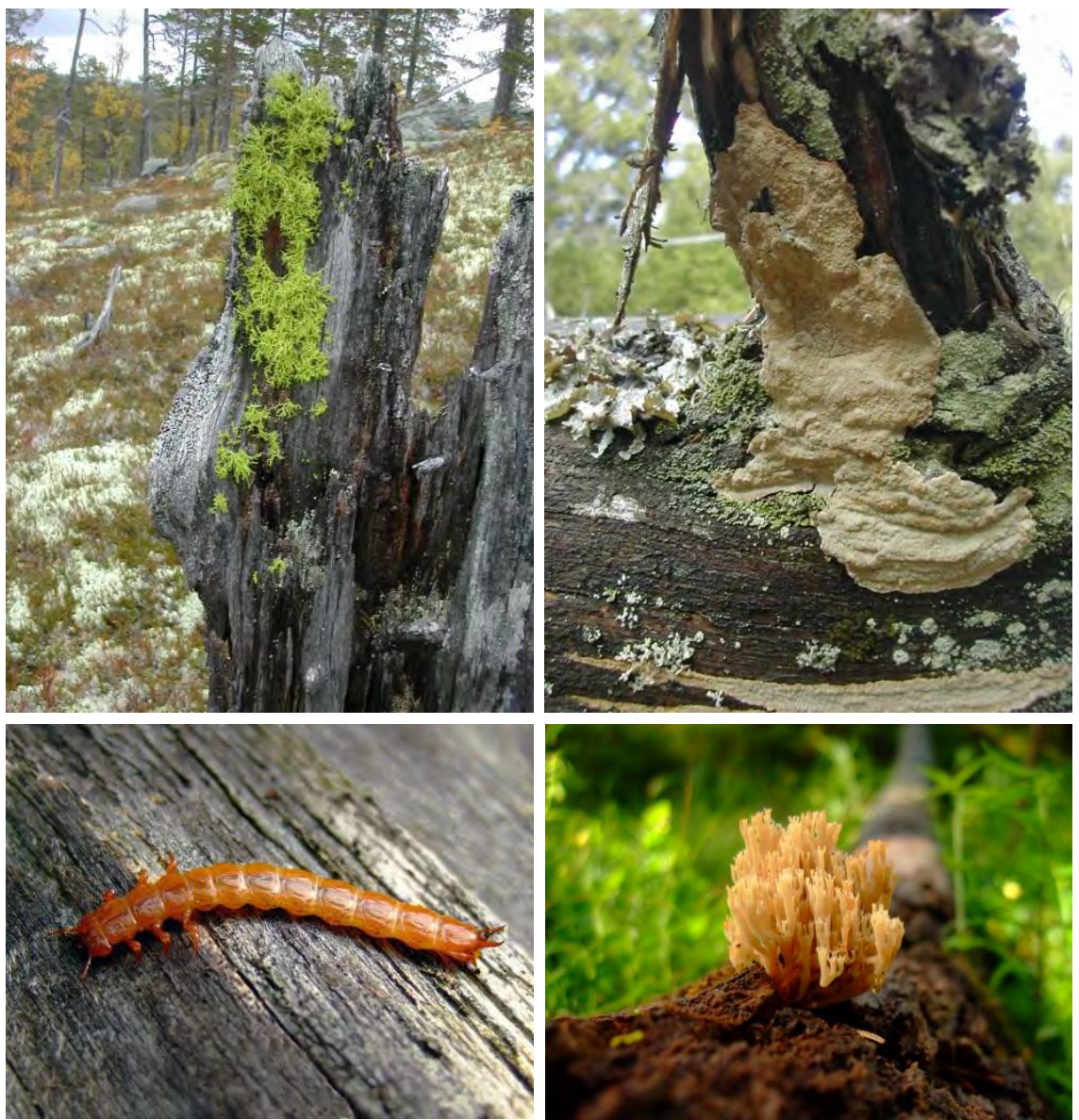

All photos: Anne Sverdrup-Thygeson, NINA.

Real fragmentation effects and critical levels of key habitat elements for boreal forest species are difficult to document. A review of published habitat threshold values for species using dead wood (Müller \& Bütler 2010) indicates that an amount of dead wood of $20-30 \mathrm{~m}^{3} \mathrm{ha}^{-1}$ would be adequate for most species in boreal forests, whereas a level of $30-50 \mathrm{~m}^{3} \mathrm{ha}^{-1}$ would be needed for most species in temperate lowland forest. However, various species and species groups have different requirements for amounts of dead wood, and to ensure the long-term survival of most species, including the most threatened, amounts of dead wood in boreal forest landscapes should probably be closer to that of natural forests, i.e. 50-100 m $\mathrm{ha}^{-1}$. The importance of fragmentation history has also been documented for fungi (polypores) on dead wood (Penttilä et al. 2006, Berglund et al. 2011). In study areas in southern Finland with the longest history of old forest fragmentation and the lowest amounts of relevant 
qualities of dead wood, both overall species richness and abundance of the most threatened species were lower than in study areas in eastern Finland with a shorter history of old forest fragmentation. The importance of long-term habitat isolation has also been shown for fungi and lichens on forest remnants in Northern Sweden, where the newly isolated forest remnants had higher species richness for lichens but not for wooddwelling fungi compared to long-isolated forest remnants (Berglund \& Jonsson 2004), indicating that lichens on newly isolated forest remnants may suffer future local extinctions whereas the fungi seem to have already adapted to the recent isolation. Hence, the landscape distribution of key habitat elements and the history of forest exploitation, as well as the amounts of such habitat elements, are important determinants for the long-term survival of forest biodiversity.

\subsection{Forest types or habitats of particular conservation value}

In the previous section we addressed important ecosystem properties for biodiversity associated with natural forests, where these properties depend primarily on the disturbance or management regime. However, the value of the forest for biodiversity also varies with site-specific factors linked to climate, productivity or specific terrain or substrate features. The value of such site specific factors for biodiversity is closely linked to the disturbance or management regime. Nevertheless, it may be instructive to try to identify the site-specific factors and the resulting forest types that are of particular value for forest biodiversity.

In general, the value for biodiversity will be linked to:

- Climate: Warmer winter and/or summer temperatures will generally be associated with higher primary production, higher species richness, higher numbers of threatened species, and more varied forest types of limited areal extent, these forest types also tend to be more threatened due to the higher population pressure in southern/lowland parts of the Nordic countries. Special climates such as very oceanic or continental will also have specialized forest biodiversity (species and habitats) that is not found elsewhere, except perhaps in particular topographic settings with a microclimate deviating from that of the surroundings.

- Site productivity: A richer supply of base cations, such as in calcareous forests, will generally be associated with higher species richness and more threatened species, as well as special forest types or habitats of limited areal extent. The supply of macronutrients like nitrogen and phosphorous, i.e., reflected in general site productivity, are also positively related to species richness in boreal forests (e.g., Gjerde et al. 2005, Heikkinen \& Mäkipää 2010), although high levels 
of macronutrients may also favour fast-growing, competitive species at the expense of overall species richness.

- Special terrain or substrate features such as stream canyons, rock walls, swamp forests, or waterfall spray zones. Such sites will often have some special biodiversity characteristics associated with the particular substrate, microclimate or growth conditions offered by such features.

- Tree species composition (within a given region) is a result of sitespecific factors (climate, productivity) as well as disturbance or management regime. Overall, higher species diversity is associated with temperate broadleaved deciduous trees (particularly oaks), than for boreal deciduous trees (particularly high for aspen and willows, less so for birches), which again tend to have higher associated species diversity than pine or spruce (Figure 4.1). These patterns are also partly reflected in the forest composition (Figure 4.2). In any case, old trees are generally more valuable for biodiversity than young trees (cf above), although for ground-dwelling fungi age may be less important than continuous presence of the associated tree species.

As we have seen in section 3.3, classification of forests into specific types are generally based on site-specific factors, either directly, like climate and site productivity, or indirectly through information on dominating tree species and/or ground vegetation composition. Such information, as well as data on stand age or development class, will often be available from forest inventories, thereby allowing a linkage to data on tree biomass and carbon stocks.

Boreonemoral oak forest from Froland, Aust-Agder county, S Norway

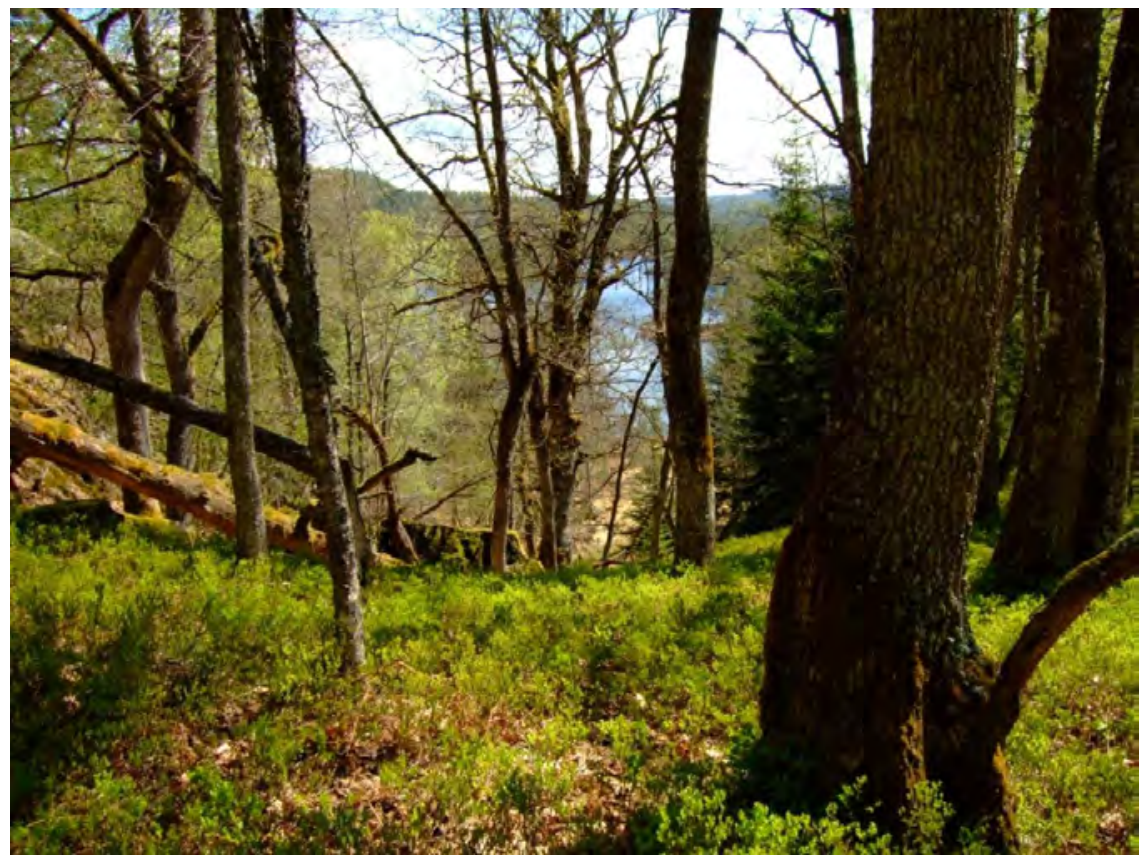

Photo: Anne Sverdrup-Thygeson, NINA. 
Figure 4.1. Number of Swedish wood-living red-listed species associated with main groups of tree species, compared to the standing volume of these groups of tree species

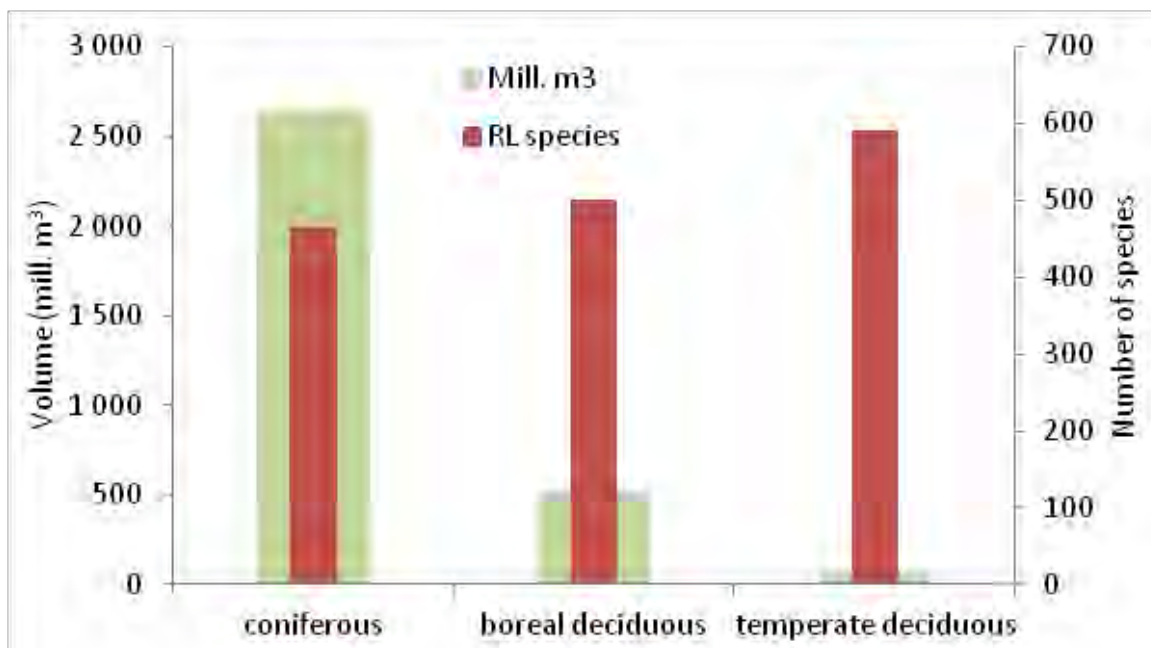

Source: Data on red-listed species from Dahlberg \& Stokland (2004); data on standing volume from SLU (2011)

Figure 4.2. Number of Norwegian red-listed species associated with various forest types, compared to the area of the respective forest types

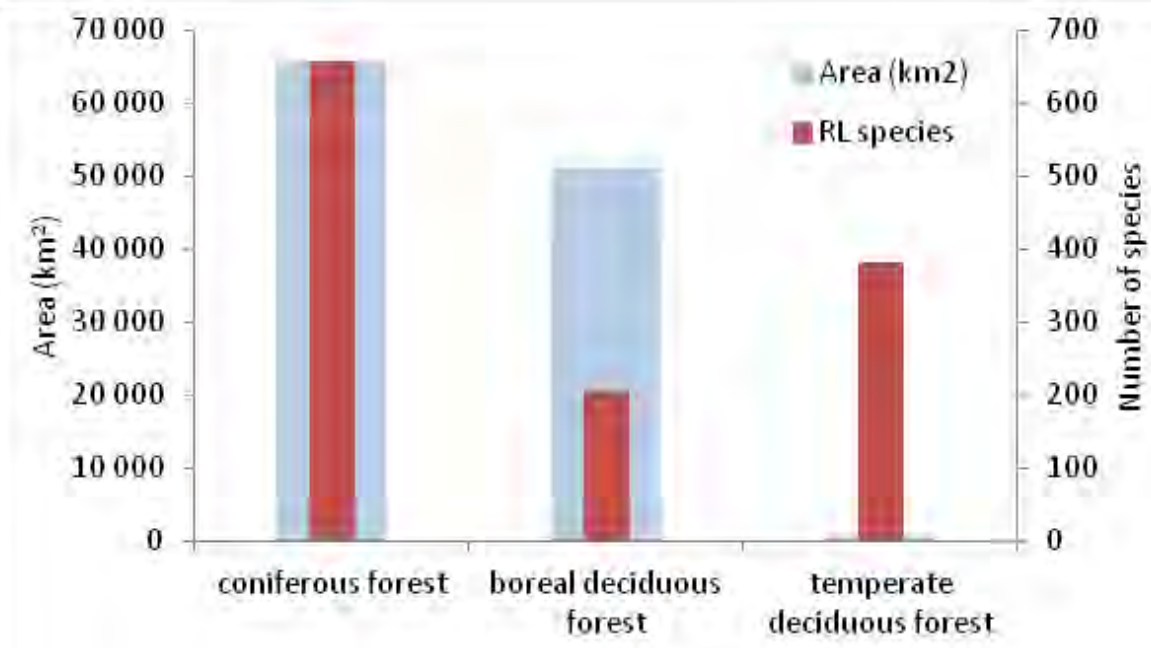

Source: Modified from Gjerde et al. (2010)

In addition, management authorities from the European to the national level have identified specific forest types of conservation interest, more or less based on underlying site-specific factors but also assuming forest conditions (tree species composition, age structure) reflecting low human impact. 


\section{European forests of conservation interest}

The European Union's Habitat Directive ${ }^{7}$ Annex I specifies habitat types (or nature types) of conservation interest at the European level. Annex I lists 81 different forest types of European conservation interest, of which 19 are represented in the EU members of the Nordic countries and seven of these are listed as priority habitat types (Table 4.2). These forest types include some very widely defined and common types (e.g., types 9010, 9020,9040,91D0), where it is sometimes specified that this should be natural (or natural-like) forests (e.g., types 9010, 9020). Other types have a more specific definition linked to particular geomorphological or hydrological structures (e.g., types 9030, 9060, 9080, 9180, 91D0, 91E0, 91F0), to more productive site conditions as indicated by the ground vegetation (e.g., types 9050, 9130, 9150, 9160, 9170) or to the influence of long-term traditional management (e.g., type 9070).

The variable defining criteria and spatial scales applying to the Annex I forest types make it quite difficult to link these types to underlying environmental gradients or other consistent environmental criteria for biodiversity value. This implies that it will be difficult to relate Annex I types to more general assessments of carbon stocks for relevant forest types in published studies or by analysis of forest inventory data. Only direct estimates of carbon stocks in a representative sample of the relevant types in the established Natura 2000 network would provide us with adequate information of the carbon stocks for the Annex I forest types. As far as we know, no such estimates exist.

\section{Nordic forest types of conservation value}

At the national level, various management authorities have attempted to classify forests into priority types for biodiversity value in order to facilitate management of forest biodiversity. Two Norwegian approaches may serve as examples, and may also be quite relevant for similar efforts in Finland and Sweden (perhaps less so for Denmark due to differences in forest characteristics).

The Norwegian Directorate for Nature Management (DN) has for several years conducted a system of inventories and mapping of valuable habitats or nature types for biodiversity (DN 2007). The identified biologically valuable areas shall be delimited, ranked, and recorded in the DN database for conservation sites, valuable nature areas etc, to be taken into consideration in physical planning. This inventory scheme has specified 13 forest types (Table 4.3). This classification seems to suffer from some of the same problems as the classification of the Habitat Directive Annex I, i.e., a mixture of defining criteria, operational at quite

${ }^{7}$ http://ec.europa.eu/environment/nature/legislation/habitatsdirective/index_en.htm 
different spatial scales. Most of the defining criteria are related to sitespecific factors (mostly nutrients, partly climate), whereas others are mainly defined by the forest state (by forest age or disturbance agent), and in most cases dominant tree species are included as an important criterion. Nevertheless, the DN forest types appear to be easier to associate with a few underlying environmental gradients (climate, site quality), supplemented by information on forest age and tree species composition, to provide a link to data from forest inventories and thus the possibility of assessing tree biomass, carbon stocks and even carbon uptake or loss for the various forest types.

Table 4.2. Forest types of the EU Habitat Directive, Annex I, in Denmark, Finland, and Sweden. Priority habitat types are indicated by *

\begin{tabular}{|c|c|c|c|}
\hline Codes and names of forest types & DK & FI & SE \\
\hline \multicolumn{4}{|l|}{ 90. Forests of Boreal Europe } \\
\hline 9010 * Western Taïga & & $\mathrm{x}$ & $\mathrm{x}$ \\
\hline 9020 * Fennoscandian hemiboreal natural old broadleaved deciduous forests (Quercus, & & $x$ & $\mathrm{x}$ \\
\hline \multicolumn{4}{|l|}{ Tilia, Acer, Fraxinus or Ulmus) rich in epiphytes } \\
\hline $9030 *$ Natural forests of primary succession stages of landupheaval coast & & $\mathrm{x}$ & $\mathrm{x}$ \\
\hline 9040 Nordic subalpine/subarctic forests with Betula pubescens ssp. czerepanovii & & $\mathrm{x}$ & $\mathrm{x}$ \\
\hline 9050 Fennoscandian herb-rich forests with Picea abies & & $x$ & $\mathrm{x}$ \\
\hline 9060 Coniferous forests on, or connected to, glaciofluvial eskers & & $\mathrm{x}$ & $\mathrm{x}$ \\
\hline 9070 Fennoscandian wooded pastures & & $x$ & $\mathrm{x}$ \\
\hline $9080 *$ Fennoscandian deciduous swamp woods & & $\mathrm{x}$ & $\mathrm{x}$ \\
\hline \multicolumn{4}{|l|}{ 91. Forests of Temperate Europe } \\
\hline 9110 Luzulo-Fagetum beech forests & $\mathrm{x}$ & & $\mathrm{x}$ \\
\hline $\begin{array}{l}9120 \text { Atlantic acidophilous beech forests with llex and sometimes also Taxus in the } \\
\text { shrublayer (Quercion robori-petraeae or Ilici-Fagenion) }\end{array}$ & $\mathrm{X}$ & & \\
\hline 9130 Asperulo-Fagetum beech forests & $\mathrm{x}$ & & $\mathrm{x}$ \\
\hline 9150 Medio-European limestone beech forests of the Cephalanthero-Fagion & $\mathrm{x}$ & & \\
\hline $\begin{array}{l}9160 \text { Sub-Atlantic and medio-European oak or oak-hornbeam forests of the Carpinion } \\
\text { betuli }\end{array}$ & $\mathrm{x}$ & & $\mathrm{x}$ \\
\hline 9170 Galio-Carpinetum oak-hornbeam forests & $x$ & & $x$ \\
\hline $9180 *$ Tilio-Acerion forests of slopes, screes and ravines & & $\mathrm{x}$ & $\mathrm{x}$ \\
\hline 9190 Old acidophilous oak woods with Quercus robur on sandy plains & $\mathrm{x}$ & $\mathrm{x}$ & $\mathrm{x}$ \\
\hline $91 \mathrm{D0} *$ Bog woodland & $\mathrm{x}$ & $x$ & $\mathrm{x}$ \\
\hline $\begin{array}{l}\text { 91E0 * Alluvial forests with Alnus glutinosa and Fraxinus excelsior (Alno-Padion, Alnion } \\
\text { incanae, Salicion albae) }\end{array}$ & $\mathrm{x}$ & $\mathrm{x}$ & $\mathrm{x}$ \\
\hline $\begin{array}{l}\text { 91F0 Riparian mixed forests of Quercus robur, Ulmus laevis and Ulmus minor, Fraxinus } \\
\text { excelsior or Fraxinus angustifolia, along the great rivers (Ulmenion minoris) }\end{array}$ & & & $\mathrm{x}$ \\
\hline
\end{tabular}

Source:

http://ec.europa.eu/environment/nature/natura2000/sites_hab/biogeog_regions/docs/Boreal_ref _list.pdf

http://ec.europa.eu/environment/nature/natura2000/sites_hab/biogeog_regions/docs/Alpine_ref list.pdf

http://ec.europa.eu/environment/nature/natura2000/sites_hab/biogeog_regions/docs/Atlantic_re f_list.pdf

http://ec.europa.eu/environment/nature/natura2000/sites_hab/biogeog_regions/docs/Continental _ref_list.pdf

Framstad et al. (2011) used Norwegian forest inventory data to estimate the carbon stocks of the biologically valuable forest types, defined as a somewhat more elaborate version of the DN forest types. The main criteria employed to select appropriate plots with biomass data from the forest inventory were ground vegetation type and dominating tree spe- 
cies, biologically relevant representation of stand age (based on development class and dominating tree species), climate zone, and some special terrain features. However, to avoid too few data points per category, it was necessary to group selected forest types into broader units, mainly representing older forests with various main dominating tree species, rich forest types (based on ground vegetation criteria), and coastal forest. For these broader units it was possible to collate data on tree biomass from the forest inventory and use this as a basis for calculating carbon stocks and changes in these stocks between two successive inventory cycles. A brief summary of the results is given in chapter 6.2 .

Table 4.3. Forest types in the scheme for inventory and mapping of biologically valuable nature types of the Norwegian Directorate for Nature Management. Codes refer to DN (2007)

\begin{tabular}{ll}
\hline Forest types & Main defining criteria \\
\hline F01 Rich, temperate, broadleaved forests & Site conditions (nutrients), tree species \\
F02 Old, poor temperate broadleaved forests & Site conditions (nutrients), state (forest age), tree species \\
F03 Calcareous forests & Site conditions (nutrients) \\
F04 Birch forests with tall herbs & Site conditions (nutrients) \\
F05 Alnus incana-Prunus padus forests & Site conditions (nutrients), tree species \\
F06 Rich swamp forests & Site conditions (nutrients, hydrology) \\
F07 Old deciduous forests & Forest state (forest age) \\
F08 Old coniferous forests & Forest state (forest age) \\
F09 Stream canyon, rock wall & Site conditions (terrain) \\
F10 Burnt forests & Forest state/disturbance agent \\
F11 Coastal spruce forests & Site conditions (climate), tree species \\
F12 Coastal pine forests & Site conditions (climate), tree species \\
F13 Rich mixed, lowland forests & Site conditions (nutrients), tree species \\
\hline
\end{tabular}

The other Norwegian example of classifications of forest properties of high value for biodiversity is the Complementary Hotspot Inventory (CHI) (Gjerde et al. 2007), conducted as part of the forest inventory as well as in the management plans of forest owners. The primary purpose of these inventories is to identify and map concentrations of habitat elements considered to be of particular value for red-listed species (Table 4.4), with the intention that the most significant concentrations should be taken into account in forest owners' management plans. Consideration of these habitat elements is part of the environmental requirements for the main Norwegian forest certification scheme under the Programme for Endorsement of Forest Certification (PEFC). Several of the habitat elements under the CHI scheme have defining criteria (Table 4.4) that are difficult to link independently to other forest inventory information. However, the abundance of $\mathrm{CHI}$ habitat elements is now routinely assessed as part of the Norwegian forest inventory, giving a direct linkage between $\mathrm{CHI}$ habitat element abundance and other inventory data like tree volume, thus allowing calculation of carbon stocks for plots with identified concentrations of CHI habitat elements. Such mechanisms for direct linkage between data on biomass/carbon stocks and habitat types or elements of importance for biodiversity may not be readily available in other forest inventory schemes. 
Table 4.4. Habitat elements for red-listed forest species as defined in the scheme for inventories of environmental values in forests (MiS) (Gjerde \& Baumann 2002)

\begin{tabular}{|c|c|c|}
\hline Habitat elements & Main criterion & Main influencing factors \\
\hline Standing dead wood, snags & Forest state & Management, tree species, stand age, climate \\
\hline Lying dead wood, logs & Forest state & Management, tree species, stand age, climate \\
\hline Trees with rich bark & Forest state & $\begin{array}{l}\text { Specific deciduous tree species with bark of high } \mathrm{pH} \text {, } \\
\text { linked to site conditions, climate, management }\end{array}$ \\
\hline Trees with pendulous lichens & Forest state & Climate, tree species, management \\
\hline $\begin{array}{l}\text { Older successions of deciduous } \\
\text { trees }\end{array}$ & Forest state & Succession stage, linked to site conditions, climate \\
\hline Old trees & Forest state & Management, tree/stand age \\
\hline Hollow deciduous trees & Forest state & Tree species, tree age, management \\
\hline Fire area & Forest state & Management, linked to terrain, climate \\
\hline Rich ground vegetation & Site conditions & Nutrient supply \\
\hline Rock walls & Terrain & Value depends on forest state \\
\hline Clay gullies & Terrain & Value depends on forest state \\
\hline Stream canyons & Terrain & Value depends on forest state \\
\hline
\end{tabular}

Large aspens with a rich flora of epiphytic lichens (inset), Dividalen, Troms county, N Norway

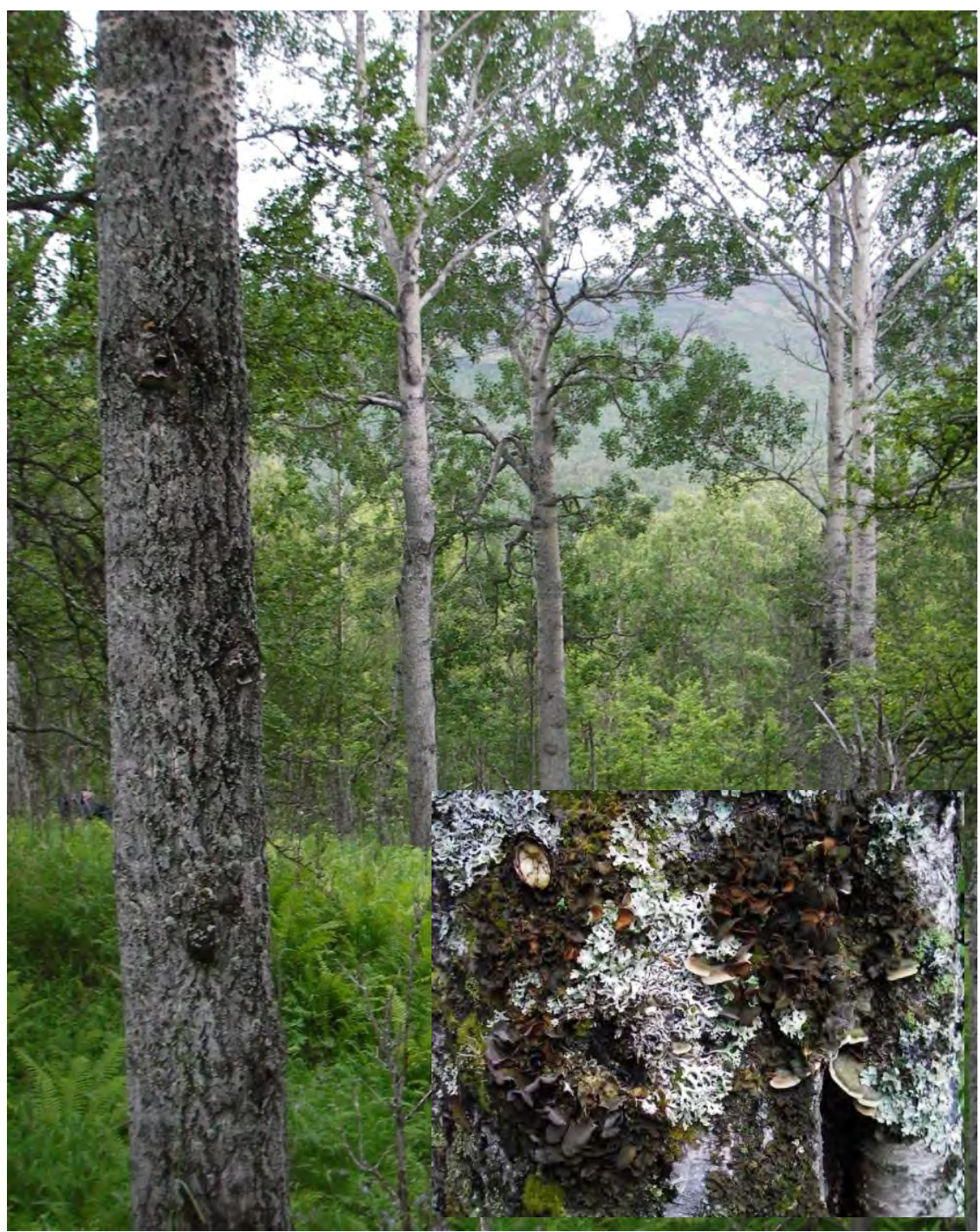

Photos: Erik Framstad, NINA. 


\section{Forest carbon pools and fluxes}

\subsection{Definitions of ecosystem carbon accumulation}

Comparison of published estimates of carbon accumulation in forests requires clear concepts that are explicit with regard to time and spatial boundaries. Carbon fluxes are determined across different temporal and spatial scales and it is not always transparent which carbon fluxes are included in a given estimate (Chapin et al. 2005, Randerson et al. 2002).

The following definitions have been proposed:

- The Net Ecosystem Carbon Balance (NECB) is the term applied to the total rate of organic carbon accumulation (or loss) from ecosystems (Chapin et al. 2005). Integrated over time and space, NECB equals net biome productivity (NBP) (Schulze et al. 1999) or Net Ecosystem Productivity (NEP) (Randerson et al. 2002).

- NBP has been defined as the net rate of carbon accumulation across different ecosystems on longer time scales, including effects of disturbance such as forest management and forest fires (Schulze et al. 1999). More recently, also lateral fluxes of carbon by rivers have been included in NBP (Randerson et al. 2002).

- Net Ecosystem Productivity (NEP) has been defined as the difference between Gross Primary Production (GPP) and Ecosystem Respiration (ER, autotrophic (Ra) and heterotrophic (Rh) respiration) (Schulze et al. 1999) or as the rate of change in carbon stocks within an ecosystem (Randerson et al. 2002). The first definition does not included carbon losses with regard to riverine fluxes or non-respiratory losses related to logging and fire, and it is not specific with regard to physical ecosystem boundaries, in contrast to the second definition. The second definition implies that NEP is the sum of all carbon fluxes in and out of the system, and is thereby identical to the change in carbon pools within an ecosystem. A third definition was used by Liski et al. (2006), who quantified NEP by subtracting heterotrophic respiration (Rh) from Net Primary Productivity (NPP). Thereby, exported wood products were also included in the NEP estimate, and NEP was extended to yield also carbon stocks outside the physical boundaries of the forest.

- Net Primary Productivity (NPP) is the difference between Gross Primary Productivity (GPP) and autotrophic respiration (plant respiration), and thus equal to all produced plant material. 
- GPP is the production of organic compounds from atmospheric or aquatic carbon dioxide $\left(\mathrm{CO}_{2}\right)$ by plant photosynthesis.

- Heterotrophic respiration ( $\mathrm{Rh})$ is $\mathrm{CO}_{2}$ production by decomposition of plant material by organisms that use plant material as an energy source, primarily microorganisms and herbivores.

- Autotrophic respiration (Ra) is defined as respiratory losses by plants for maintenance, construction and nutrient uptake.

- Non-respiratory losses of carbon are losses from fire, harvested biomass and aquatic carbon transport.

NBP and NEP have been proposed to be identical because it is conceptually and practically difficult to differentiate between episodic disturbances and regular patterns of disturbance, and thereby to distinguish between NBP and NEP (Randerson et al. 2002). However, the use of NEP is not straightforward and in some cases it is used for the forestry sector rather than for a spatially defined ecosystem. For example, Liski et al. (2006) defined NEP as NPP minus heterotrophic respiration (estimated using a soil model), which means that non-respiratory carbon losses (exported wood products) were included in the NEP for Finnish forests, and NEP was not limited to a spatially defined ecosystem. Similarly, NBP for the Canadian forest sector was found to be very small due to harvesting and disturbance while NEP was much larger because export of wood products and mortality was included in NEP (Stinson et al. 2011). Here, NBP was defined to be similar to the net change in storage of forest carbon stocks within the spatial boundaries of the forest, while NEP related also to carbon stocks in wood products outside the forest.

\subsection{Methods for studying forest carbon accumulation}

Methods used for the quantification of forest carbon accumulation include empirical and modelling approaches and combinations of both. Models are often used to predict soil carbon accumulation because measurement of changes in the soil carbon stocks is difficult, since the expected change is small compared to the stock. Models are also important tools for describing and predicting the forest carbon cycle. The credibility of model results depends on the quality of the input data, a meaningful model structure, and appropriate parameterization of the model. Empirical approaches cover sampling-based inventories with representative sets of measurements, direct measurements of single pools and fluxes over time (repeated measurements), and stand-level top down measurements of $\mathrm{CO}_{2}$ exchange between the atmosphere and the ecosystem (eddy covariance). Smaller scale flux measurements with chamber methods are also used to measure $\mathrm{CO}_{2}$ fluxes from soils to the atmosphere and to estimate overall greenhouse gas fluxes from peatlands. An indirect way to study temporal developments of carbon stores 
is by using chronosequences, i.e., replacing time with space and measuring similar sites covering a range of ages.

The eddy covariance technique is a micrometeorological method that measures the vertical $\mathrm{CO}_{2}$ exchange between an ecosystem and the atmosphere, and results in an estimate of net ecosystem exchange (NEE) (Baldocchi 2003). NEE is usually estimated on a scale of several ha up to $1 \mathrm{~km}^{2}$, seasonally or up to more than a decade, and does not differentiate between soil and vegetation carbon uptake. The technique requires that the underlying surface is horizontally homogeneous, a requirement that is not often met in old forest stands with uneven canopy structures and topographies characterized by low favourability for other human land use and low accessibility (Knohl et al. 2009). Sites unaffected by disturbances such as harvest, fire or insect infestations will typically have an NEE that is larger than NBP. Upscaling of NEE from stand to larger spatial scales is therefore not straightforward and meets questions of representativity of the specific forest stand, in addition to the size of nonrespiratory losses of carbon at regional scales. Chamber techniques are used to measure soil respiration, but do not differentiate between autotrophic versus heterotrophic respiration. For using total soil $\mathrm{CO}_{2}$ fluxes to quantify soil carbon storage, additional estimates of autotrophic soil respiration are needed and these can be estimated using modelling approaches (Janssens et al. 2000, Moren \& Lindroth 2000). Additionally, chamber methods suffer from artefacts related to chamber pressure and lack of turbulence (Lund et al. 1999, Pumpanen et al. 2004a).

Instead of studying forest carbon accumulation at the site level, chronosequences may be used as a space-for-time approach, where changes in carbon pool sizes between stands of different ages are interpreted as standage dependent carbon accumulation rates (Peltoniemi et al. 2004, Walker et al. 2010). Walker et al. (2010) discuss the use of chronosequences for studies of ecological succession and soil development. Sound conclusions from chronosequences require that the sites in the chronosequence follow the same predictable trajectory, and that spatial heterogeneity and differences in initial conditions (e.g., soil parent material) of the chronosequence stands play a minimal role. Chronosequences may be of particular value for measuring soil carbon accumulation, because soil carbon pool changes are hard to measure at short time scales due to the destructive nature of soil sampling, and since the relatively small changes in soil carbon relative to the size of the soil carbon pool are difficult to quantify.

At larger spatial and temporal scales, forest inventories can be used to estimate changes in forest carbon uptake. Data on tree volume from forest inventories are used together with allometric equations, factors for litter production and mortality, and regional statistics on forest harvest and fellings to produce regional estimates of changes in forest biomass carbon storage. Forest NPP (all produced plant material) can be quantified by summarizing the change in biomass (trees and ground vegetation), litter production, mortality and fellings (see Liski et al. 
2006). Because forest inventories collect data on existing forests, effects of disturbances and logging are included.

In the Nordic countries, only the Swedish forest inventory includes nation-wide repeated measurements of soil carbon stocks. In the other Nordic countries, available soil data is not representative for monitoringsoil carbon stock changes. Repeated measurement of soil organic matter is destructive and requires large spatial replication for detection of temporal changes. Spatial variability may be high, while changes in soil organic matter stocks in boreal forests are usually small compared with existing stocks (Häkkinen et al. 2011). Therefore, models are developed with an aim to quantify soil carbon sequestration and many of them are applicable for nation-wide soil carbon assessment (Peltoniemi et al. 2007).

Classical soil carbon turnover models usually include different pools with decay rates according to first-order kinetics with pool-specific turnover constants. These models lead logically to a steady state situation when inputs are kept constant. In the absence of information on initial soil carbon stocks and the size of the soil carbon sink, a steady state between carbon inputs (litter) and outputs $\left(\mathrm{CO}_{2}\right.$ from decomposing soil organic matter) at the beginning of the time series is a common assumption. Because soil carbon stocks respond slowly to changes in litter inputs and environmental conditions, assumptions about the initial state of the soil carbon stocks (loosing carbon, steady state, or a sink) are critical for the calculation of forest soil carbon accumulation. Reaching a steady state soil carbon stock may take millennia of constant litter input (Ågren et al. 2007). However, soil models can be applied if variation in litter production (i.e., dynamics of the mortality and litter fall from living trees) of the old forests can be estimated. Reichstein et al. (2009) address the implications of steady state models for soil carbon accumulation in more detail and propose alternatives based on more detailed process descriptions.

In Finland and Norway, regional forest carbon accumulation estimates are based on forest inventory data and the Yasso soil carbon model (Liski et al. 2006, Rantakari et al. 2012). The Yasso model describes soil organic matter accumulation as a function of litter flow, litter quality and temperature and is not differentiated according to soil horizon (Liski et al. 2005). This model is constructed as a classical soil carbon model, as described above. Yasso has been calibrated to litter decomposition studies of very different litter types.

Forest soil carbon accumulation in Swedish forest for the period 1926 to 2000 was calculated in a very similar way as done by Liski et al. (2005), but using different factors to calculate litter production and a different soil carbon model, i.e., the Q model (Ågren et al. 2007). The Qmodel takes into account litter quality and invasion rates of litter by decomposers. The vertical distribution of soil organic matter is not included. Validation of the model was done by modelling known soil carbon stocks in well-studied forest stands. 
Initialization of the models is challenging when only short time series are available, and in addition to temperature, also precipitation and soil drainage affect soil carbon stocks. It should be noted that also model predictions of changes in soil carbon is associated with different forms of uncertainty. The problem is the same as for repeated measurements: the predicted changes in soil organic carbon are small compared to the soil organic carbon pool. Parameter uncertainty and uncertainty in input variables like, e.g., litter fall leads to uncertainty in the predictions which in many cases prevents conclusive results about the direction of change (Ortiz et al. 2011).

Pristine pine forest very rich in dead wood, Norddalen, Nordland county, N Norway

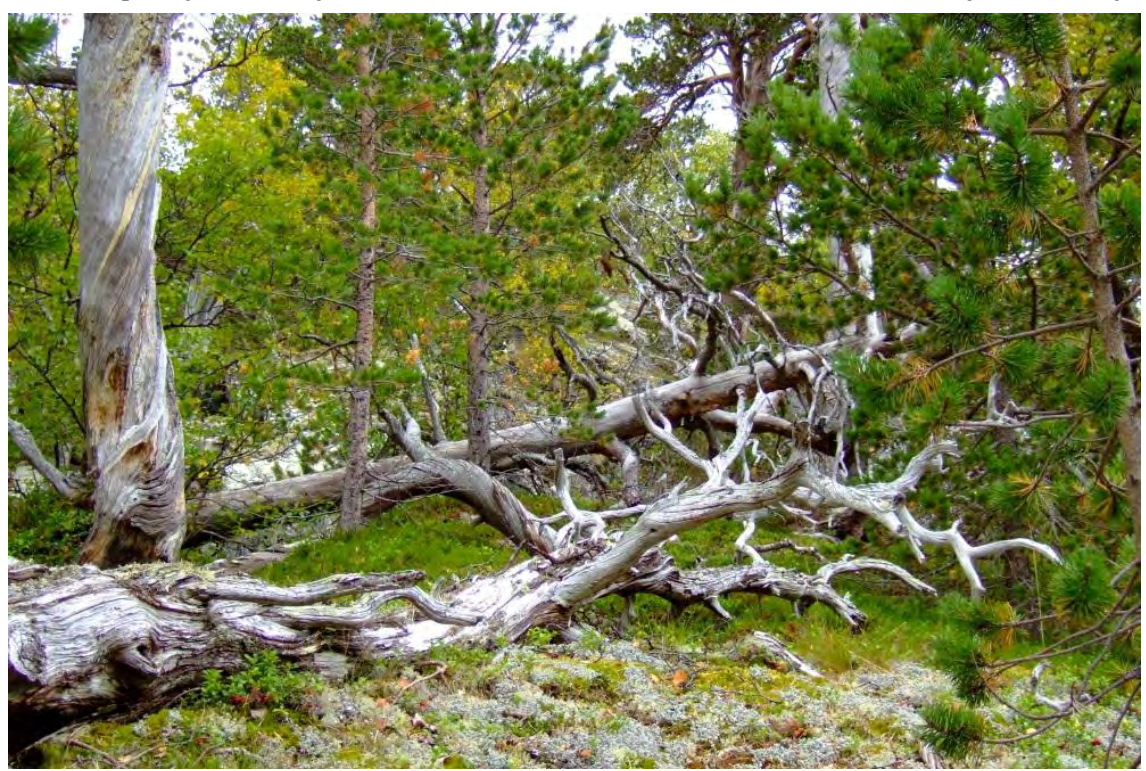

Photo: Anne Sverdrup-Thygeson, NINA.

\subsection{Driving factors of forest biomass growth}

Biomass, i.e., dry mass of living organisms, constitutes a relatively large carbon pool in Fennoscandian forest ecosystems and roughly half of this biomass is carbon (Thomas \& Martin 2012). Animals, understory vegetation, and trees all contribute to the total forest biomass but the role of understory vegetation and especially animals is minuscule compared to trees. For example, in Southern Finland in pine stands 5-120 years of age, low shrubs contained 44-277 $\mathrm{g} \mathrm{m}^{-2}$, mosses $34-208 \mathrm{~g} \mathrm{~m}^{-2}$ and grasses and herbs $0-163 \mathrm{~g} \mathrm{~m}^{-2}$ (Kulmala 2011). These figures are low compared to the average tree biomass in Finnish forests of $6,900 \mathrm{~g} \mathrm{~m}^{-2}$ (Metla 2011).

Stokland et al. (2003) made a synthesis of the variation in forest growing stock and productivity across Finland, Norway and Sweden based on data from the respective national forest inventories (Figure 5.1 A, B). A somewhat similar map of the variation in Danish forest growing 
stock is presented by Nord-Larsen et al. (2012) (Figure 5.1 C). This gives an impression of how the variation in growing stock and productivity may be related to the geographic variation in climate.

Foresters have traditionally focused on growth of stem volume. This gives an idea of carbon accumulation of a tree and a stand, but for a better picture other organs and wood density also need to be considered. The biomass of trees is distributed on stems, roots, branches and foliage. Most of the biomass is in the stem (Figure 5.2). Despite its physiological importance, the biomass of foliage is relatively low. Pines, spruces and birches have similar stem biomass and spruces and birches have similar branch biomass relative to their stem diameter at breast height $(1.3 \mathrm{~m})$.

Figure 5.1. Geographical variation in (A) growing stock ( $\left.\mathrm{m}^{3} \mathrm{ha}^{-1}\right)$ and (B) productivity ( $\mathrm{m}^{3} \mathrm{ha}^{-1} \mathrm{yr}^{-1}$ ) for forests in Finland, Norway, and Sweden (from Stokland et al. 2003) and (C) mean growing stock ( $\left.\mathrm{m}^{3} \mathrm{ha}^{-1}\right)$ for Danish municipalities (Nord-Larsen et al. 2012).

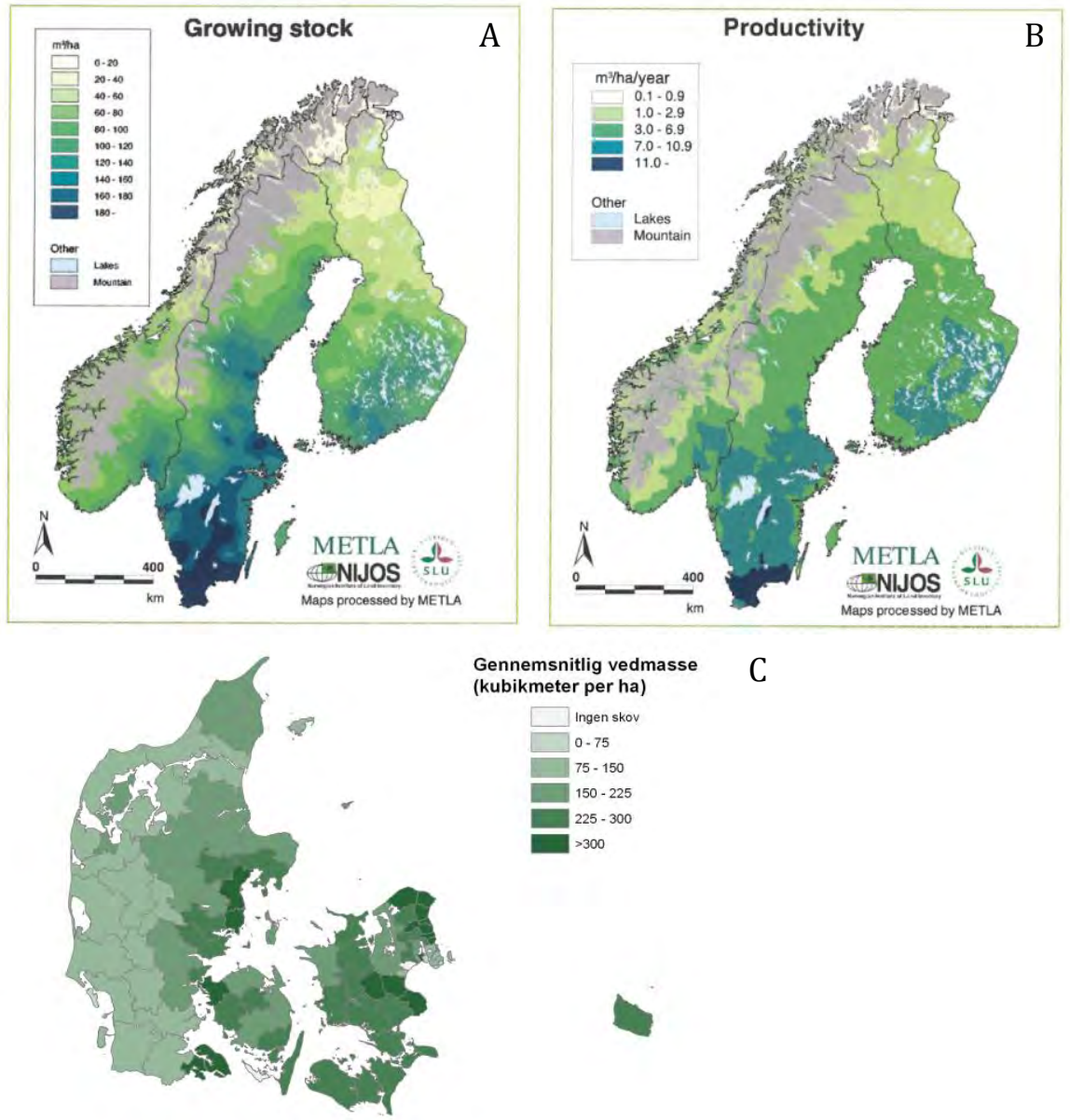

Source: The maps for Finland, Norway, and Sweden have been constructed by Metla and are based on data from the respective national forest inventories carried out during 1986-1994 (Finland), 1995-1999 (Norway), and 1993-1997 (Sweden). The map for Denmark is based on data from the Danish forest inventory in 2006-2010. Reproduced by permission from the Finnish Forest Research Institute, the Swedish University of Agricultural Sciences (SLU), The Norwegian Forest and Landscape Institute, and the Forest and Landscape Centre of the University of Copenhagen 
Figure 5.2. Biomass of four main organs of individual Scots pine and Norway spruce trees in Sweden. Data for birch stems and branches is from both silver and downy birch individuals. (Data from Marklund 1988)

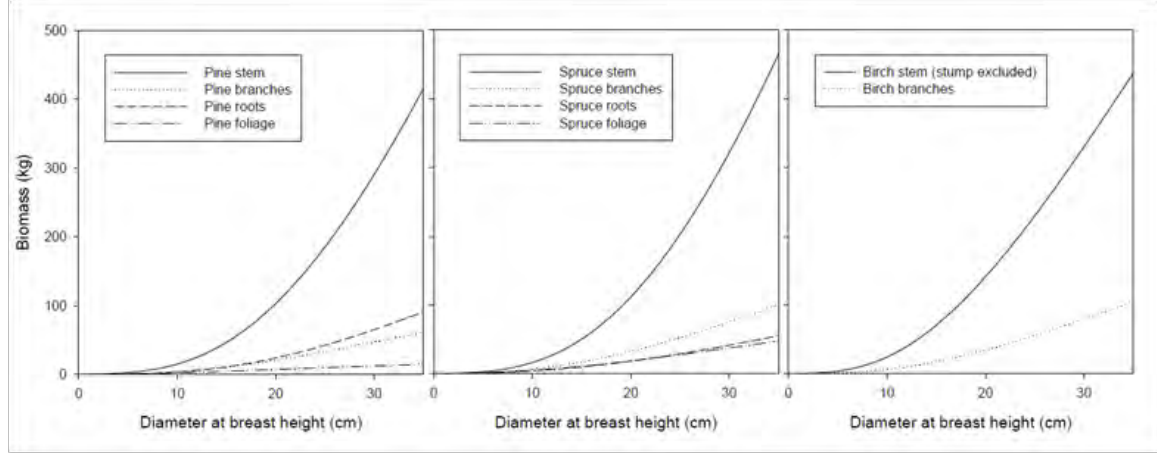

However, spruce trees have significantly higher branch and foliage biomass than pines, whereas pine trees have higher root biomass than spruces (Figure 5.2). Similar relationships have also been documented for spruce and beech in Denmark (Skovsgaard et al. 2011, Skovsgaard \& Nord-Larsen 2012). Often, the biomass of all trees per unit area is of interest and not the biomass of individual trees. To obtain biomass per unit area the biomass of individuals would need to be multiplied by the number of individuals per unit area. However, in practice in Fennoscandian countries stem volumes per unit area are typically converted directly to total biomass per unit area (e.g., Lehtonen et al. 2004).

Theoretically, the role of soils and climate on aboveground biomass can be understood based on energy budgets. Trees produce the energy they need via photosynthesis that for a given tree species depends largely on leaf area per unit land area (which increases with increasing soil fertility). They consume the energy by building their biomass or by respiring (autotrophic respiration). Both production and consumption are size dependent. Production increases until canopy closure but is relatively stable thereafter. Consumption increases with increasing tree size. Both are also temperature dependent. Production first increases with increasing temperature but is relatively stable or even decreases above typical Fennoscandian summer temperatures. Consumption on the other hand increases consistently with increasing temperatures. Therefore, globally one would expect the fastest growth of small trees in the tropics, the highest old forest biomasses per unit area in maritime temperate climates similar to that of England, and faster growth and higher old forest biomass on fertile soils (Larjavaara \& Muller-Landau 2012). Hot spells that dramatically increase the respiration costs without equivalent increase in production are rare or non-existent in the relatively maritime and cool Fennoscandia. Therefore in Fennoscandia one would expect both faster growth and higher old forest biomass in warmer climates and more fertile soils. 
An extensive dataset of successional forests collected in Finland (Ilvessalo \& Ilvessalo 1975) supports the expected trends of increasing temperature and soil fertility resulting in faster biomass accumulation in successional forests. In addition, they report valuable data on species specific differences in stem wood volume accumulation speed. In the mesic (Myrtillus type) fertility class, pine stands had accumulated $407 \mathrm{~m}^{3}$, spruce $398 \mathrm{~m}^{3}$, silver birch $269 \mathrm{~m}^{3}$, downy birch $212 \mathrm{~m}^{3}$ at the age of 80 years.

Theoretically, higher old forest biomass was expected on fertile and warm sites. Vucetich et al. (2000) studied old pine forest stands (aged 66 - 178) in a South-North transect from southern Poland to northern Finland. The aboveground biomass decreased from $13,600 \mathrm{~g} \mathrm{~m}^{-2}$ in the southernmost plot to $2,800 \mathrm{~g} \mathrm{~m}^{-2}$ close to the northern tree line. These correspond to basal areas of trees at breast height of $27.3 \mathrm{~m}^{2} \mathrm{ha}^{-1}$ and $11.2 \mathrm{~m}^{2} \mathrm{ha}^{-1}$. The much higher aboveground biomass of spruce dominated forests in more fertile soils is evident from a dataset of 57 old-growth plots in southern and central Finland in which the average basal area was $38.9 \mathrm{~m}^{2}$ ha-1 $^{-1}$ (Isomäki et al. 1998).

\subsection{Driving factors of soil organic matter pools}

Soil organic matter pools are the resulting balance of inputs of plantderived materials, decomposition and outputs of plant-derived carbon. Soil formation, and thereby the development of soil organic matter pools, is driven by the five classical soil forming factors, i.e., climate, parent material, topography or landscape position, biology (vegetation, fauna, microbes, and humans) and time. More generally speaking, soil organic matter pools are the result of physical, chemical, biological and anthropogenic impacts over time. Boreal forest soils may also contain charcoal, a product of forest fires and an almost inert form of carbon that is considered a small, but long-term sink for atmospheric carbon (Ohlson et al. 2009).

Most boreal and temperate forests are nitrogen limited, i.e. the access to nitrogen is determining the growth rate of the forests (Tamm 1991). Through the positive effects on growth, nitrogen input will result in increased litter production which in turn increases the formation of soil carbon. Positive effects of nitrogen addition on soil carbon sequestration have been found both for atmospheric nitrogen deposition (De Vries et al. 2006) and for addition through fertilization (Johnson \& Curtis 2001). Since all organic matter in forest soils except charcoal contains nitrogen, all carbon sequestration implies nitrogen sequestration. Depending on the soil properties and the efficiency of soil organic matter degradation the effect on soil carbon sequestration may lie in the range of 15 to $40 \mathrm{~kg}$ of carbon for each added $\mathrm{kg}$ of nitrogen. The effect will be larger when taking biomass increment into account. The effects of nitrogen on carbon sequestration can not only be explained by increased litter input. Increased ni- 
trogen availability seems to reduce $\mathrm{CO}_{2}$ mineralization leading to sequestration of a higher proportion of the litter (Sjöberg et al. 2003).

Forest soils in boreal and temperate regions usually have an organic horizon on top of the mineral soil. The organic (0) horizon, or forest floor, consists of fresh plant litter on the top and gradually more decomposed organic material below. Several layers can be distinguished for the $\mathrm{O}$ horizon: litter $(\mathrm{L})$, fermentation $(\mathrm{F})$ and humified $(\mathrm{H})$ layer. The $\mathrm{O}$ horizon is the most dynamic part of the soil profile, most exposed to disturbance and climate. Depending on the level of biological activity, the division between the 0 horizon and the mineral soil can be clear or poorly defined. In some cases, an organic-rich A horizon is formed at the top of the mineral soil. The dissolved humic compounds in excess rain water collect iron (Fe) and aluminium (Al) on their way down, thereby creating an eluviation horizon (E horizon, grey or light-coloured, low in organic matter) and gradually decreasing their solubility, to precipitate further down in an illuviation horizon (B horizon) which is usually dark, rich in $\mathrm{Fe}$ and $\mathrm{Al}$ and with varying thickness. Root distribution and litter production is also an important contributor to soil organic matter in mineral soils. The older, and more well-developed the soil, the deeper and thicker the B horizon usually is. Underneath, the unaltered parent material is characterized as the $\mathrm{C}$ horizon.

In all Nordic countries, podzolic soils are common in forests because of the poor parent material (acidic, nutrient-poor geological substrate), the acidic litter quality from coniferous trees combined with a surplus of precipitation which transports humic compounds from the 0 horizon to the mineral soil. Organic histosols are particularly common in Finland, and other soil types such as cambisols and arenosols are also quite common in boreal forests. On more clay-rich parent materials luvisols and cambisols are also common in Denmark. Table 5.1 indicates the distribution of major soil types for the whole territory of each country.

\begin{tabular}{|c|c|c|c|c|}
\hline Major soil types & Denmark & Finland & Norway & Sweden \\
\hline Podzols (structured by iron/aluminium chemistry) & $30 \%$ & $50 \%$ & $40 \%$ & $45 \%$ \\
\hline Histosols (peat soils) & $5 \%$ & $30 \%$ & $x$ & $5 \%$ \\
\hline Leptosols (shallow soils) & $x$ & $x$ & $50 \%$ & $15 \%$ \\
\hline Luvisols (clay-enriched subsoil) & $30 \%$ & & & \\
\hline Cambisols (brown soils) & $10 \%$ & $8 \%$ & $\mathrm{x}$ & $10 \%$ \\
\hline Arenosols (sandy soils) & $10 \%$ & & $\mathrm{x}$ & $13 \%$ \\
\hline Umbrisols (acidic dark top soil) & $x$ & & $x$ & \\
\hline Regosols (soils with no profile development) & $\mathrm{x}$ & $\mathrm{x}$ & & $5 \%$ \\
\hline Gleysols (groundwater affected soils) & $5 \%$ & $\mathrm{x}$ & & $\mathrm{x}$ \\
\hline Fluvisols (floodplain soils) & $5 \%$ & & $x$ & \\
\hline Stagnosols (soils with stagnating water) & $\mathrm{x}$ & & $\mathrm{x}$ & \\
\hline
\end{tabular}


The ratio of soil organic matter stored in the 0 horizon versus in the mineral soil can vary considerably depending on soil age, litter production, climate and so forth. In the mineral soil, organic matter stocks usually decrease strongly with depth, with a possible exception for the E horizon where the soil carbon concentration is low (Gleixner et al. 2009).

Several climatic gradients exist in the Nordic countries (Figure 3.2), from warm southern lowlands to cold subarctic and alpine regions, and from oceanic, cool and moist in western Norway to more continental and drier in the interior of Finland, Norway, and Sweden. These climatic gradients also control net primary production (NPP) (cf Stokland et al. 2003). Additionally, the time since the last glaciation and isostatic uplift, thereby creating new parent material, varies within Fennoscandia, reaching its maximum in the Kvarken area of the Bay of Bothnia (Andersen \& Borns 1997). Thus, soil formation has been subject to different drivers within Fennoscandia and this is likely to have caused regional differences in soil organic matter pools (Callesen et al. 2003, Strand \& De Wit in prep). Although the global latitudinal trend in soil carbon is that soil carbon content increases towards higher latitudes, there is an evident gradient with higher soil carbon contents in the southern part of Scandinavia than in the north on mineral soils (Callesen et al. 2003). A possible explanation for this gradient is the difference in nitrogen deposition (Svensson et al. 2008) but it is difficult to separate the nitrogen effect from the precipitation gradient since they are almost identical.

Another element concerning soil organic matter accumulation and productivity in old forests is abundance and turnover of understory vegetation. Understory vegetation can be an important driver of forest productivity (Nilsson \& Wardle 2005, Turetsky 2003) and soil organic matter accumulation (Muukkonen \& Mäkipää 2006). Old natural forests are multi-layered and are characterized by self-replacement through gap-fill dynamics, which creates a unique, heterogeneous understory environment that differs from second-growth, more even-aged stands (Messier et al. 2009). Usually, percent light transmitted to the forest floor is strongly reduced by the understory vegetation layer, especially in boreal forests. In old natural forests, understory light availability is more variable than in second-growth forests. Understory vegetation diversity is related to more factors than light, such as soil and moisture conditions, micro-topography and time since last disturbance. In boreal forests, understory diversity is low compared with other biomes and vascular plant diversity decreases from early to late succession due to decreases in light and nutrient availability (but see Wardle et al. 2012). By contrast, bryophyte communities tend to increase their richness and cover in old forests. Under the closed canopy of old forests, the understory is generally sparse and dominated by shade-tolerant, low-nutrient requiring species (Messier et al. 2009). However, because the Leaf Area Index (LAI) in old forests can decline, because of structural changes in the stands (Luyssaert et al. 2007, Kutsch et al. 2009), understory vegeta- 
tion may contribute more to stand net primary production (NPP) in old forests than in younger second-growth forest, but this topic appears to be understudied (Hart \& Chen 2006). Including ground vegetation as a source of litter production in Norwegian forests increased modelled soil carbon stocks and the soil carbon sink (De Wit et al. 2006)

De Wit \& Kvindesland (1999) analysed approximately 1000 forest soil profiles from the Norwegian forest inventory. Soil carbon stocks were estimated for each profile and related to possible driving factors, and summarized by soil type, vegetation type and other explaining variables. For mineral soil types, productive forests had higher soil carbon stocks than unproductive forests $\left(13 \mathrm{~kg} \mathrm{C} \mathrm{m}^{-2}\right.$ and $12 \mathrm{~kg} \mathrm{C} \mathrm{m}^{-2}$, respectively) but this was largely due to lower soil depth in unproductive forests. Soil type was also a strong controlling factor, where podzols and gleysols had the highest average soil carbon stocks (c. $18 \mathrm{~kg} \mathrm{C} \mathrm{m}^{-2}$ ) of the mineral soil types, and organic soils had carbon stocks of c. $33 \mathrm{~kg} \mathrm{C} \mathrm{m}^{-2}$. Carbon stocks in organic horizons in productive forests were found to vary strongly with dominating tree species (mean values between 5 and $7.5 \mathrm{~kg} \mathrm{C} \mathrm{m}^{-2}$ ), although the internal variation within dominating tree species exceeded variation between tree species. Mixed-forests had usually higher soil carbon stocks in organic horizons than forests dominated by single-tree species. Carbon stocks in organic horizons increased with development or cutting class (related to but not equivalent to age class) for forest stands of single tree species (for spruce, $4.8-7.0 \mathrm{~kg} \mathrm{C} \mathrm{m}^{-2}$ ), especially going from cutting class IV (old production forest) to $\mathrm{V}$ (mature forest). Soil carbon stocks in 0 horizons of mineral soil types were largest for the lowest site index for spruce forest, and lowest for the medium site index stands. Highest total soil carbon stocks (mineral soil types) were found in western Norway, indicating that carbon stocks may be higher in oceanic than in continental climates.

Vesterdal et al. (2008) studied soil carbon stocks in relation to common European tree species in a replicated garden design in Denmark. Norway spruce was the only coniferous tree species that was included. Differences were most pronounced in the organic horizon, and spruce forest had $1.6 \mathrm{~kg}$ $\mathrm{C} \mathrm{m}^{-2}$ stock in the organic horizon, versus 0.2 to $0.5 \mathrm{~kg} \mathrm{C} \mathrm{m}^{-2}$ for the deciduous tree species. Total soil C stocks were not significantly different between tree species, and varied between 6.5 and $7.5 \mathrm{~kg} \mathrm{C} \mathrm{m}^{-2}$. However, forests of tree species that accumulated thick 0 horizons (spruce and beech) tended to have smaller topsoil carbon stocks than species with thin and apparently fast decomposing organic horizons. This may indicate that the stability of stored carbon could be higher in certain deciduous species than in typical 0 horizon accumulating species. An earlier study of $\mathrm{O}$ horizon carbon stocks in a conifer species trial at seven sites included the five conifers Norway spruce, sitka spruce, lodgepole pine, Douglas fir and grand fir along with oak and beech (Vesterdal \& Raulund-Rasmussen 1998). Here, carbon stocks decreased in the order lodgepole pine $\left(1.7 \mathrm{~kg} \mathrm{C} \mathrm{m}^{-3}\right)>>$ Norway spruce $=$ Sitka spruce $>$ Douglas fir $=$ beech $>$ grand fir $>$ oak $\left(0.3 \mathrm{~kg} \mathrm{C} \mathrm{m}^{-3}\right)$. 
Callesen et al. (2003) analysed 234 well-drained Nordic soil profiles from Norway, Sweden, Finland, and Denmark in relation to climate and texture. Soil organic carbon stocks increased with mean annual temperature and mean annual precipitation. This was especially clear for coarsetextured soils. This climate relationship was interpreted as an indirect effect of higher net primary productivity. The general north to south pattern of increasing nitrogen deposition in Fennoscandia may have contributed significantly to this pattern (Svensson et al. 2008).

Stendahl et al. (2010) reported forest soil carbon stocks in Swedish pine and spruce forests based on the national forest inventory. Mean forest soil carbon stocks (down to $1 \mathrm{~m}$ depth) for spruce-dominated and pinedominated forests were 9.2 and $5.7 \mathrm{~kg} \mathrm{C} \mathrm{m}^{-2}$, respectively. Soil carbon stocks were positively related with temperature, site quality, cation exchange capacity in the $\mathrm{O}$ horizon, and mean tree height, but negatively related to latitude, $\mathrm{pH}$ in the $\mathrm{C}$ horizon, and soil base saturation. The reason may be the general co-occurring south to north gradients in temperature (lower), soil $\mathrm{pH}$ in the mineral soil (higher), nitrogen deposition (lower), and soil carbon (lower), where the latter two may be causally related.

\subsection{The role of northern forests in the global carbon cycle}

Terrestrial ecosystems play an important role in mitigating climate change by absorbing a substantial part of all global fossil fuel emissions. The land sink between 2000 and 2006 was assessed to be $2.8 \mathrm{Pg} \mathrm{C} \mathrm{yr}^{-1}$, corresponding to $38 \%$ of global fossil fuel emissions (Canadell et al. 2007). An assessment of $\mathrm{CO}_{2}$ uptake in boreal, temperate and tropical forests based on a global database resulted in an estimate of the land sink of 2.1 Pg C yr-1 (Luyssaert et al. 2007). The size and location of the terrestrial $\mathrm{CO}_{2}$ sink are under debate while its future strength is uncertain (Schimel 2007).

Bottom-up estimates of the land carbon sink, including land cover changes coupled with biomass and soil carbon stocks, suggest that deforestation and forest fires in the tropics contribute significantly to global carbon emissions (Achard et al. 2004), whereas the northern hemisphere is a substantial $\mathrm{CO}_{2}$ sink, largely due to forest regrowth from past land use (Goodale et al. 2002). Based on forest inventory data and models, Goodale et al. (2002) estimated that the forest carbon pool in the northern hemisphere (living biomass, dead wood and soil organic matter) during the early 1990s increased with a rate of $0.5 \mathrm{Pg} \mathrm{C} \mathrm{yr}^{-1}\left(24 \mathrm{~g} \mathrm{C} \mathrm{m}^{-2} \mathrm{yr}^{-1}\right)$. The most uncertain component was the change in soil organic matter $\left(6 \mathrm{~g} \mathrm{C} \mathrm{m}^{-2} \mathrm{yr}^{-1}\right)$. Forests in Europe had a higher carbon uptake than average, i.e., $67 \mathrm{~g} \mathrm{C} \mathrm{m}^{-2} \mathrm{yr}^{-1}$ (69\% in biomass, $31 \%$ in soils and dead wood). 
Net biome productivity (NBP, here defined as the difference between $\mathrm{CO}_{2}$ assimilation and ecosystem respiration, accounting for non-respiratory carbon losses related to fire, logging and riverine carbon export) for European forests was estimated at $75 \pm 20 \mathrm{~g} \mathrm{C} \mathrm{m}^{-2} \mathrm{yr}^{-1}\left(0.1 \mathrm{Pg} \mathrm{C} \mathrm{yr}^{-1}\right)$ between 1990 and 2005, using primarily a model approach in addition to information from national forest inventories (Luyssaert et al. 2009). Roughly $30 \%$ was sequestered in forest soils $\left(22 \pm 3 \mathrm{~g} \mathrm{C} \mathrm{m}^{-2} \mathrm{yr}^{-1}\right)$. Again, the uncertainty regarding the sink strength of the soils was mentioned, in addition to the uncertainty connected with the carbon sequestration capacity of old forests. Luyssaert et al. (2009) validated their NBP estimates by comparing with plot-scale eddy covariance measurements of Net Ecosystem Exchange (NEE) of carbon, adjusted for average carbon losses related to fire and management, which were between 53 and $98 \mathrm{~g} \mathrm{C} \mathrm{m}^{-2} \mathrm{yr}^{-1}$. However, these plotscale measurements were biased towards young and productive forest, which are expected to have higher carbon uptake rates than forests of mixed stand age.

Uptake of carbon in forests in Finland and Norway has been estimated using similar methods, i.e., national forest inventories, allometric equations (converting volume, or tree diameter and height, to tree biomass) and the Yasso soil carbon model (Liski et al. 2005). During the 1990s, the annual increase in forest biomass in Finland was $28 \mathrm{~g} \mathrm{C} \mathrm{m}^{-2} \mathrm{yr}^{-1}$, while forest floor and soil carbon pools increased with $11 \mathrm{~g} \mathrm{C} \mathrm{m}^{-2} \mathrm{yr}^{-1}$. Ground vegetation as a source of litter input was included. Summed for the whole country, the annual increase in forest carbon was approximately $8 \mathrm{Tg} \mathrm{C} \mathrm{yr}^{-1}$ (i.e., $8^{*} 10^{12} \mathrm{~g} \mathrm{C} \mathrm{yr}^{-1}$ or 8 mill. tonnes C) in Finland. For southeast Norway between 1971 and 2000, carbon stocks in forests, dead wood and soil organic matter increased with respectively 30,2 and $5 \mathrm{~g} \mathrm{C} \mathrm{m}^{-2} \mathrm{yr}^{-1}$, but without including the role of ground vegetation (De Wit et al. 2006). A new estimate for annual carbon uptake in forest in all of Norway between 1990 and 2008, including the role of ground vegetation, is $5.6 \mathrm{Tg} \mathrm{C} \mathrm{yr}^{-1}$ (biomass and soils) or $39 \mathrm{~g} \mathrm{C} \mathrm{m}^{-2} \mathrm{yr}^{-1}$ in biomass and $7 \mathrm{~g} \mathrm{C} \mathrm{m}^{-2} \mathrm{yr}^{-1}$ in soils (De Wit et al. in prep).

Forest carbon accumulation in Swedish forest for the period 1926 to 2000 (Ågren et al. 2007) was calculated in a very similar way as done by Liski et al. (2005), but using different factors to calculate litter production and a different soil carbon model, the Q model (Ågren et al. 2007). Average annual forest carbon accumulation between 1926 and 2000 was $7.11 \mathrm{Tg} \mathrm{C} \mathrm{yr}^{-1}$ (5.36 Tg C yr-1 in trees and 1.74 Tg C yr-1 in soils, or 23.1 and $7.5 \mathrm{~g} \mathrm{C} \mathrm{m}^{-2} \mathrm{yr}^{-1}$, respectively). These figures for the sink strength of forest biomass and soil are of the same size as reported in Sweden's national greenhouse gas inventory, i.e., $30 \mathrm{~g} \mathrm{C} \mathrm{m}^{-2} \mathrm{yr}^{-1}$ in biomass and $10 \mathrm{~g} \mathrm{C} \mathrm{m}^{-2} \mathrm{yr}^{-1}$ in the soil (SEPA 2011). 


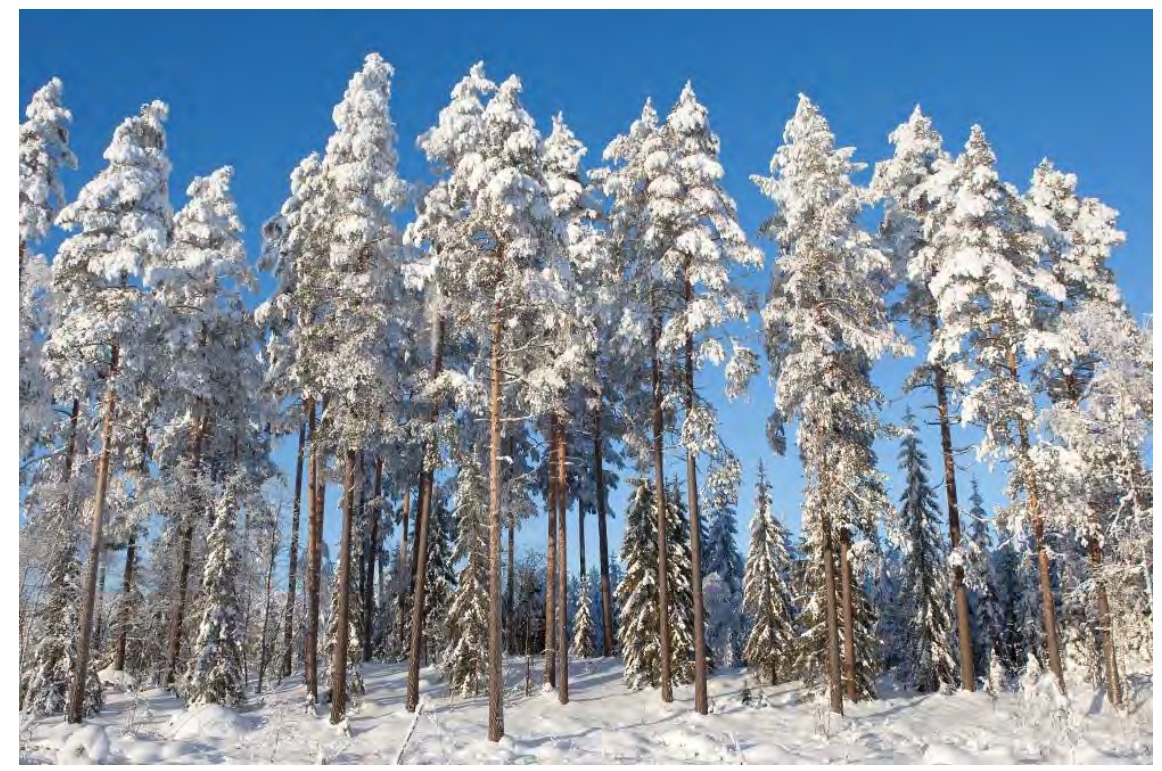

Photo: Erkki Oksanen/Metla.

For Denmark, annual carbon uptake in forests on the national scale is currently under revision. Based on estimated growth rates after the first rotation of the NFI and harvesting statistics, the annual carbon uptake was estimated at $1.34 \mathrm{Tg} \mathrm{C} \mathrm{yr}^{-1}$ or $250 \mathrm{~g} \mathrm{C} \mathrm{m}^{-2} \mathrm{yr}^{-1}$ for total tree biomass in 2002-2006 (Nord-Larsen et al. 2008). However, lower estimates are expected based on plot-based repeated measurements in the NFI plots.

Uncertainties in forest inventory-based assessments of forest carbon accumulation are connected to the use of allometric equations, estimations of tree litter production, ground vegetation as a source of litter, and the soil carbon model (De Wit et al. 2006). Allometric equations were developed for Swedish pine, spruce and birch forest (Marklund 1988) for trees with a diameter up to $45 \mathrm{~cm}$ (pine), $50 \mathrm{~cm}$ (spruce) and $35 \mathrm{~cm}$ (birch) below $500 \mathrm{~m}$ above sea level (cf Figure 5.2). The equations should be applicable for diameters up to $100 \mathrm{~cm}$ without resulting in particular bias, according to the authors, but no evaluation was done to substantiate this claim. This is of particular relevance for old forest, where trees might allocate more carbon to stems than to the canopy compared to younger stands, for instance. Ground vegetation models have been developed for Finnish forest (Muukkonen \& Mäkipää 2006) and relate aboveground understory biomass to vegetation type, stand characteristics and stand age. Understory vegetation does not add much to the total forest carbon pool, but has high turnover rates and can thereby contribute significantly to net primary production (NPP) and hence to soil carbon accumulation. Old forests may have a different stand structure than younger production forests, with lower density and more light, and therefore possibly a more abundant understory layer. 
Thus, NPP in old forests could receive a larger contribution from ground vegetation than in younger forests.

\subsection{Effects of forest management on forest carbon sequestration}

\section{Forest carbon dynamics in managed stands}

Forest management can greatly influence the carbon balance in forests (e.g., Thornley \& Cannell 2000, Jandl et al. 2007, Mäkipää et al. 2011). Harvesting of timber, stump biomass or harvest residues removes carbon from the forest in thinnings and the final felling. For most of the rotation period, however, a stand is a carbon sink due to the carbon sequestration of the growing vegetation and accumulation of carbon in the soil and coarse woody debris (Aber et al. 1978, Mäkipää et al. 1999, Janisch \& Harmon 2002, Peltoniemi et al. 2004, Häkkinen et al. 2011, Palosuo et al. 2008) (Figure 5.3). According to both model simulations and empirical flux measurements, forest stands act as a carbon source for some years after final harvest or thinning, because the rate of decomposition of soil organic matter and felling residues is higher than the accumulation of carbon in the vegetation and soil (Aber et al. 1978, Covington 1981, Olsson et al. 1996, Mäkipää et al. 1999, Kolari et al. 2004, Palosuo et al. 2008).

Figure 5.3. Development of biomass (left) as well as soil and dead organic matter (right) carbon stocks ( $\mathrm{kgC} \mathrm{ha}^{-2}$ ) over a rotation period in managed and unmanaged Norway spruce stands in central Finland (figure based on Mäkipää et al. 2011)
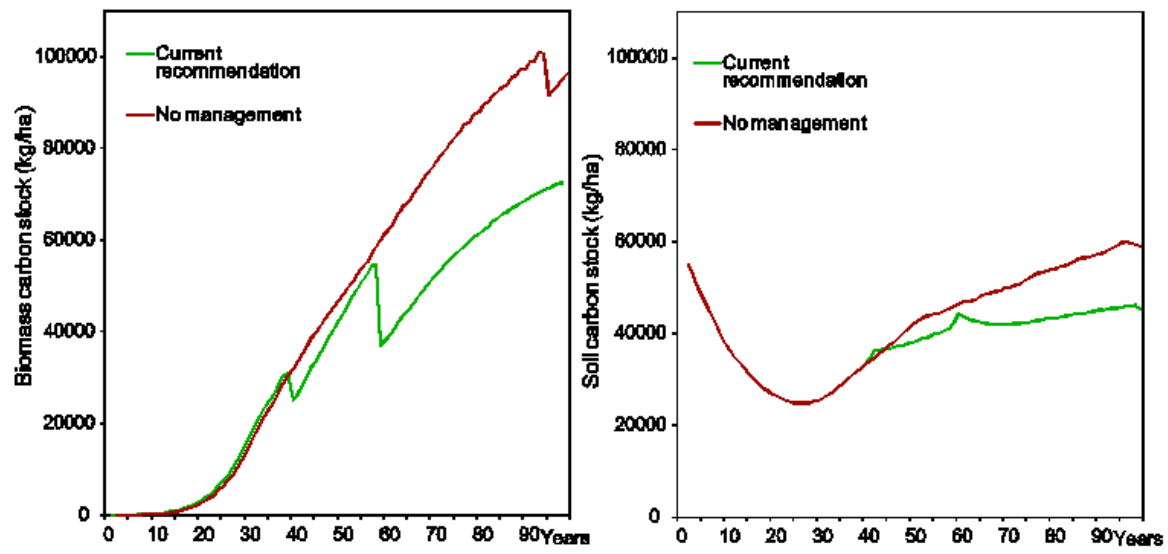

According to a recent review by Nave et al. (2010), harvesting resulted in decreased soil carbon stocks in temperate forests, and carbon stored in the organic layer was more vulnerable to harvest-induced loss than carbon in the mineral soil. Loss of soil carbon after harvesting is observed also in boreal forests with $\mathrm{CO}_{2}$ flux measurements (Kolari et al. 2004, Pumpanen et al. 2004b) and with soil carbon measurements after final harvesting (Olsson et al. 1996). However, the soil carbon loss after clear- 
cutting has also been questioned. Yanai et al. $(2000,2003)$ repeated the sampling of the merged organic layer with the A horizon of the mineral soil layer in the chronosequence established by Covington (1981). Resampling did not confirm the trajectory of the chronosequence and it seemed that the pattern was partly caused by forest floor carbon being transferred during logging disturbance to the mineral soil. Georgiadis (2011) used data from more than 5,000 plots in the Swedish forest soil inventory to study the effect of stand age on carbon stocks in the 0 horizon and the mineral soil. He found that $\mathrm{O}$ horizon carbon decreases in young stands until a stand age of 30-40 years and thereafter it increases and reaches a maximum at a normalized stand age of $90-100$ years and thereafter it tends to stabilize or decrease. There was no variation in mineral soil carbon stocks with stand age. The decline in the 0 horizon is explained by lower litter input in younger stands. The differences with stand age was more pronounced in southern than in northern Sweden, more pronounced for higher site index than lower site index, but soil moisture and tree species did not influence the fluctuation over stand age differently. The maximum carbon stock at 90-100 years of stand age was higher than the carbon stock just after clear cutting. The variation followed the same temporal pattern as Covington (1981) but was less pronounced, i.e. the relative loss of the 0 layer was less. In 278 Danish NFI plots, Boveland (2012) found that $O$ horizon carbon stocks increased with stand age, but only for coniferous stands that develop the largest carbon stock in 0 horizons. Moreover, conifers are generally regenerated by clear-cutting and replanting whereas deciduous stands are often regenerated using shelterwood self-seeding, i.e., more comparable to continuous cover forestry. Similar to Swedish conditions there was no stand age effect on mineral soil carbon stocks.

At the regional scale, the forest carbon balance is determined by applied thinning regime and resulting stand density as well as by rotation lengths and the resulting age-class distribution of the forests. Management practices such as liming, fertilization and drainage are designed to alter growth conditions in a way that increases tree growth, which may also enhance forest carbon sequestration.

\section{Rotation length}

Rotation length, the length of time from the establishment of a stand to its final felling, is commonly used to manage timber yield and income from forests, but is also one of the effective ways to manage the carbon budget of forests (Liski et al. 2001, Pussinen et al. 2002). At stand scale, shortening of the rotation length decreases the average carbon stock of trees. This is also reflected in the soil, because smaller tree biomass produces less litter and frequent harvests decrease the natural mortality of trees and the amount of dead wood in the forests. Reduced input of organic matter to the forest floor may decrease soil carbon stocks. Understanding soil responses to altered rotation length and more frequent 
harvests is, however, not trivial and shortening of the rotation length may also increase average carbon stocks of forest soils, due to increased inputs of harvest residues and thereby increased litter inputs to the soil, according to a model analysis (Liski et al. 2001).

In a simulation study Pussinen et al. (2002) found that increasing rotation length from 40 to 110 years increased the mean carbon stock of forests biomass and soil from about 60 to over $85 \mathrm{t} \mathrm{C} \mathrm{ha}^{-1}$. Seely et al. (2002) reported a similar increase in modelled forest carbon stock with increased rotation length. The increase in stand average carbon stock is attributable largely to changes in the live biomass pool (Liski et al. 2001, Pussinen et al. 2002, Seely et al. 2002). However, the rate of carbon accumulation was highest in the relatively young stands (Pussinen et al. 2002, Seely et al. 2002). Liski et al. (2001) analysed with model simulations how a 30-year change in rotation length from the recommended 90 years in boreal commercial forests would change the carbon budget of forests in Finland. The total amount of carbon stored in the Scots pine stands increased with increasing rotation length, but decreased slightly in the Norway spruce stands. The carbon stock of vegetation and soil changed in different directions in response to changing rotation length. The carbon stocks in vegetation increased but that of the soil decreased with increased rotation length, because of less frequent input of harvest residues. In the Scots pine stands the vegetation carbon stock increased more than the stock in the soil decreased, and the largest mean carbon stock over a rotation period was obtained when the longest 120-year rotation period was applied. In the Norway spruce stands, the carbon stock of the soil decreased slightly more than that of the vegetation increased, and the forests stored slightly larger amounts of carbon when the shortest 60-year rotation length was applied. Similar results with an increase in the carbon sequestration of biomass and decrease in the soil as a result of increased rotation length was also reported by Seely et al. (2002) and Lasch et al. (2005). In their simulation study in Germany, the total carbon accumulation of the forests was increased by increasing rotation length from 120 to 160-years (Lasch et al. 2005).

Ericsson (2003) studied the effect of rotation length on forest carbon accumulation in Sweden. When the rotation was prolonged with $20 \%$, the total accumulation of carbon in biomass during 100-year simulation period was $13 \%$ larger than in the base scenario and the total carbon stock of biomass was $50 \%$ smaller when rotation was shortened. The accumulation of new carbon in forest soil was $10 \%$ larger for the prolonged rotation and 10\% lower for shortened rotation in comparison with base scenario. However, he considered only new soil carbon resulting from litter production over a simulation period, which means that the initial carbon stock of the soil was assumed to respire the same amount in all scenarios. 


\section{Stand vs selective management}

Uneven-aged forest management with continuous forest cover and selective cuttings is expected to result in higher average carbon stocks than conventional stand-level regeneration practices (Harmon et al. 2009, Taylor et al. 2008, Shanin et al. 2011), since the period of low vegetation biomass and net release of soil carbon after final harvesting is avoided. Therefore, a shift from conventional harvesting and regeneration practices towards a selective cutting regime can lead to maintenance of larger average biomass and soil carbon stocks at the stand level (Taylor et al. 2008). Assuming that the same amount of biomass is harvested from the forest landscape, the effects on carbon input to (litter) and output from (decomposition) the soil is not sufficiently well documented by empirical research to say whether continuous cover harvesting results in higher carbon stocks than clear-cutting.

\section{Whole-tree harvesting and site preparation}

Harvesting of stumps, branches and treetops beside merchantable timber has become a widely applied practice in response to the increased demand for bioenergy. Such whole-tree harvesting increases the amount of harvested biomass (Poudel et al. 2012), but also results in nutrient losses and may cause growth reduction and nutrient imbalance (Tamminen et al. 2012). Whole-tree harvesting reduced the volume increment by 5-6\% during the first 10-year period (Jacobson et al. 2000). Furthermore, the growth reduction seemed to be long-lasting phenomena, since volume growth in pine stands was decreased by $8 \%$ and that of spruce stands by $13 \%$ in comparison to conventional harvesting during the second 10 -year period after harvesting (Helmisaari et al. 2011). A meta-analysis of the effects of harvest practices on soils showed that whole-tree harvesting decreased soil carbon stocks by 6\% (Johnson \& Curtis 2001). This is mainly due to the transfer of nutrients out of the forest along with harvested biomass, since the effect of stump harvesting on soil decomposition processes is small or absent compared to site preparation such as mounding in a short-term perspective of months and years (Strömgren et al. 2012). In general, site preparation affects the soil carbon balance by changing the soil moisture content, but effects are modest in comparison to those induced by biomass harvesting (Pumpanen et al. 2004b).

\section{Thinning}

Thinning is an active reduction in stem number during the rotation with an aim to enhance the growth of the remaining trees, to influence tree species composition or stem quality. Such thinning may also influence forest carbon sequestration, but the effect is considered to be modest as long as thinning operations are not severe. According to Lasch et al. (2005), the most effective management option to maximise total carbon stock is to apply a low thinning intensity and a long rotation length. After heavy thinning, litter production of the remaining biomass is decreased 
and the soil may change to a carbon source if the rate of decomposition is higher than litter production (Mäkipää et al. 2011). Vesterdal et al. (1995) found decreasing forest floor carbon stocks in Norway spruce stands with increasing thinning intensity at two out of three sites. Since the rate of litter decomposition is not greatly affected by harvesting (Prescott et al. 2000 ), the soil carbon balance is mostly driven by changes in the litter fall.

\section{Forest fertilization}

Forest fertilization may be pure nitrogen $(\mathrm{N})$ addition, mixtures of for example NPK, liming or wood ash application. In general, Nordic forests are nitrogen limited (Tamm 1991) and additional nitrogen supply increases vegetation carbon stocks and leads also to increased carbon stocks of soils due to enhanced litter production (Mäkipää et al. 1998, Mäkipää et al. 1999, Pussinen et al. 2002). Direct effects of nitrogen fertilization on the rate of decomposition can be positive (Hobbie 2005) or negative (Prescott 1995) depending on site conditions. According to a review by Knorr et al. (2005) nitrogen fertilization had a negative influence on sites where ambient litter quality was low (high lignin content). A meta-analysis by Johnson \& Curtis (2001) clearly demonstrated that fertilization had an overall increasing effect on soil carbon storage. On the other hand, nitrogen fertilization slightly increased forest floor emissions of the powerful greenhouse gas nitrous oxide $\left(\mathrm{N}_{2} \mathrm{O}\right)$ (Brumme \& Beese 1992, Klemedtsson et al. 1997).

\section{Species mixture}

Studies on mixed stands have shown that growth and yield of competing tree species as well as the yield of entire stands are affected by the proportions of tree species (e.g., Mielikäinen 1980, 1985, Jongiste 1998, Hynynen et al. 2011). In general, mixtures of coexisting species that have complementary niches lead to higher overall production, which is a case in forests with spruce-birch and pine-birch mixtures (Mielikäinen 1980, 1985, Ge et al. 2011). Stands that are more productive have also higher mean carbon stocks of trees and higher soil carbon stocks than less productive pure stands (Shanin et al. 2011). Coniferous stands and especially productive spruce-dominated stands tend to reach the highest biomass stocks (Shanin et al. 2011). 
Table 5.2. Qualitative effects of forest management measures on carbon stocks in biomass and soil

\begin{tabular}{|c|c|c|c|}
\hline \multirow[b]{2}{*}{ Forest management } & \multicolumn{2}{|c|}{ Effects on carbon stocks in } & \multirow[b]{2}{*}{ Effects on harvesting } \\
\hline & biomass & soil & \\
\hline Non-logging, protected areas & + preserves $C$ stocks & + preserves $C$ stocks & - \\
\hline Rotation length - longer & + preserves $\mathrm{C}$ stocks & $\begin{array}{l}\text { ? depends on tree species (pine: } \\
\text { +, spruce: }- \text { ) }\end{array}$ & $\begin{array}{l}\text { - relative to optimal harvest } \\
\text { rotation }\end{array}$ \\
\hline Rotation length - shorter & - reduced C stocks & $\begin{array}{l}\text { ? depends on tree species (cf } \\
\text { above) }\end{array}$ & $\begin{array}{l}\text { - relative to optimal harvest } \\
\text { rotation }\end{array}$ \\
\hline Continuous cover harvesting & $\begin{array}{l}+ \text { if higher average growing } \\
\text { stock }\end{array}$ & ? depends on litter production & $\begin{array}{l}\text { ? depends on forest condi- } \\
\text { tions }\end{array}$ \\
\hline Logging residues harvesting & $\begin{array}{l}\text { - reduced } C \text { stocks and } \\
\text { nutrient supply }\end{array}$ & - reduced C stocks & $\begin{array}{l}\text { - reduced growth due to } \\
\text { loss of nutrients }\end{array}$ \\
\hline $\begin{array}{l}\text { Whole-tree and stump } \\
\text { harvesting }\end{array}$ & - reduced C stocks & - reduced C stocks & $\begin{array}{l}\text { - reduced growth due to } \\
\text { loss of nutrients }\end{array}$ \\
\hline Drainage & + better tree growth & $\begin{array}{l}\text { - reduced } \mathrm{C} \text { stocks, + less } \mathrm{CH}_{4} \\
\text { emissions }\end{array}$ & $\begin{array}{l}\text { + earlier harvest due to } \\
\text { better regeneration and } \\
\text { growth }\end{array}$ \\
\hline Site preparation & + better tree growth & reduced $\mathrm{C}$ stocks & $\begin{array}{l}\text { + earlier harvest due to } \\
\text { better regeneration and } \\
\text { growth }\end{array}$ \\
\hline Prescribed burning & $\begin{array}{l}\text { ? possibly better tree regene- } \\
\text { ration }\end{array}$ & - reduced C stocks & $\begin{array}{l}\text { + earlier harvest due to } \\
\text { better regeneration }\end{array}$ \\
\hline Forest fire reduction & + preserves $\mathrm{C}$ stocks & + preserves $C$ stocks & + \\
\hline Increased stocking density & + increased C stocks & + increased C stocks & $\begin{array}{l}\text { - increased mortality, but } \\
\text { higher quality }\end{array}$ \\
\hline Increased thinning & - reduced mortality & - reduced litterfall & + earlier income \\
\hline Fertilization $(\mathrm{N})$ & + better tree growth & $\begin{array}{l}+ \text { increased litterfall, release of } \\
\mathrm{N}_{2} \mathrm{O}\end{array}$ & + \\
\hline Liming & ? marginal effect? & - faster decomposition & ? \\
\hline Intensified regeneration & + faster regeneration & + increased litterfall & + earlier harvest \\
\hline Tree species - mixed & $\begin{array}{l}+ \text { assumes mixed stand is } \\
\text { more productive, higher } \\
\text { resilience against disturbance }\end{array}$ & $\begin{array}{l}\text { ? depends on tree species, } \\
\text { negative with increased propor- } \\
\text { tion of deciduous trees }\end{array}$ & ? \\
\hline $\begin{array}{l}\text { Tree species - more deci- } \\
\text { duous }\end{array}$ & ? lower biomass? & - higher litter decomposition rate & - \\
\hline $\begin{array}{l}\text { Tree species - most produc- } \\
\text { tive }\end{array}$ & + increased C stocks & + increased C stocks & + \\
\hline
\end{tabular}

\section{Summary of forest management effects of carbon stocks}

Table 5.2 presents a qualitative summary of the effects of various forest management measures on the carbon stocks of forest biomass and soils (not all of which have been discussed above). More is known about effects on biomass than on soil carbon stocks. Biomass carbon stocks tend to show a stronger response to management actions than soil carbon stocks, and changes in the latter seem to be mainly driven by changes in 
litter inputs as a consequence of management. Changes in decomposition seem to be less important:

- No logging will preserve ecosystem carbon stocks and apparently maintain a certain carbon sequestration capacity with increasing forest age. However, the long-term biomass development is not well documented and some studies indicate maximum soil carbon stocks around or just after the normal rotation period.

- Management measures to increase stand productivity, like high stocking density, using the most productive tree species, site preparation, and nitrogen fertilization, will increase biomass carbon stocks and litter production and therefore often also soil carbon stocks, although decomposition rates may also increase and the net effect is uncertain for some measures.

- Forest ecosystem carbon stocks will be reduced by measures to increase harvesting rates, such as shorter rotation period, thinning during the rotation, and logging residue and whole tree harvesting.

- Effects on carbon stocks of continuous cover harvesting versus clear-cut

- ting (given the same level of harvesting) is inadequately documented. Clear-cutting will lead to more disturbance at final harvesting per stand, with stronger effects on carbon dynamics, but continuous cover harvesting will lead to more frequent interventions over a larger area.

Forest landscape with large clearcut and regeneration areas from eastern Finland (Kuopio-Suonenjoki)

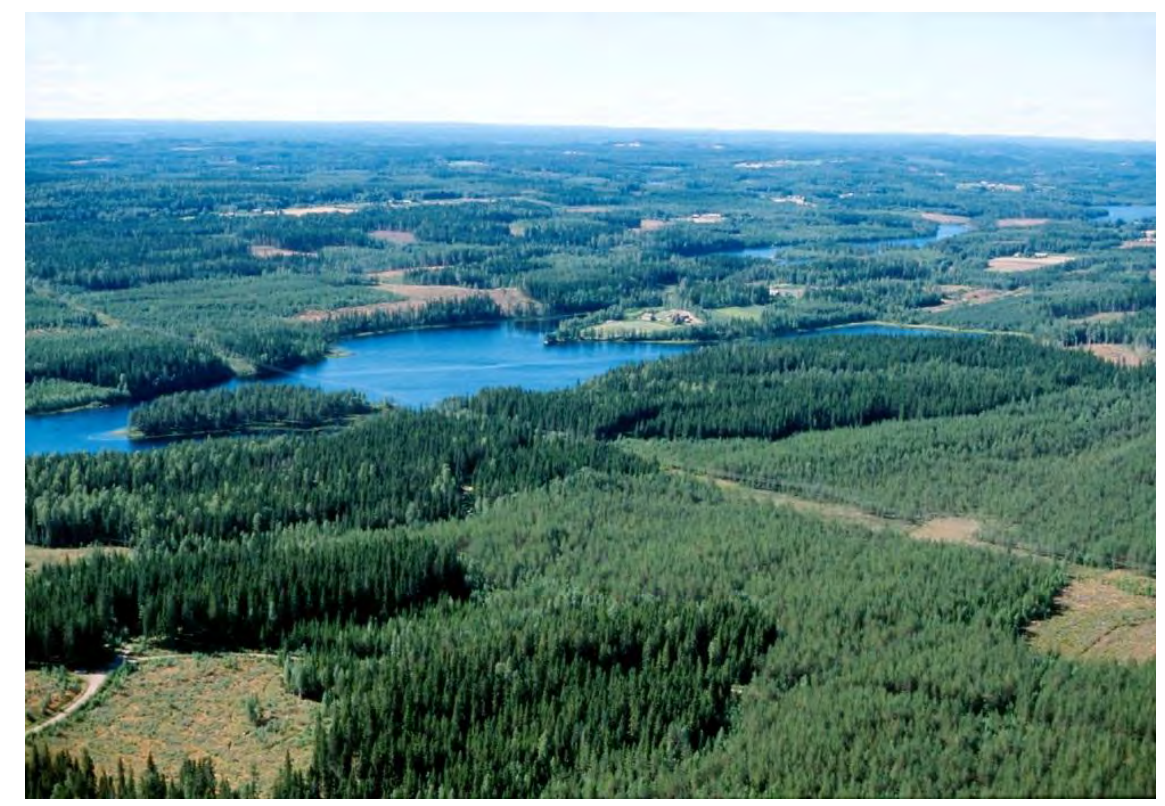

Photo: Erkki Oksanen/Metla 


\subsection{Old forests - carbon sources or carbon sinks?}

There is considerable uncertainty about the role of old forests in the global carbon cycle. In part, this is due to the assertion of equilibrium behaviour in old forests as proposed by Odum (1969). Odum referred to the "law of maximum energy in biological systems," which involves a shift in energy flow as more energy is allocated from building biomass to maintenance of the system. Thus, the "bioenergetics" of an ecosystem affects the ratio of primary production $(\mathrm{P})$ to respiration $(\mathrm{R})$ - the $\mathrm{P} / \mathrm{R}$ ratio - to approach 1 during the development of an ecosystem. This implies that the biomass supported by available energy flows increases to a maximum at maturity or the climax stage of development, with a net production of zero in mature natural ecosystems. Thus, old forests were assumed to be carbon-neutral based on the concept proposed by Odum (1969). In the past decade, however, a growing body of evidence indicates that many old forests are active carbon sinks and accumulate carbon in biomass and in soils (Carey et al. 2001, Luyssaert et al. 2008, Wardle et al. 2003).

\section{Critique of the assumption of carbon equilibrium in old forest}

Forests older than about 100 years are often viewed to be in equilibrium with the atmosphere or at least insignificant as carbon sinks (Kira \& Shidei 1967, Odum 1969). The conceptual model for forest growth is that net productivity declines with age because the photosynthetic capacity is reduced relative to respiration of sapwood. Thereby, a steady state between gross primary productivity (GPP) and autotrophic respiration is reached, resulting in no additional sequestration of carbon in old forests.

Whether tall, old trees eventually become less efficient at growth because of an increased respiratory demand is discussed in Kutsch et al. (2009). Ecophysiological characteristics of individual trees - increased respiratory demand for transport of water in tall trees, maintenance costs of stems and leaves - may determine lower growth at high age which then is also expressed at stand level. Alternatively, stand dynamics - succession, structural changes - may determine the decline in productivity with stand age. Stand level net primary productivity (NPP) may decline because of (1) a decline in assimilation rate at a given leaf area, or (2) a decline in leaf area at a constant assimilation rate. In the first case, the decline is related to ecophysiological factors, thus, at the individual tree level. In the second case, the decline is related to structural changes of the canopy. A global database of forest productivity supplied with explanatory variables on climate and stand characteristics (Luyssaert et al. 2007) was analysed further in Kutsch et al. (2009). NPP and ANPP (aboveground NPP) were modelled as functions of the leaf area index (LAI) and stand age, in addition to climatic variables. When corrected for climate, LAI was a stronger predictor of NPP and ANPP than stand age, suggesting that structural changes in stands rather than 
photosynthetic performance of individual trees (physiology) were important for changes in stand productivity.

In a chronosequence of second-growth stands (35, 70, 90, 135 year plots) in an oak forest in New York state (USA), aboveground biomass accumulation was investigated in relation to tree physiology, stand structure and mortality (Xu et al. 2012). The decline in biomass accumulation rates in older forest stands was found to be related to mortality, not to a reduction in net primary productivity associated with stand structure, tree physiology or tree growth. This study supports the claim that stand structural changes determine biomass accumulation.

Carey et al. (2001) criticized the conceptual model of ecosystem equilibrium that was developed mainly based on even-aged forests which differ in some substantial ways from natural forests. Production in natural, subalpine forests (67-458 years) was compared with modelled estimates of simple even-aged stands. They found that measured sapwood to leaf mass ratios (indicative of the ratio of autotrophic respiration versus photosynthetic capacity) were considerably lower than the modelled ratio, especially in forest older than 175 years. This was because of recruitment of a late-successional species with low sapwood to leaf mass ratio, indicating that this particular forest lost less photosynthates to respiration than was modelled. Other indicators of productivity, i.e. ANPP (aboveground net primary productivity) and biomass were also much higher than modelled in older forest. The temperature-dependent sapwood respiration rate in models was found to result in 2-5 times too high estimations of respiration in older stands, because it did not account for size- and age-dependent declines in stem maintenance respiration per unit sapwood. Measured ANPP for stands older than 200 years was approximately $500 \mathrm{~g} \mathrm{C} \mathrm{m}^{-2} \mathrm{yr}^{-1}$, while modelled ANPP was approximately $50 \%$ of measured ANPP. The underestimation of NPP in old forests was assessed to be equal to approximately $145 \mathrm{Tg} \mathrm{C} \mathrm{(145} \mathrm{Pg} \mathrm{C)} \mathrm{an-}$ nually, assuming that NPP for temperate forests $\left(465 \mathrm{~g} \mathrm{C} \mathrm{m}^{-2} \mathrm{yr}^{-1}\right.$ from Melillo et al. 1993) should be doubled. For comparison, estimates of the land carbon sink are 2.1 $\mathrm{Pg} \mathrm{C} \mathrm{yr}^{-1}$ (Luyssaert et al. 2007) and 2.8 $\mathrm{Pg} \mathrm{C} \mathrm{yr}^{-1}$ (Canadell et al. 2007). An important conclusion from Carey's work is that models of forest growth designed for managed, even-aged forests fail to describe stand development in natural forests.

An alternative conceptual model of successional patterns in forest biomass, rather than equilibrium, is the "stand break-up" hypothesis, where biomass declines after reaching a peak (Bormann \& Likens 1979). This is also incorporated in forest growth models (Botkin et al. 1972). The stand break-up requires a certain synchrony in tree mortality. However, mortality in natural forests does not follow a pattern of stand break-up. By contrast, mortality in natural forests is more evenly distributed over time compared with managed forests, except for natural large stand-replacing disturbance events. Mortality in natural forests is higher than in managed forests (Jonsson \& Siitonen 2012). Description 
of mortality dynamics in forest models is key to modelling carbon dynamics in old forests.

\section{Direct evidence of carbon accumulation in old forest: eddy covariance studies}

Carbon accumulation in old forests can be measured directly using the eddy covariance technique. However, this method is technically challenging and needs supplementary studies and corrective measures to give robust information on all major fluxes in the ecosystem (cf chapter 5.2).

In an old-growth forest of Douglas fir in Washington, USA (stand age c. 500 years), net ecosystem exchange (NEE) was measured, and the problem of non-turbulent conditions were explicitly addressed, using corrective models and by measuring advection in the field ( $U$ et al. 2004). Net carbon uptake in this old-growth forest was between 150 and $190 \mathrm{~g} \mathrm{C} \mathrm{m}^{-2} \mathrm{yr}^{-1}$.

A 250-year mixed boreal forest stand on the Siberian taiga was a carbon sink during the growing season, sequestering circa $100 \mathrm{~g} \mathrm{C} \mathrm{m}^{-2}$ (Röser et al. 2002). Measurements were done for 200 days and started before snowmelt (early April) and lasted until a complete snow cover had been established (late October). The lack of measurements during the winter (165 days) implies that the annual C sink was lower than 100 $\mathrm{g} \mathrm{C} \mathrm{m}^{-2}$, due to soil respiration, which was circa $1 \mathrm{~g} \mathrm{C} \mathrm{m}^{-2} \mathrm{yr}^{-1}$ at the start and end of the study period. The authors conclude that this old-growth forest was a carbon sink, the size of which is uncertain due to the lack of information on winter soil conditions.

Storage of carbon and carbon fluxes in a young (recently clear-cut old-growth forest, 14 years stand age) and an old ponderosa pine stand (mixed age classes, predominantly 50 and 250 years) in Oregon were examined using the eddy covariance technique (NEE), chamber methods (soil respiration) and by measuring carbon pools empirically (soils, detritus; biometric methods for tree biomass; coring of trees to determine growth; foliage litter production) (Law et al. 2001). Soil respiration was subtracted with root respiration (estimated using field methods and empirical models). Total carbon stocks were higher in the old stand ( 21 vs $10 \mathrm{~kg} \mathrm{C} \mathrm{m}^{-2}$ ). NPP was highest in the oldest stand (472 vs $\left.357 \mathrm{~g} \mathrm{C} \mathrm{m}^{-2} \mathrm{yr}^{-1}\right)$, and Net Ecosystem Productivity (NEP = NPP $-\mathrm{Rh}$ ) was $28 \mathrm{~g} \mathrm{C} \mathrm{m}^{-2} \mathrm{yr}^{-1}$ in the old stand (accumulating C) while the young stand was losing carbon $\left(-32 \mathrm{~g} \mathrm{C} \mathrm{m}^{-2} \mathrm{yr}^{-1}\right)$. NEP was also estimated in a Monte Carlo calculation using uncertainties in foliage and fine root production, which resulted in a larger sink $\left(168 \pm 68 \mathrm{~g} \mathrm{C} \mathrm{m}^{-2} \mathrm{yr}^{-1}\right)$ and a larger carbon source $\left(-68 \pm 21 \mathrm{~g} \mathrm{C} \mathrm{m}^{-2} \mathrm{yr}^{-1}\right)$ for the older and the younger stand, respectively. The authors concluded that after clear-cutting, a stand may take up to 30 years to become a carbon sink while oldgrowth forests can be a carbon sink even at an age of 250 years.

Net ecosystem exchange (NEE) was measured with the eddy covariance technique during two years in old-growth ( $>300$ years) and mid- 
dle-aged hardwood stands (70 years) in the upper Midwest in USA (Desai et al. 2005). Additional measurements included biometric and chamber flux measurements, including soil, coarse woody debris and stem $\mathrm{CO}_{2}$ efflux measurements, sap flux, stem growth measurements, leaf light response, and site characterizations in the vicinity of the flux towers. Turbulence flux quality measurements were done. Ecosystem respiration was modelled. In both years, the old-growth forest was a carbon sink (72 and $147 \mathrm{~g} \mathrm{C} \mathrm{m}^{-2} \mathrm{yr}^{-1}$ ) but carbon uptake in the 70-year old stand was considerably higher ( 438 and $490 \mathrm{~g} \mathrm{C} \mathrm{m}^{-2} \mathrm{yr}^{-1}$ ). The lower carbon uptake in the old-growth forest was mostly related to higher ecosystem respiration, which was speculated to be related to more respiration of coarse woody debris (CWD). Ecosystem respiration and NEE were partitioned using a model, essentially using NEE and soil temperature. Stores of CWD were significantly higher in the old-growth forest than in the 70year old forest, but no empirical data were collected on decomposition rates of CWD while soil respiration measured using chamber methods was similar in both stands. However, the uncertainty connected to the chamber method measurements was considerable. The old-growth site was less productive than the 70-year old site, which was believed to be related to structural characteristics (LAI, species composition).

In a deciduous 250-year old beech forest in Germany, NEE was measured with the eddy covariance technique, supported with biometric measurements and measurements of carbon pools in soils and CWD. The measurements were corrected for conditions of low turbulence, but no measurements were made to assess advective transport of carbon. The carbon sink was estimated at 494 and $490 \mathrm{~g} \mathrm{C} \mathrm{m}^{-2} \mathrm{yr}^{-1}$ in 2000 and 2001. A later study at the same site concluded that measurements of advective transport of $\mathrm{CO}_{2}$ are necessary for a good estimation of NEE, even at sites with gentle hill slopes (Kutsch et al. 2008).

Eddy covariance studies need additional measurements to partition carbon fluxes to vegetation and soil, as only the total ecosystem exchange above the canopy is measured. In the ponderosa pine study (Law et al. 2001), Rh (heterotrophic respiration) was estimated to be $444 \mathrm{~g} \mathrm{C} \mathrm{m}^{-2} \mathrm{yr}^{-1}$ while litter inputs (aboveground foliage and detritus, and belowground fine and coarse root production) were estimated to be $431 \mathrm{~g} \mathrm{C} \mathrm{m}^{-2} \mathrm{yr}^{-1}$. This indicates a soil carbon loss of $-13 \mathrm{~g} \mathrm{C} \mathrm{m}^{-2} \mathrm{yr}^{-1}$. However, the difference between two uncertain numbers of similar size cannot become significantly different from zero, according to simple rules of error propagation.

The various eddy covariance studies are summarized for comparison in Table 5.3. 
Table 5.3. Summary of eddy covariance studies providing direct evidence of carbon accumulation in old forest

\begin{tabular}{|c|c|c|c|c|c|c|}
\hline Reference & Age & Species & Region & Description & NEE\# & NEP\# \\
\hline Knohl et al. 2009 & 250 & temperate beech & Germany & unmanaged & 494,490 & \\
\hline \multirow[t]{2}{*}{ Desai et al. 2005} & 70 & hardwood & Upper Midwest, USA & regrowth & 438,490 & \\
\hline & $>300$ & hardwood & Upper Midwest, USA & never logged, old-growth & 72,147 & \\
\hline \multirow[t]{2}{*}{ Law et al. 2001} & 14 & ponderosa pine & Oregon, USA & clear-cut old-growth & & $-32 /-68 * *$ \\
\hline & 250 & ponderosa pine & Oregon, USA & old-growth & & $28 / 168^{* *}$ \\
\hline Röser et al. 2002 & 250 & mixed boreal & Siberia, Russia & old-growth & $<100^{*}$ & \\
\hline U et al. 2004 & 500 & Douglas fir & Washington, USA & old-growth & 150,190 & \\
\hline
\end{tabular}

* only 200 days

** estimates from different methods

$\# \mathrm{~g} \mathrm{C} \mathrm{m} \mathrm{yr}^{-1}$

\section{Direct evidence of soil carbon accumulation in old forest: repeated samplings}

As described above, addressing changes in soil carbon storage related to stand development presents methodological challenges (Post et al. 2001). Eddy covariance techniques need additional biometric measurements to quantify above- and belowground biomass stock changes, decomposition rates of coarse woody debris, and annual litter production. Soil carbon stock changes can then be inferred by the difference, and net ecosystem exchange (NEE) can be attributed to different compartments in the ecosystem. However, the fluxes are associated with uncertainties, and differences between flux estimates need to be large in order to exceed their uncertainty. Annual soil carbon stock changes are typically small compared with annual litter fall or changes in biomass stocks, and compared with the size of the existing soil carbon pool.

One of the rare examples of direct measurement of soil carbon stock changes in the same stand is given by Zhou et al. (2006). In old-growth ( $>400$ year) forests in the Guangdong province in south China, soil carbon stocks in the top 0-20 cm layer were measured between 1979 and 2003, with 6 samplings between 1979 and 1985, and 5 samplings between 1998 and 2003. Bulk density and carbon contents (\%) were both measured, and especially carbon content had increased substantially. Soil carbon stocks had accumulated at a rate of between 54 and $68 \mathrm{~g} \mathrm{C} \mathrm{m}^{-2} \mathrm{yr}^{-1}$ between 1979 and 2003. Thus, the soil was far from steady state and a considerable sink for carbon.

In a relatively undisturbed forested catchment in south Norway, soil carbon stocks were estimated in 1974 and 1992 (De Wit \& Kvindesland 1999). Soil profiles in 1992 were dug close to the original soil profiles that were sampled in 1974. The catchment was dominated by spruce and pine. Organic horizons on top of rocky substrates all showed increases in carbon stocks with an average of $110 \mathrm{~g} \mathrm{C} \mathrm{m}^{-2} \mathrm{yr}^{-1}$, but with considerable variation. In podzolic soils, increases in soil organic matter pools were found for four soil profiles, and losses were found for two 
soil profiles. On average, soils increased with $60 \mathrm{~g} \mathrm{C} \mathrm{m}^{-2} \mathrm{yr}^{-1}$ but variations were so large that uncertainty was deemed to exceed carbon accumulation rates (De Wit \& Kvindesland 1999). Total forest soil carbon stocks (podzols) were between 15 and $38 \mathrm{~kg} \mathrm{C} \mathrm{m}^{-2}$.

Soil carbon accumulation in old-growth temperate beech forest (c. 250 years of age) was measured by paired sampling of soils in 2000 and 2004 (Tefs \& Gleixner 2012). Total soil carbon stocks were $5 \mathrm{~kg} \mathrm{C} \mathrm{m}^{-2}$. The upper $20 \mathrm{~cm}$ of the soil lost carbon, while the lower 20 to $60 \mathrm{~cm}$ gained carbon, with the net estimated carbon accumulation rate of $164 \mathrm{~g} \mathrm{C} \mathrm{m}^{-2} \mathrm{yr}^{-1}$, which indicates a doubling of the soil carbon stock in about 30 years. Compared with the stand age of 250 years, the doubling of the soil carbon stock in 30 years appears rather high. Other carbon fluxes of leaf and fine root litter production were also measured, to 440 and $410 \mathrm{~g} \mathrm{C} \mathrm{m}^{-2} \mathrm{yr}^{-1}$.

The various studies based on repeated measurements of soil carbon are summarized in Table 5.4.

\begin{tabular}{|c|c|c|c|c|c|}
\hline Reference & Age & Species & Region & Description & Soils* \\
\hline Zhou et al. 2006 & $>400$ & subtropical evergreen & south China & old-growth & $54-68$ \\
\hline Tefs \& Gleixner 2012 & 250 & temperate beech & Germany & unmanaged & 164 \\
\hline De Wit \& Kvindesland 1999 & $\approx 90$ & boreonemoral spruce & Norway & unmanaged & 60,110 \\
\hline
\end{tabular}

$* \mathrm{gC} \mathrm{m}^{-2} \mathrm{yr}^{-1}$

\section{Indirect evidence of carbon accumulation in old-growth forests: chronosequences}

Chronosequences are potentially powerful tools to assess changes in carbon stocks but suffer from uncertainties connected to the initial state of the stands and soil heterogeneity that may account for differences in soil carbon stocks rather than successional development (Walker et al. 2010). These uncertainties might be counteracted by a sufficient number of chronosequence studies showing similar patterns, or by including a sufficient number of sites within each developmental stage in a chronosequence. Chronosequences are defined by the time since the last standreplacing disturbance, which can be fire, harvesting or other types of disturbances.

One of the chronosequences with the longest time span is the chronosequence of boreal islands in northern Sweden (Wardle et al. 2012). The time since the last major disturbance by fire varies from 60 to more than 5000 years ago for these islands. Thus, this chronosequence has a millennial perspective. The differences in ecological properties between these younger and older forest islands can be summarized as follows:

- There is a distinct succession of tree species with age, from pine and birch-dominated forest on the younger islands to spruce and birchdominated forest on the older. There is a similar shift from billberry 
(Vaccinium myrtillus) domination of the field layer on younger islands to crowberry (Empetrum hermaphroditum) domination on the older.

- Although total nitrogen $(\mathrm{N})$ and total phosphorus (P) are rather similar for younger and older islands, the fraction of $\mathrm{N}$ and $\mathrm{P}$ available for plant growth is lower for older islands. Decomposition rates of plant litter are also lower for older islands. These differences reflect reduced activity and biomass of microbes, as well as less degradable litter on older islands than on younger ones.

- Older islands have lower net plant productivity (NPP), for both trees and shrubs, than younger ones, whereas the productivity for mosses is higher for older islands. The lower overall plant productivity with age leads to a reduction in carbon input to the ecosystem.

- There is also a lower carbon release through soil respiration and litter decomposition for older versus younger islands.

- Lower NPP for older islands results in less aboveground carbon storage, whereas the lower belowground decomposition and respiration result in greater carbon storage belowground. Overall, the ecosystem tends to store more carbon for older islands than for younger ones. Nevertheless, total ecosystem carbon sequestration rates appear to be similar for younger and older islands, at about 4.5 $\mathrm{g} \mathrm{m}^{-2} \mathrm{yr}^{-1}$, over several thousand years.

In an assessment of 15 boreal and temperate forest chronosequences that included stands with ages between 211 and 795 years, all stands showed an increase of biomass stock with stand age. Median biomass increase declined with stand age, but remained positive even for stands older than 400 years. Biomass accumulation rates were $91,32,19$ and $9 \mathrm{~g} \mathrm{C} \mathrm{m}^{-2} \mathrm{yr}^{-1}$ for pioneer stands ( $0-100$ years), transition forest (100-200 years), early old-growth (200-400 years) and late old-growth stands (400-600 years), respectively (Wirth \& Lichstein 2009). The authors stated that there were very few documented cases of late-successional biomass stock decline. One should note that the boreal island chronosequence (with a millennial time span) (Wardle et al. 2012) is such an example, where aboveground biomass was lowest on the islands with the highest forest age. Still, total ecosystem carbon storage was largest on the oldest islands.

A database of carbon pools in boreal, temperate and tropical forests natural and managed, deciduous, coniferous, evergreen - was compiled by Pregitzer \& Euskirchen (2004). Stand age was found to be the decisive factor for accumulation of carbon stocks and productivity. Forests were categorized in five age classes. For temperate and tropical forests these age classes were $0-10,11-30,31-70,71-120$ and $120-200$ years, while boreal forests were classified in age classes of 0-30, 31-70, 71$120,120-200$, and 200 years and older. The age class of 200 years and older contained fewest data. Thus, in contrast to Wirth \& Lichstein (2009), old-growth forest was not well represented. In all biomes, NPP 
declined with stand age. NEP increased from younger to middle-aged stands and declined with higher stand age, but remained positive.

Carbon fluxes and stocks in chronosequences in Northwest USA (Oregon, Washington) were reported by Sun et al. (2004) and Law et al. (2003). These papers build partly on the same datasets. The chronosequences are located in climatically contrasting areas, which confounds the expected relationship between stand age and ecosystem carbon storage. Soil carbon storage was described as a function of NPP (positive relation), annual precipitation (positive relation) and forest floor mean residence time (negative). The 13 sites of the chronosequence in Sun et al. (2004) include forests with various dominating tree species spanning a stand age $<13$ years to $>600$ years, while Law et al. (2003) present a chronosequence of 12 ponderosa pine sites spanning an age $<13$ years to $>300$ years. The authors did not find support for continued soil carbon accumulation in older forests, and suggested that soil carbon stocks reach a steady state (an asymptote) after about 150-200 years of stand development. The lack of change of soil carbon stocks with stand age or developmental phase might be a good illustration of the weaknesses of chronosequences where the stands must be sufficiently similar (soil conditions, climate, disturbance history) to allow sound conclusions about the effect of time on carbon storage. Biomass, however, increased consistently with stand age. In the ponderosa pine chronosequence, NEP was estimated assuming that fine root and soil organic matter stocks remained constant. Total ecosystem carbon stocks - determined by biomass, as soil carbon stocks were assumed constant - increased with stand age and did not level off, and biomass stocks in the oldest forests did not decline compared with mature stands.

In Norway, an increase of $4.5 \mathrm{~g} \mathrm{C} \mathrm{m}^{-2} \mathrm{yr}^{-1}$ in soil $\mathrm{O}$ horizons was reported for a Norway spruce chronosequence spanning stand ages of 0 to 100 years (Sogn et al. 1999).

The various studies based on chronosequences are summarized in Table 5.5. 
Table 5.5. Indirect evidence from chronosequences of carbon accumulation in old forests

\begin{tabular}{|c|c|c|c|c|c|c|c|c|c|}
\hline Reference & Age & Species & Region & Description & NEP* & $\begin{array}{l}\text { Bio- } \\
\text { mass }\end{array}$ & Total\# & AGB & Remarks \\
\hline \multirow[t]{3}{*}{$\begin{array}{l}\text { Wardle et al. } \\
2012\end{array}$} & 585 & boreal & N Sweden & $\begin{array}{l}\text { natural, from young } \\
\text { to old-growth, no } \\
\text { fire }\end{array}$ & 4.5 & & 10 & 4.5 & read from figures \\
\hline & 2180 & & & & 4.5 & & 20 & 4.2 & read from figures \\
\hline & 3250 & & & & 4.5 & & 28 & 1.8 & read from figures \\
\hline \multirow[t]{4}{*}{$\begin{array}{l}\text { Wirth \& } \\
\text { Lichtstein } 2009\end{array}$} & $0-100$ & $\begin{array}{l}\text { boreal, } \\
\text { temperate }\end{array}$ & $\begin{array}{l}\text { temperate, } \\
\text { boreal }\end{array}$ & pioneer & & 91 & & & \\
\hline & $100-200$ & $\begin{array}{l}\text { boreal, } \\
\text { temperate }\end{array}$ & & transitional & & 32 & & & \\
\hline & $200-400$ & $\begin{array}{l}\text { boreal, } \\
\text { temperate }\end{array}$ & & early old-growth & & 19 & & & \\
\hline & $400-600$ & $\begin{array}{l}\text { boreal, } \\
\text { temperate }\end{array}$ & & late old-growth & & 9 & & & \\
\hline \multirow[t]{4}{*}{ Law et al. 2003} & $9-23$ & $\begin{array}{l}\text { ponderosa } \\
\text { pine }\end{array}$ & Oregon, USA & $\begin{array}{l}\text { time since stand- } \\
\text { repl. }\end{array}$ & -124 & & & & $\begin{array}{l}\text { no soils and fine } \\
\text { root changes }\end{array}$ \\
\hline & $56-89$ & $\begin{array}{l}\text { ponderosa } \\
\text { pine }\end{array}$ & & disturbance & 118 & & & & $\begin{array}{l}\text { no soils and fine } \\
\text { root changes }\end{array}$ \\
\hline & 95-106 & $\begin{array}{l}\text { ponderosa } \\
\text { pine }\end{array}$ & & & 170 & & & & $\begin{array}{l}\text { no soils and fine } \\
\text { root changes }\end{array}$ \\
\hline & $190-316$ & $\begin{array}{l}\text { ponderosa } \\
\text { pine }\end{array}$ & & & 35 & & & & $\begin{array}{l}\text { no soils and fine } \\
\text { root changes }\end{array}$ \\
\hline $\begin{array}{l}\text { Bisbing et al. } \\
2010\end{array}$ & & & NW USA & & & & & & \\
\hline \multirow{11}{*}{$\begin{array}{l}\text { Pregitzer \& } \\
\text { Euskirchen } \\
2004\end{array}$} & $0-10$ & temperate & global & & -190 & & & & \\
\hline & $11-30$ & temperate & & & 450 & & & & \\
\hline & $31-70$ & temperate & & & 240 & & & & \\
\hline & $71-120$ & temperate & & & 190 & & & & \\
\hline & $120-200$ & temperate & & & 170 & & & & \\
\hline & $0-10$ & boreal & global & & -10 & & & & \\
\hline & $0-30$ & boreal & & & 34 & & & & \\
\hline & $31-70$ & boreal & & & 267 & & & & \\
\hline & $71-120$ & boreal & & & 255 & & & & \\
\hline & $120-200$ & boreal & & & 137 & & & & \\
\hline & $>200$ & boreal & & & 32 & & & & age set at 300 \\
\hline $\begin{array}{l}\text { Sogn et al. } \\
1999\end{array}$ & $0-100$ & spruce & SE Norway & managed & 4.5 & & & & O horizon only \\
\hline
\end{tabular}

$* \mathrm{gC} \mathrm{m}^{-2} \mathrm{yr}^{-1}$

$\# \mathrm{~kg} \mathrm{C} \mathrm{m}{ }^{-2}$

AGB Aboveground biomass 


\section{Indirect evidence of carbon accumulation in old forests: stand comparisons}

Stand comparisons are different from chronosequences in that only two stages in forest development are compared, which makes it difficult to draw conclusions about carbon accumulation rates with regard to stand age. However, a consistent pattern of higher carbon stocks in old forests compared with younger stands supports the hypothesis that forests may continue to function as net sinks for atmospheric carbon well beyond the normal rotation time.

A study of typical carbon stocks in dead and live organic matter stocks in old-growth forests in northeastern USA showed that oldgrowth forests had higher total, aboveground biomass, forest floor and soil carbon stocks than second-growth forest (Hoover et al. 2012). Oldgrowth forest was defined as having shade-tolerant tree species with a stand age over 150 years, in addition to some trees approaching their maximum age of $300+$ years.

In another study in northwestern USA (western Montana), carbon stocks in old-growth (stand age 185 to 200 years) and second-growth (stand age 30 to 45 years) stands of western larch and Douglas fir were investigated (Bisbing et al. 2010). In three study areas, 15 paired stands were studied. Ecosystem carbon stocks were 3 times higher in oldgrowth than in second growth stands, which primarily related to higher tree biomass (144 $\mathrm{Mg} \mathrm{C}^{-1}$ vs $24 \mathrm{Mg} \mathrm{C} \mathrm{ha}^{-1}$, respectively) and secondly to higher organic (0) horizon carbon pools (24 and $5 \mathrm{Mg} \mathrm{C}^{-1}$, respectively) while mineral soil carbon stocks did not differ. Coarse root biomass and coarse woody debris was also much larger in old-growth stands. It was concluded that old-growth forests contribute to long-term storage of carbon compared with younger, second-growth stands. However, the study did not consider how stand age correlates with ecosystem carbon storage - the second-growth stands had a considerably lower stand age than the old-growth stands. If the 0 horizon carbon stock difference would be solely driven by stand age, the annual carbon accumulation rate would be $12 \mathrm{~g} \mathrm{C} \mathrm{m}^{-2} \mathrm{yr}^{-1}$, but this would be typical for the transition of second-growth to old-growth forest, not for the forest itself.

In the Danish temperate deciduous forest reserve Suserup Skov there are no repeated measurements of soil carbon stocks. However, soil carbon stocks were higher $\left(13.2 \mathrm{~kg} \mathrm{~m}^{-2}\right)$ than in managed beech forests on similar soils $\left(8.8 \mathrm{~kg} \mathrm{~m}^{-2}\right)$. This was attributed to the absence of disturbance and input of dead wood over centuries (Vesterdal \& Christensen 2007).

\section{Carbon accumulation in woody debris in old forests}

Coarse woody debris is a feature of old forests that has received much attention as an important biodiversity indicator. Debris has not been much studied as a component of the forest carbon cycle, which is why it is treated separately here. 
Woody debris can be a large carbon pool in old forests, and undergoes large changes in stocks during succession (Harmon 2009). In a report for the Nordic Council of Ministers, Stokland et al. (2003) focused on forest biodiversity indicators. Coarse woody debris (CWD) is such an indicator because it is a habitat for many species (Siitonen 2001, Stokland et al. 2012). Fine woody debris (FWD, typically $<7.6-10 \mathrm{~cm}$ diameter) and CWD (typically $>7.6 \mathrm{~cm}$ diameter, up to $>1 \mathrm{~m}$ diameter) can originate from twigs, branches, roots, stems, stumps. For roots, the division between fine roots and coarse roots is usually made at a diameter of $2 \mathrm{~mm}$. Disturbance is a key driver of woody debris, either by producing (mortality of trees from insect and fungi infestations, wind throws, harvest residues after logging, mortality related to stand density (selfthinning)) or removing debris (harvest by removing trees prior to mortality, fires).

Decomposition is the key natural process controlling the loss of woody debris, and is related to size (large logs decompose more slowly than smaller logs), quality (hardwood versus softwood) and climate with very fast decay rates in warm and humid conditions as opposed to dry and cold conditions (Chambers et al. 2000, Harmon 2009, Yatskov et al. 2003). CWD in old forests spans several orders of magnitude because of differences in input - and decomposition rates. Forests of high productivity tend to have more CWD than forests of low productivity.

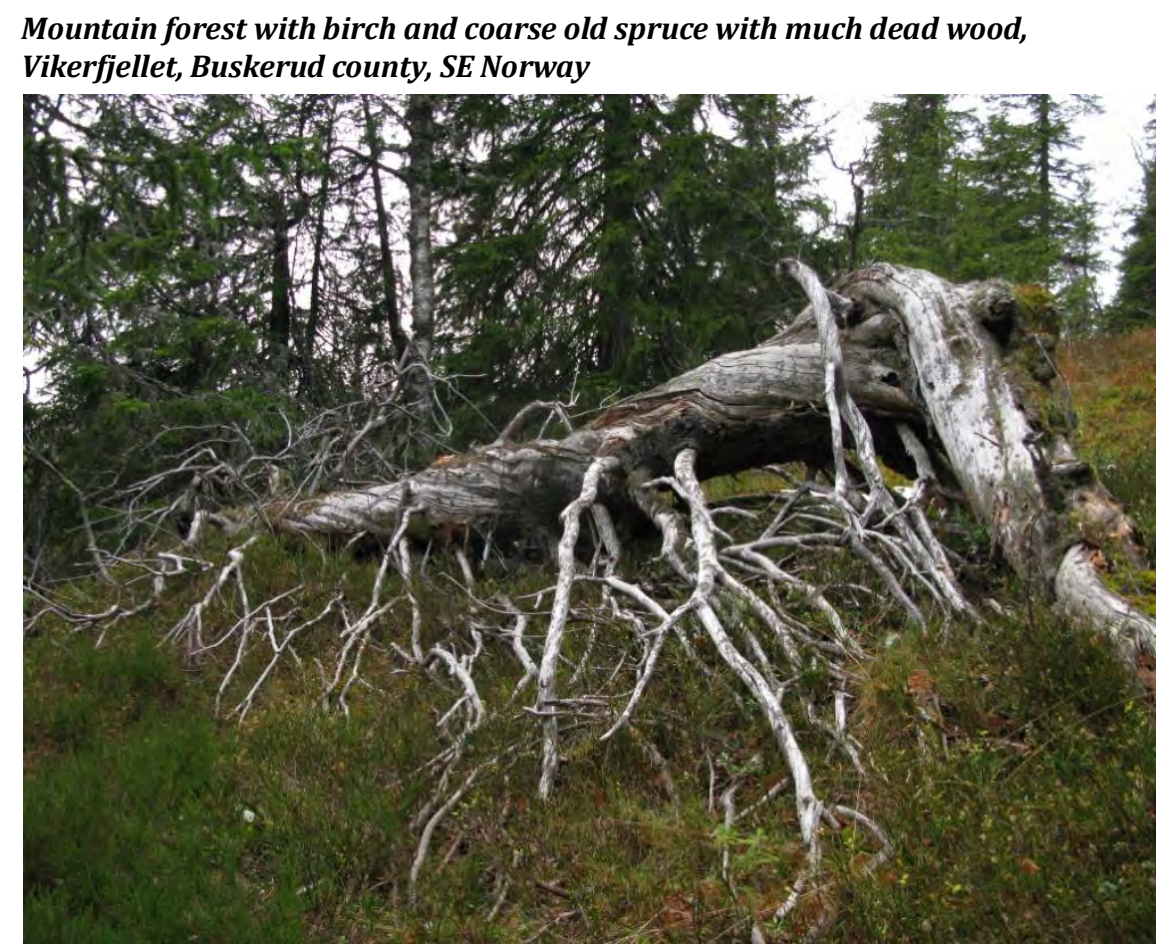

Photo: Egil Bendiksen, NINA. 
In evaluations of the long-term fate of CWD after disturbance, one can distinguish between legacy CWD (created by the disturbance) and new CWD created by "regular" causes (Harmon 2009). Studies of CWD in chronosequences often show an initial high peak of CWD right after the disturbance, followed by a minimum of CWD in early succession stages and an increase in mature and old forest. This seems to be a general pattern, although how many of the trees are killed and consumed by the disturbance (particularly various types of fires) will affect the amount and trajectory of CWD after the disturbance (Siitonen 2001). In the mainly less severe fires in boreal forests of Fennoscandia, fires are likely to leave considerable amounts of legacy dead wood as well as living but damaged trees that may persist over many decades before dying (cf Kuuluvainen 2009).

The amount of legacy CWD at the start of the succession has a major impact on net ecosystem carbon balance (NECB) during succession after disturbance. Decomposition of legacy CWD is a likely cause for net losses of carbon from stands in early succession. There is evidence from eddy covariance studies that forests are a source of carbon to the atmosphere during the first 14 years (Schulze et al. 1999) or the first 12-24 years after clear-cutting (Wirth et al. 2002), after which the forests turn into net carbon sinks. Removing all legacy wood after harvesting (whole-tree harvesting) is likely to have a negative impact on the carbon balance as part of the legacy wood decomposes outside the forest (Harmon 2009).

In the semi-natural forest reserve Suserup Skov in Denmark, dead wood carbon stocks accounted for $21 \mathrm{Mg} \mathrm{C}^{-1}$ or $6 \%$ of the total ecosystem carbon stock (Vesterdal \& Christensen 2007). In Danish managed forests, this carbon pool on average accounts for only $1.1 \mathrm{Mg} \mathrm{C}^{-1}$ (Nord-Larsen et al. 2009).

In the eddy covariance study of net ecosystem exchange (NEE) in an old-growth ( $>300$ years) and middle-aged hardwood stand (70 years) in the upper Midwest in USA (Desai et al. 2005), stocks of CWD were also measured. Stocks of CWD were significantly higher in the old-growth forest than in the 70-year old forest, but they could not be linked to NEE because of lacking data on respiration from CWD. In the eddy covariance study of a young (recently clear-cut old-growth forest, 14 years stand age) and old ponderosa pine stand (mixed age classes, predominantly 50 and 250 years) in Oregon, stocks of woody debris were measured (Law et al. 2001). Both CWD and FWD were largest in the recently clear-cut stand, and annual respiration from these carbon stocks was also highest in the youngest stand. Respiration from woody debris was $10 \%$ (old stand) and $20 \%$ (young stand) of heterotrophic respiration and of similar size as NEP (in absolute terms). This illustrates that the contribution of respiration of woody debris is significant for net ecosystem carbon balances. 


\section{Old forests: Data syntheses}

The global database on forest productivity which was referred to earlier (Kutsch et al. 2009, Luyssaert et al. 2007) was analysed for relations between net ecosystem production NEP (= GPP $-\mathrm{Ra}-\mathrm{Rh})$ and stand age. The data were compiled from literature and databases and included observations of carbon cycle components such as biometry-based NPP (bottom-up measurements), eddy-covariance and biometry-measured NEP, and chamber-based Rh. Managed sites were included. NEP in forests between 15 and 800 years of age was generally found to be positive (Luyssaert et al. 2008). Biomass continued to increase for centuries both in temperate and boreal forests, with an observed maximum of 500-700 Mg C ha-1 (in the Pacific Northwest USA). The authors speculate that the continuous increase of biomass in old forests is due to gap-filling dynamics, where individual trees lost because of lightning, insect and fungal attacks are replaced by new recruitment or second-growth canopy. The (mostly modelled) ratio of NPP to Rh was above 1, even in old forest, suggesting that plant productivity exceeded respiration and thus resulting in net carbon accumulation. Old forests ( $>200$ years) were estimated to sequester $240 \pm 80 \mathrm{~g} \mathrm{C} \mathrm{m}^{-2} \mathrm{yr}^{-1}$, of which 40,70 and $130 \mathrm{~g} \mathrm{C} \mathrm{m}^{-2} \mathrm{yr}^{-1}$ in stem biomass, coarse woody debris and soils, respectively. The total sink of old forests was estimated to be approximately $1.3 \pm 0.5 \mathrm{Pg} \mathrm{C} \mathrm{yr}^{-1}$.

The different methods for estimating soil carbon accumulation appear to lead to very different rates of soil carbon accumulation (Gleixner et al. 2009). Repeated sampling (Table 5.2) gives usually much higher rates of carbon accumulation (50 to $170 \mathrm{~g} \mathrm{C} \mathrm{m}^{-2} \mathrm{yr}^{-1}$ ) than chronosequences (Table 5.3; 5 to $35 \mathrm{~g} \mathrm{C} \mathrm{m}^{-2} \mathrm{yr}^{-1}$ ). Very old forests (age of millennia; Wardle et al. 2012) appear to store carbon at much lower rates than "old forest" of several 100 years, although Wardle et al. (2012) did not find any difference in accumulation rates between their younger islands (mean age 585 yrs) and the very old ones (mean age 3250 yrs). Reconciliation of results obtained from various methods remains a matter of discussion. 


\section{Old forest conservation: relevance for biodiversity and climate change mitigation}

The apparent value of old forests for biodiversity as well as carbon stocks raises the issue to what extent forest and environmental properties important for biodiversity and for carbon stocks are overlapping and what policy implications such a coincidence may have. Here we will draw on the insights presented in previous chapters, put these into a wider context, and identify key knowledge gaps as well as possible policy implications.

\subsection{Forest carbon stocks and sequestration}

\section{Old forests and the carbon cycle}

Forests play a major role in the global carbon cycle and take up between $30 \%$ and $40 \%$ (2.1-2.6 $\left.\mathrm{Pg} \mathrm{C} \mathrm{yr}^{-1}\right)$ of annual fossil fuel $\mathrm{CO}_{2}$ emissions. Biomass is a larger carbon sink than soils and dead wood. In boreal and temperate forests, carbon stocks in soils represent $60 \%-85 \%$ of total forest carbon stocks (Prentice et al. 2001). Estimates of forest biomass and soil carbon sequestration in Finland and Norway during the past two decades are 8 and $5.6 \mathrm{Tg} \mathrm{C} \mathrm{yr}^{-1}$, respectively, or 39 and $46 \mathrm{~g} \mathrm{C} \mathrm{m}^{-2} \mathrm{yr}^{-1}$ (Liski et al. 2005 , De Wit et al. in prep.). For Sweden, forest carbon accumulation between 1920 and 2000 was estimated to be $7.1 \mathrm{Tg} \mathrm{C} \mathrm{yr}^{-1}$, or $31 \mathrm{~g} \mathrm{C} \mathrm{m}^{-2} \mathrm{yr}^{-1}$ (Ågren et al. 2007). The soil carbon sink was about $19 \%$ to $28 \%$ of the total carbon sink, estimated using models. Preliminary assessments for Denmark also indicate an increase in forest carbon stocks during the last decades. Hence, forests in Fennoscandia contribute to approximately 1\% of the global forest carbon sink. There are insufficient data to assess the contribution of old forests to the total carbon sink in Fennoscandia.

Old forests were previously thought to be carbon neutral because maintenance respiration (loss of carbon) would equal production (binding of carbon) as trees would grow older. One may even have assumed that ecosystem respiration would exceed plant production in old forests, partly as a result of increased susceptibility of old forests to external disturbances (such as storms, insect or fungal attacks). At the stand level, this has been shown to be incorrect as biomass can continue to increase even at high stand ages, while the stands continue to produce 
litter (coarse woody debris, leaves and needles, roots). Filling of gaps in the canopy following tree mortality will also in many cases ensure that biomass carbon stocks do not decrease with forest age. Changes in stand structure, not changes in the ecophysiological capacity of individual trees, determine changes in stand productivity. Continued litter production - with decomposition rates being constant - can lead to continued accumulation of soil carbon and woody debris. Decomposition rates may even decline as the forest ages (cf Wardle et al. 2012).

There is accumulating evidence, based on various methodological approaches, indicating that old forests may continue to function as carbon sinks even as they age far beyond normal harvesting age in managed forests (cf chapter 5.7). A handful of eddy covariance studies, including some of old-growth forests (Table 5.3), consistently show net carbon accumulation of the studied old-growth forest ecosystems. However, the complexity of the method and the need for additional studies of some important carbon fluxes of the ecosystem make it hard to extrapolate these results to larger regions. The rather few studies based on repeated sampling of soil carbon also tend to confirm that old forest soils are carbon sinks (Table 5.4). However, the problems associated with this method (large spatial variation in soil carbon relative to temporal changes) and the limited number of these studies, also raise questions about the possibility to draw conclusions about other ecosystems than those investigated. Results from various studies of carbon stocks in forests forming chronosequences of comparable sites of different ages since the last major disturbance also tend to confirm that soils in old forests function as carbon sinks (Table 5.5). Not all these studies seem to rest on well-defined chronosequences. Comparisons of carbon stocks in paired stands of different ages provide similar but more static results to chronosequence studies, and suffer from some of the same issues of comparability between sites. Although the measurement of changes in soil or total ecosystem carbon stocks is difficult, and the various methods have their problems, the consistent direction of the results of the various studies provides convincing evidence that old forest soils and especially dead wood pools (as well as biomass) function as carbon sinks for a long time, and usually a significant number of years beyond their usual rotation time. In view of the lack of studies on carbon accumulation in Nordic old forests, methodological issues and uncertainties about the results of individual studies, additional carefully designed studies are needed to provide robust estimates of carbon accumulation relevant for Nordic old forests.

Based on the studies reviewed here, we conclude that carbon stocks in biomass of old forests continue to increase with age, possibly for several hundred years. However, the rate of biomass accumulation will be reduced with increasing age. Furthermore, carbon stocks of forest soil and dead organic matter (including coarse woody debris) appear to increase with stand age. Biomass accumulation may level off at some 
point, although that point may be considerably later than represented in current forestry models.

\section{Variation in carbon stocks with climate, site productivity}

Variation in forest biomass and soil carbon stocks in boreal and northern temperate forests is largely determined by the tree species and the age of the forest stand, the site productivity, and the disturbance history of the site. Site productivity is primarily related to climate and soil nutrient status. Forest soil carbon stocks are driven by site productivity (primarily driving litter production but also influencing the microbial community and activity), litter quality, and local topography and disturbance history. The relationships between external drivers and soil carbon stocks are complex, and it is therefore difficult to describe clear patterns in the response of soil carbon stocks to such drivers.

Nevertheless, we may suggest the following provisional summary of the response of carbon stocks to environmental drivers:

- Forest biomass and associated carbon stocks tend to follow climate and site productivity: the climate and site conditions most suitable for fast growth of trees, i.e., warm and moist climates (within the variation normally found in the Nordic countries), also tend to produce the largest carbon stocks in biomass as well as input of dead organic matter to soils.

- The response of soil carbon stocks to climate and site productivity is less clear. Whereas warmer climates and higher site productivity will generally produce more litter as input to soil carbon stocks, decomposition rates will also increase. Litter quality will also often be higher for productive sites, resulting in faster decomposition. In spite of lower litter production in unproductive cold and dry climates, low decomposition rates in such climates may result in high soil carbon stocks, especially in moist sites with anaerobic conditions and peat formation. On a global scale it appears to be a south to north increase in soil carbon stocks. However, within the Nordic countries soil carbon stocks increase from north to south, linked to site productivity and nitrogen availability as well as temperature.

- Soil carbon stocks also vary with soil type (mainly linked to parent material and climate). Organic soils have considerably higher soil carbon stocks than mineral soils (e.g., see Krogh et al. (2003) for Denmark; De Wit \& Kvindesland (1999) for managed forests in Norway: organic soils $33 \mathrm{~kg} \mathrm{C} \mathrm{m}^{-2}$, podzols, gleysols: $18 \mathrm{~kg} \mathrm{C} \mathrm{m}^{-2}$ ).

- The most productive tree species have faster biomass accumulation and tend to produce more litter as input to soil carbon stocks. In general, the highest biomass and litter production of boreal forests are in Norway spruce dominated stands, where also soil carbon stock are highest. 
- Generally, variation in soil carbon stocks with environmental drivers is most pronounced for the organic layer, less so for total soil carbon stocks.

Old pine forest on olivine ultra alkaline bedrock in Bjørkedalen, Møre og Romsdal county, W Norway

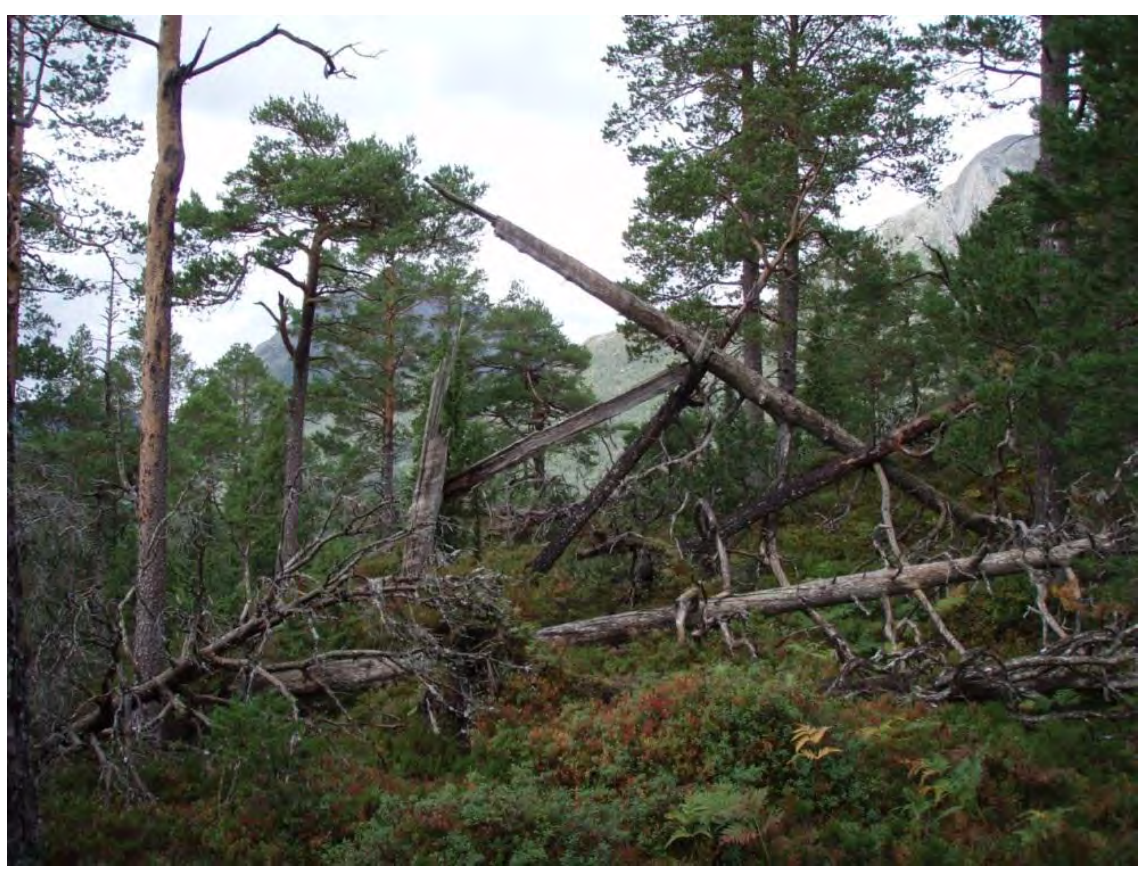

Photo: Tor Erik Brandrud, NINA.

\section{Effects of biomass harvesting on carbon stocks and fluxes}

Modern forest management incorporates various management measures which influence biomass, carbon stocks and carbon fluxes. The most fundamental effect, however, comes with the removal of biomass from the forest. This directly reduces the carbon stocks represented by the tree biomass, and its wider effects on the global climate will depend on how this harvested biomass is used. The questions are (1) how does harvesting influence other, non-targeted parts of the carbon stocks, in particular woody debris and soil carbon stocks, and (2) how can forestry measures be modified to improve the overall carbon sink function of forests?

The act of harvesting trees, at least with the currently dominating model of stand management and clear-cutting, will produce considerable amounts of logging residue of various sizes. Most of it will be of small dimensions and decompose rather quickly over a decade or so, but stumps represent coarse woody debris with a slow decay rate (lasting up to a century). The resulting litter from logging debris and natural litter production will partly be incorporated into the soil organic matter, and partly be released to the atmosphere as $\mathrm{CO}_{2}$. It is less clear how soil carbon stocks respond to the harvesting event as such. After the first 
rush of logging residues, little additional litter will be produced in a clear-cut stand for some decades. During the first few decades, decomposition of litter and soil organic matter will exceed production of biomass and the overall carbon stock will decline. However, it has generally been assumed that the reduction in soil carbon stocks after harvesting is moderate and will be rebuilt to pre-harvesting levels over a period of 30-40 years (Nilsen et al. 2008). A meta-analysis of effects on soil carbon stocks after harvesting in temperate forests showed that harvesting resulted in decreased carbon stocks of the soil 0 horizon but found no effect for the mineral soil (Nave et al. 2010). Similar reductions in soil carbon stocks have also been found by studies from boreal forests (Kolari et al. 2004, Pumpanen et al. 2004b). The finding by De Wit \& Kvindesland (1999) that soil carbon stocks increase with the stand development class (related to stand age) indicate that soil carbon stocks are not back to their former size within a few decades after harvesting but continue to increase (cf also Figure 5.3). Studies looking at the effect of changing harvesting rotation length, also (mostly) support the hypothesis that soil carbon is depressed after harvesting for a long time. However, modelling studies (Liski et al. 2001) point to the critical role of logging residues as a source of litter and input to soil carbon stocks. Overall, effects of harvesting regime on the input of litter and coarse woody debris will be more important for soil carbon stocks than changes in decomposition rates.

When it comes to adaptation of forestry measures to improve maintenance of the forest carbon stocks under harvesting, we may draw the following tentative conclusions from the discussion in chapter 5.6 (cf Table 5.2):

- Increased rotation period between harvesting events will result in higher carbon stocks in forest biomass.

- Limiting harvesting to the most valuable products (i.e., quality timber) will result in higher overall carbon stocks. Increased harvesting of logging residues, stumps and other economically marginal biomass will reduce carbon stocks and the nutrient capital in forests, thereby potentially limiting future growth rates and the magnitude of the carbon sink.

- Low thinning activity is likely to maximize overall forest carbon stocks.

- Management of regenerated sites to ensure early establishment of fully stocked stands will increase the rate of carbon accumulation in tree biomass.

- Forest fertilization (with nitrogen fertilizer) will increase biomass growth, litter production, and soil carbon stocks. Although fertilization will increase carbon stocks, it may also increase the production of nitrous oxide $\left(\mathrm{N}_{2} \mathrm{O}\right)$, a powerful greenhouse gas. 
- Species composition or growing stock consisting of the most productive species or provenances will generally result in the highest biomass carbon stocks and sequestration rates. Exotic species or provenances may have higher productivity than native ones under certain climate or site conditions, e.g., sitka spruce in coastal districts of western and northern Norway. Within a similar climate, tree species composition may affect soil carbon stocks, mostly in the less stable forest floor carbon stocks. However, some species, via associated soil fauna or root turnover, may be better engineers for sequestration of carbon in stable forms in the mineral soil.

\subsection{Forest biodiversity and the carbon cycle}

Forests represent important ecosystems for the biodiversity of the Nordic countries, harbouring more than $50 \%$ of all known terrestrial species in Finland, Norway and Sweden and almost as large a share of the threatened species. Forest ecosystems vary according to gradients in climate and productivity, as well as terrain and disturbance regimes, resulting in a range of forest types with specific ecological characteristics and associated species. As we have seen in chapter 3, the extensive human influence of the Nordic forests, especially over the last century with most forests strongly shaped by industrial forestry, has had profound effects on ecological properties of primary importance to biodiversity. This particularly pertains to properties shaped by natural forest dynamics and typical of old-growth forests, such as a rich and varied supply of dead wood and old and large trees, as well as forests with longterm intact canopy cover and hydrological regime.

The importance of forest biodiversity pertains partly to the conservation of intact ecosystems and native species and partly to the maintenance of robust ecosystem functions. As we have seen in chapter 3, natural forest dynamics provide an important paradigm or framework for the conservation of biodiversity, as native species and ecosystems have evolved under such dynamics over millions of years. The long evolutionary history under natural forest dynamics has also shaped the important ecosystem functions of forests, although not all these functions may be optimal from a human perspective. For instance, long-term succession without external disturbance will most likely gradually reduce the productivity of the forest (cf the concept of retrogression in Wardle et al. (2012)).

From a conservation perspective, the most valuable forest for biodiversity will be forests with the following characteristics (cf chapter 4.1):

- Extensive amounts and diversity of dead wood, in particular a rich supply of coarse woody debris 
- Old and/or large trees of all species, but where old temperate broadleaved deciduous trees and aspens, willows and rowans are particularly valuable for biodiversity

- Forests recently disturbed by fire and associated substrates like burnt dead wood and ground

- Swamp forests and other wetlands, especially those on productive or calcareous sites

In addition, forest species diversity tends to increase from north to south and to be higher on moderately productive or calcareous sites than on sites poor in nutrients. Species-rich forests also tend to harbour more threatened species (although threatened species also occur elsewhere).

Key forest properties for biodiversity of old forests, such as the supply of dead wood and old trees, as well as productive site conditions seem to coincide with important properties for forest carbon stocks and partly for carbon sequestration (in the case of site productivity). However, we lack knowledge of the more specific distribution of carbon stocks with various environmental properties or in relation to forest types. Hence, there are currently limited opportunities of relating the distribution of forest biodiversity to carbon stocks via specific variation in forest environmental properties. The relevant data should exist in national forest inventories and could be related to relevant environmental properties, but as far as we know such analyses are mostly lacking and only rather coarse relationships can be described at the Nordic level (cf chapters 5 and 6.1).

Recently, however, Framstad et al. (2011) compared carbon stocks and $\mathrm{CO}_{2}$ uptake in various Norwegian forest types judged to have high value for biodiversity. The analysis was based on information on biomass stocks and changes in selected national forest inventory plots satisfying specific criteria for forests of value to biodiversity. They concluded that:

- The biologically valuable forest types have approximately the same significance for carbon stocks and uptake of $\mathrm{CO}_{2}$ as other forests with similar productivity.

- The largest carbon stocks per unit area are found in old forests, especially old spruce and mature temperate deciduous forests, whereas unproductive mature deciduous forest has the lowest carbon stocks per unit area.

- High annual $\mathrm{CO}_{2}$ uptake per unit area is associated with the more productive forests, such as rich deciduous and coniferous forests and productive mature deciduous forest, and is lowest for unproductive deciduous forest.

- Assessed value for biodiversity of the respective forest types coincides rather well with their value for $\mathrm{CO}_{2}$ uptake per unit area and, with some exceptions, also for carbon stocks per unit area. Rich 
(calcareous) coniferous and temperate broadleaved forests, in particular, have great value for biodiversity, carbon and uptake of $\mathrm{CO}_{2}$ per unit area. Rich deciduous forests, productive deciduous forests and coastal forests have rather high values for biodiversity, but their carbon stocks are lower. Old spruce and partly old pine forests are important for carbon stocks and somewhat less important for biodiversity.

- Relative to the profitability of forestry, potential conflicts seem to be greatest for rich and old coniferous forests, and less so for rich deciduous forests, mature productive deciduous forests, and coastal forests. Conflict with forestry is least likely for unproductive deciduous forests, but here values for biodiversity or carbon stocks are lower.

\section{Calcareous lime forest with characteristic stem "clones" on limestone outcrops,} near Porsgrunn, Telemark county, SE Norway

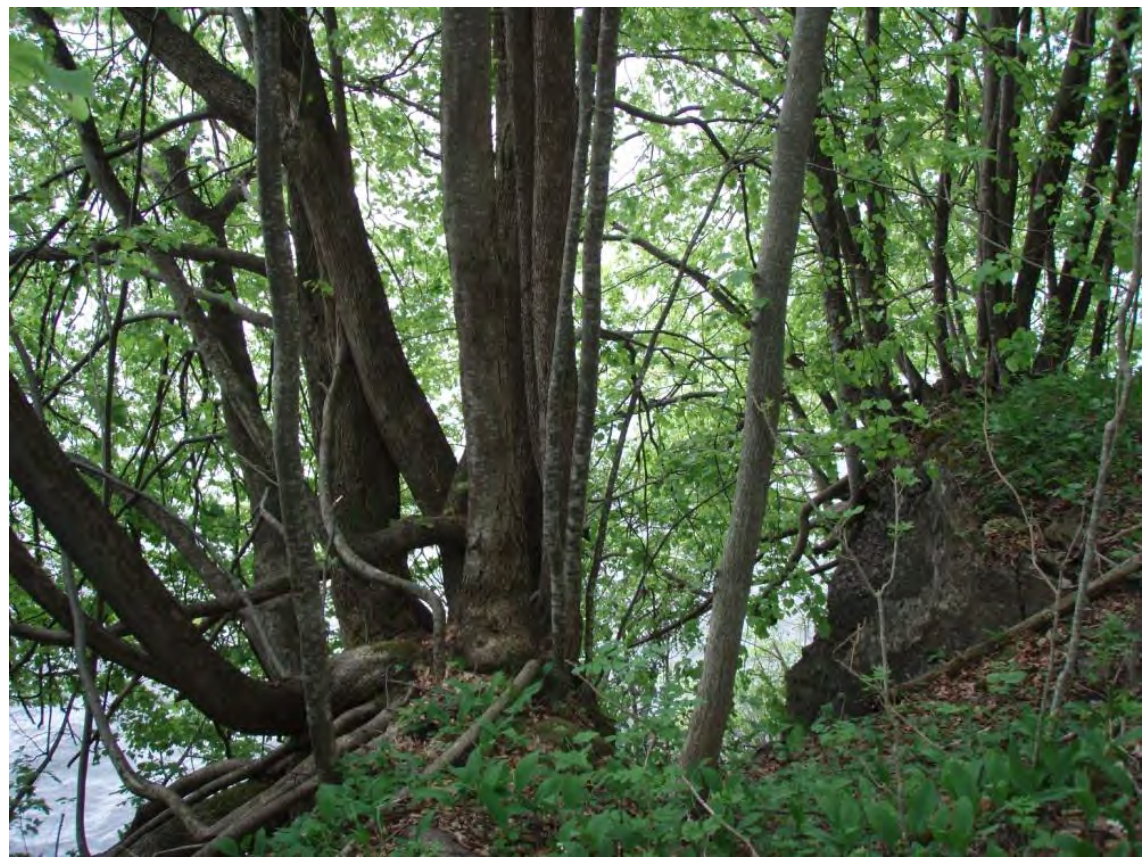

Photo: Tor Erik Brandrud, NINA.

\subsection{Albedo and other biophysical climate impacts of forest management}

The main objective of this report has been to collate published information and synthesize current understanding of the dynamics of carbon stocks in Nordic forests and how this may vary with environmental conditions, forest age and management. Whereas sound management of forest carbon stocks will be an important aspect of mitigation of climate change, the dynamics of forest carbon stocks are only part of the links between 
forests and the climate system. In this context the albedo and other biophysical properties of the land surface will also have to be considered.

Albedo is the fraction of incident sunlight reflected back into space. Forests have different surface properties and have a lower surface albedo than non-forest vegetation. Forests will also influence other biophysical properties of climate relevance, such as surface roughness affecting convective heat transfer and the amount of water recycled to the atmosphere by evapotranspiration. These biophysical factors may strengthen or weaken the albedo effect, depending on the particular system properties. In boreal regions, snow-covered fields or tundra may have albedos approaching 0.6-0.8, compared to only $0.2-0.3$ for evergreen conifer forest during winter and around 0.1 during summer (Anderson et al. 2011, Bright et al. 2011). Actual albedo values will depend on specific ecosystem and climate factors like the angle of incoming radiation, clouds, terrain, and snow conditions. Several modelling studies have indicated that the positive climate effects of $\mathrm{CO}_{2}$ uptake in boreal forest biomass will most likely be exceeded by the negative effects of lower albedo of forests relative to non-forested (especially snow-covered) fields, tundra etc (e.g., Betts 2000, Bala et al. 2007, synthesis in Bonan 2008, Anderson et al. 2011). Local cooling as a consequence of deforestation in higher latitudes has also been documented by observations (Lee et al. 2011). In an estimate of the climate effect of expanding deciduous forests in arctic regions, Swann et al. (2010) found that evapotranspiration had a greater effect than albedo, both leading to increased warming, in particular when including positive feedbacks from lower albedo and higher evaporation from increasing ice-free ocean areas. In temperate regions, the climate effects of increased albedo and $\mathrm{CO}_{2}$ release to the atmosphere from forest removal seem to balance each other (Bala et al. 2007). Most of these studies have been applied at a global biome scale without specific input of climate, forest and management characteristics at regional levels like Northern Europe or the Nordic countries. However, recent modelling studies for Norway have reached similar conclusions. Bright et al. (2011) modelled the climate effects of additional forest harvesting for biofuels, combining changes in the carbon cycle and albedo. They found that radiative forcing from increased albedo approximately balanced the effect of released $\mathrm{CO}_{2}$ for about the first 30 years, i.e., the time assumed for logged areas to reach an albedo equivalent to forests. Bright et al. (2011) suggest that the overall combined climate forcing of albedo and released $\mathrm{CO}_{2}$ can be reduced by shorter harvesting cycles and more intensive forest cultivation to speed up forest growth. The model of Bright et al. (2011) is quite complex and they have had to make several simplifying assumptions. They have also ignored the feedback from increased global temperatures on the length of the snow season, leading to considerable uncertainty about the actual climate effects of changes in albedo versus carbon stocks under increased forest harvesting. 
More realistic assessments of all climate effects pertaining to forests are still confronted by a number of challenges:

- To take proper account of the biophysical climate effects of different forest management models, there is a clear need for better information on the influence of forest cover, density and other forest properties related to management on albedo and other heat flux mechanisms such as evapotranspiration.

- Regional or national models incorporating both carbon cycle and biophysical (especially albedo) effects of forest management also need to be more realistic by incorporating spatially explicit information on terrain and forest characteristics. Such spatially explicit data may become available through the new multisource forest inventories including remote sensing data.

- Both changes in the carbon cycle and the biophysical properties of forests under various management regimes will have important feedbacks with the global climate system. These feedbacks should be taken into account but will lead to great complexity if local realism is to be maintained.

- The long-term and global effects of $\mathrm{CO}_{2}$ emissions must be balanced against the short-term and more local effects of albedo and other biophysical effects. The weighing of costs and benefits associated with these often conflicting climate effects is essentially a normative issue.

\subsection{Gaps in knowledge}

As will be apparent from this review of forest carbon dynamics, especially soil carbon dynamics, several topics are still poorly understood. Whereas the general dynamics of the biomass and carbon associated with forest trees up to and just beyond their harvestable age are reasonable well understood, this is much less the case for carbon dynamics in old forests and of soil carbon in particular. We also have several poorly known issues on the linkages between biodiversity and the ecosystem functions of the carbon cycle.

Specifically, we would like to highlight the following topics as particularly in need of further study:

- How will old forest tree mortality develop under natural dynamics? Will mortality factors like wind throws, breakage, insect and fungal attacks reduce biomass or will gap-filling dynamics balance or compensate biomass losses?

- How do carbon stocks and sequestration in soils vary with climate, site productivity, forest type and other environmental drivers?

- Can soil carbon stocks in forests increase indefinitely or do they approach a steady state? If so, is this steady state reached in the 
course of some decades (as assumed by some forestry models), a century (the "old" assumption for mature forest) or centuries to millennia? Which role do disturbances like fires, storms, and insect and pathogen attacks have for the long-term carbon sequestration?

- How do soil carbon stocks respond to harvesting events, especially relating to the amount of legacy carbon in logging residues, changes in decomposition rates, the extent of reduction in soil carbon stocks after decomposition of legacy carbon, rates of soil carbon accumulation after harvest and with stand development, and net effects of changes in rotation length on soil carbon stocks?

- How will carbon stocks and fluxes, particularly those affecting soil carbon stocks, vary with stand-replacing versus continuous crown cover harvesting models, assuming the same amount of tree biomass is removed?

- How can we best quantify the carbon sink strength, i.e. annual rate of carbon sequestration, for forests set aside as reserves, compared with the sink strength in conventionally managed forests, with and without inclusion of fossil fuel substitution effects?

- How do important components of biodiversity vary with climate, site productivity, forest type etc? Can we specify clear site-based criteria indicating value for biodiversity?

- What are the linkages between biodiversity structure (particularly tree species diversity) and ecosystem functionality, e.g., for the carbon and nitrogen cycles?

- Can the respective goods of biodiversity, carbon sequestration, forest production, recreation and other amenity values of forests by handled by a common framework for ecosystem services? And if so, how?

It is particularly important to get more well-designed empirical studies of carbon dynamics in old forests, especially forests with a long period of non-intervention or stand-replacing disturbances. Current data for old forests, particularly in temperate regions of Europe, originate to a large extent from forests regenerating after disturbance or past human exploitation, giving limited opportunity for robust empirical studies of old forest carbon dynamics.

To improve our understanding of the real climate effects of various forest management options we need better knowledge of key components of the forest carbon cycle such as soil carbon stocks, improved knowledge of the climate forcing of the various biophysical effects of forests, more realistic modelling of variation in carbon stocks in time and space, combined with biophysical effects, and not least, more realistic life cycle and cost-benefit analyses of the various uses of forest biomass in a climate perspective. 


\subsection{Implications for forest policy and management}

Climate mitigation policy has essentially three components relevant to forest management: (1) to increase (or at least not decrease) the carbon stocks in forests, (2) to substitute fossil energy efficiently with bio-based energy and products from forests, and (3) to reduce the biophysical climate forcing of forests. In this report we have focussed on the first of these - how carbon stocks in forests can be conserved to avoid emissions of greenhouse gasses to the atmosphere, without any consideration of the cost-efficiency of such measures or of alternative measures.

The climate consequences of changes in forest cover, density and/or structure are quite complex due to the relationships between biophysical and biogeochemical effects of forests and their interaction with the global climate system. From the review presented in the previous chapters, we may nevertheless draw some general conclusions on forest management in a climate context:

- Old forests continue to accumulate carbon for a long time, although at slower rates than in faster growing young forest. To conserve, and possibly increase, the carbon stocks of forests, increasing the area of old forests by protection of more forest against harvesting is clearly recommended.

- In managed forests, prolonging the harvesting cycles (i.e., increasing the rotation time between fellings) is a management option that will conserve forest carbon stocks.

- Whether continuous cover harvesting regimes will better conserve forest carbon stocks than stand-based clear-cutting, provided the same amount of forest biomass is removed, is not clear. The albedo effect for a few decades after harvesting will, however, be greater for clear-cut stands than for stands under continuous cover harvesting.

- Harvesting of logging residues and stumps will reduce forest carbon stocks and also the nutrient capital of forests, with negative effects on future forest growth (unless the nutrient loss is compensated by fertilization). Removal of logging residues (branches, tree tops without foliage) will have a less negative climate effect than removal of stumps.

- Management to ensure rapid establishment of well stocked forests stands, e.g., through site preparation and planting of productive species or provenances, will increase carbon stocks more rapidly than without such management. However, thinning of stands to increase growth in individual trees will reduce the total carbon stocks of the stands. Fertilization (primarily with nitrogen) will yield faster biomass growth, thus increasing carbon stocks, but will also risk increasing nitrous oxide $\left(\mathrm{N}_{2} \mathrm{O}\right)$ emissions. Intensive forest management will also involve extra energy use and disturbance of forest stands, with potentially negative effects on other ecosystem functions. 
- Afforestation on currently non-forested land, such as abandoned fields, pastures or peatlands, will lead to higher carbon stocks over time, provided site preparation for planting does not lead to high losses of soil carbon stocks in existing ecosystems. Some of these non-forested ecosystems may, however, already have substantial soil carbon stocks. Afforestation on non-forested land will also reduce the albedo and possibly counter-balance the climate effect of increased carbon stocks. The balance between these opposing climate effects is difficult to specify in general.

The policy objectives related to forest biodiversity are in some sense less complex, although there is considerable debate on how best to achieve them. In general terms, these objectives may be formulated as conservation of all native species and the ecosystems they depend on, as well as maintenance of sound ecosystem functions. Although there is considerable disagreement on how sensitive species and ecosystem functions are to various levels and forms of human impact on forests, there is little disagreement that maintenance of natural forest dynamics would be the best way to benefit native species and ecosystem functions. As we have seen in chapters 3 and 4 , our current understanding of natural forest dynamics puts a greater emphasis on old natural forests and their content of key resources like coarse woody debris and old trees, than perhaps was the case a decade ago.

Taking old natural forests as a model, the implications for forest management for biodiversity are rather clear:

- Old forests have a number of attributes of key importance for forest biodiversity, such as old and large trees, a large and varied supply of dead wood, long stability of substrates and microclimate. Hence, forest reserves and other non-harvested forest areas have particular values for biodiversity linked to old forests and forests under natural dynamics.

- Natural disturbance regimes represent the most robust way to maintain the structural and functional characteristics of natural forests to which most native forest biodiversity is adapted. Only large forest conservation areas, in the order of $100 \mathrm{~km}^{2}$ or more, will be able to accommodate such disturbance processes at realistic scales.

- For managed forests, prolonged harvesting cycles and closed-canopy harvesting will benefit species adapted to moderately old forests and will also maintain more robust ecosystem functions. In addition, retention of old trees, dead wood, deciduous trees, and buffer zones against mires and wetlands are important measures to maintain habitat qualities that benefit substantial parts of biodiversity in harvested forest landscapes. 
Overall, it is clearly documented that old forests are beneficial for the maintenance of forest carbon stocks as well for the conservation of biodiversity. In a society where forests will also be harvested for various human needs, the challenge is how protected areas and the various forest management measures shall be allocated in space and time to achieve an optimal balance between the policy goals of biodiversity conservation, climate mitigation, and economically and socially viable forestry. Table 6.1 illustrates how various forest management measures may affect biodiversity conservation as well as maintenance of forest carbon stocks. From a global perspective, Huston \& Marland (2003) argue that forest harvesting (for fossil fuel substitution and other purposes) should be allocated to the most productive forest areas, whereas more marginal forest areas should be conserved for maintaining carbon stocks as well as biodiversity. A similar differentiation in management between forest areas with different environmental characteristics in the Nordic countries may allow us to find a better balance between conflicting policy objectives. However, productive boreal forests tend to be important for biodiversity as well as for carbon sequestration and stocks and for forestry, and conflicts of interest may not be easily avoided. To provide more realistic analyses and models to inform policy choices we need to improve our knowledge of both carbon stocks and biodiversity and their variation with environmental properties like climate, terrain, site productivity and current and previous land use.

\begin{tabular}{l} 
Table 6.1 Illustration of co-benefits of forest management measures for biodiversity conservation \\
and maintenance of forest carbon stocks \\
\hline
\end{tabular}

* Positive effects on biomass carbon, uncertain or negative effects on soil carbon a Positive $\mathrm{C}$ balance but release of $\mathrm{N}_{2} \mathrm{O}$ 


\section{References}

Aber, J.D., Botkin, D.B. \& Melillo, J.M. (1978): Predicting the effects of different harvesting regimes on forest floor dynamics in northern hardwoods. Canadian Journal of Forest Research 8: 306-315.

Achard, F., Eva, H.D., Mayaux, P., Stibig, H.J. \& Belward, A. (2004): Improved estimates of net carbon emissions from land cover change in the tropics for the 1990s. Global Biogeochemical Cycles 18. GB2008, doi:10.1029/2003GB002142

Ågren, G.I., Hyvönen, R. \& Nilsson, T. (2007): Are Swedish forest soils sinks or sources for $\mathrm{CO}_{2}$ - model analyses based on forest inventory data. Biogeochemistry 82: 217-227.

Ahti, T., Hämet-Ahti, L. \& Jalas, J. (1968): Vegetation zones and their sections in northwestern Europe. Annales Bot. Fenn. 5(3): 169-211.

Aksenov, D., Karpachevskiy, M., Lloyd, S. \& Yaroshenko, A. (1999): The last of the last: The old-growth forests of boreal Europe. Taiga Rescue Network. 67 pp.

Andersen, B. \& Borns, H.W. (1997): The ice age world. An Introduction to Quaternary history and research with emphasis on North America and Northern Europe. Universitetsforlaget, Oslo.

Anderson, R.G., Canadell, J.G., Randerson, J.T., Jackson, R.B., Hungate, B.A., Baldocchi, D.D., Ban-Weiss, G.A., Bonan, G.B., Caldeira, K., Cao, L., Diffenbaugh, N.S., Gurney, K.R., Kueppers, L.M., Law, B.E., Luyssaert, S. \& O’Halloran, T.L. 2011. Biophysical considerations in forestry for climate protection. Frontiers in Ecology and the Environment 9: 174-182.

Andersson, L. \& Löfgren, R. (2000): Sydsvenska lövskogar och andra lövbärande marker. Naturvårdsverket Rapport 5081.173 pp.

Andersson, R. \& Östlund, L. (2004): Spatial patterns, density changes and implications on biodiversity for old trees in the boreal landscape of northern Sweden. Biological Conservation 118: 443-453.

Andrén, H. (1997): Habitat fragmentation and changes in biodiversity. Ecological Bulletins 46: 171-181.

Angelstam, P. \& Andersson, L. (1997): I vilken omfattning behöver arealen skyddad skog i Sverige utökas för att biologisk mångfald skall bevaras? SOU 1997: 98, Bilaga 4, Miljövårdsberedningen, Fritzes, Stockholm. (reference in Angelstam \& Kuuluvainen 2004)

Angelstam, P. \& Andersson, L. (2001): Estimates of the needs of forest reserves in Sweden. Scandinavian Journal of Forest Research, Supplement 3: 38-51.

Angelstam, P. \& Kuuluvainen, T. (2004): Boreal forest disturbance regimes, successional dynamics and landscape structures - a European perspective. Ecological Bulletins 51: 117-136.

Axelsson, R., Angelstam, P. \& Svensson, J. (2007): Natural forest and cultural woodland with continuous tree cover in Sweden: How much remains and how is it managed? Scandinavian Journal of Forest Research 22: 545-558.

Bala, G., Caldeira, K., Wickett, M., Phillips, T.J., Lobell, D.B., Delire, C. \& Mirin, A. (2007): Combined climate and carbon-cycle effects of large-scxale deforestion. Proceedings of the National Academy of Sciences 104: 6550-6555.

Baldocchi, D.D. (2003): Assessing the eddy covariance technique for evaluating carbon dioxide exchange rates of ecosystems: past, present and future. Global Change Biology 9: 479-492. 
Berglund, B.E. (ed.) (1991): The cultural landscape during 6000 years in southern Sweden - the Ystad project. Ecological Bulletins 41: 1-495.

Berglund, H. \& Jonsson, B.G. (2005): Verifying an extinction debt among lichens and fungi in northern Swedish boreal forests. Conservation Biology 19: 338-348.

Berglund, H., Hottola, J., Penttilä, R. \& Siitonen, J. (2011): Linking substrate and habitat requirements of wood-inhabiting fungi to their regional extinction vulnerability. Ecography 34: 864-875.

Betts, R.A. (2000): Offset of the potential carbon sink from boreal forestation by decreases in surface albedo. Nature 408: 187-190.

Bisbing, S.M., Alaback, P.B. \& Deluca, T.H. (2010): Carbon storage in old-growth and second growth fire-dependent western larch (Larix occidentalis Nutt.) forests of the Inland Northwest, USA. Forest Ecology and Management 259: 1041-1049.

Björse, G. \& Bradshaw, R. (1998): 2000 years of forest dynamics in southern Sweden: suggestions for forest management. Forest Ecology and Management 104: 15-26.

Bonan, G.B. (2008): Forests and climate change: forcings, feedbacks, and the climate benefits of forests. Science 320: 1444-1449.

Bormann, F.H. \& Likens, G.E. (1979): Pattern and Process of a Forested System. Springer-Verlag, New York. 253 pp.

Botkin, D.B., Janak, J.F. \& Wallis, J.R. (1972): Some ecological consequences of a computer model of forest growth. Journal of Ecology 60: 849-872.

Boveland, J. (2012): Carbon stocks in Danish forest types. M.Sc. thesis in Environmental Science. Environmental Science in Europe - Master's Programme, Swedish Univ. of Agric. Sciences and Univ. of Copenhagen. 83pp.

Bradshaw, R. \& Holmqvist, B.H. (1999): Danish forest development during the last 3000 years reconstructed from regional pollen data. Ecography 22: 53-62.

Bradshaw, R.H.W. (2004): Past anthropogenic influence on European forests and some possible genetic consequences. Forest Ecology and Management 197: 203-212.

Bradshaw, R.H.W. \& Hannon, G.E. (2004): The Holocene structure of north-west European temperate forest induced from palaeoecological data. pp 11-25 in Honnay, O., Verheyen, K. \& Bossuyt, B. (eds) Forest biodiversity: lessons from history for conservation. CABI Publishing. IUFRO research Series 10.

Bradshaw, R.H.W., Wolf, A. \& Møller, P.F. (2005): Long-term succession in a Danish temperate deciduous forest. Ecography 28: 157-164.

Breuning-Madsen, H. \& Jensen, N.H. (1996): Soil Map of Denmark according to the revised FAO-legend 1990. Geografisk Tidsskrift 96: 51-59.

Bright, R.M., Strømman, A.H. \& Peters, G.P. (2011): Radiative forcing impacts of boreal forest biofuels: a scenario study for Norway in light of albedo. Environmental Science and Technology 45: 7570-7580.

Brumelis, G., Jonsson, B.G., Kouki, J., Kuuluvainen, T. \& Shorohova, E. (2011): Forest naturalness in northern Europe: perspectives on processes, structures and species diversity. Silva Fennica 345: 807-821.

Brumme, R. \& Beese, F. (1992): Effects of liming and nitrogen fertilization on emissions of $\mathrm{CO}_{2}$ and $\mathrm{N}_{2} \mathrm{O}$ from a temperate forest. Journal of Geophysical Research 97: 12851-12858.

Cajander, A.K. (1949): Forest types and their significance. Acta Forestalia Fennica 56(7): 1-71.

Callesen, I., Liski, J., Raulund-Rasmussen, K., Olsson, M.T., Tau-Strand, L., Vesterdal, L. \& Westman, C.J. (2003): Soil carbon stores in Nordic well-drained forest soilsrelationships with climate and texture class. Global Change Biology 9: 358-370.

Canadell, J.G., Le Quere, C., Raupach, M.R., Field, C.B, Buitenhuis, E.T., Ciais, P., Conway, T.J., Gillett, N.P., Houghton, R.A. \& Marland, G. (2007): Contributions to accelerating atmospheric $\mathrm{CO}_{2}$ growth from economic activity, carbon intensity, and efficiency of natural sinks. Proceedings of the National Academy of Sciences of the United States of America 104: 18866-18870. 
Carey, E.V., Sala, A., Keane, R. \& Callaway, R.M. (2001): Are old forests underestimated as global carbon sinks? Global Change Biology 7: 339-344.

Chambers, J.Q., Higuchi, N., Schimel, J.P., Ferreira, L.V. \& Melack, J.M. (2000): Decomposition and carbon cycling of dead trees in tropical forests of the central Amazon. Oecologia 122: 380-388.

Chapin, F.S. III, Woodwell, G.M., Randerson, J.T., Lovett, G.M., Rastetter, E.B., Baldocchi, D.D., Clark, D.A., Harmon, M.E., Schimel, D.S., Valentini, R., Wirth, C., Aber, J.D., Cole, J.J., Goulden, M.L., Harden, J.W., Heimann, M., Howarth, R.W., Matson, P.A., McGuire, A.D., Melillo, J.M., Mooney, H.A., Neff, J.C., Houghton, R.A., Pace, M.L., Ryan, M.G., Running, S.W., Sala, O.E., Schlesinger, W.H. \& Schulze, E.-D. (2005): Reconciling carbon-cycle concepts, terminology, and methods. Ecosystems 9: 1041-1050.

Christensen, M., Hahn, K., Mountford, E.P., Odor, P., Standovar, T., Rozenbergar, D., Diaci, J., Wijdeven, S., Meyer, P., Winter, S., \& Vrska, T. (2005): Dead wood in European beech (Fagus sylvatica) forest reserves. Forest Ecology and Management 210: 267-282.

Covington, W.W. (1981): Changes in forest floor organic matter and nutrient content following clear cutting in northern hardwoods. Ecology 62: 41-48.

Dahlberg, A. \& Stokland, J.N. (2004): Vedlevande arters krav på substrat - sammanställning och analys av 3600 arter. Skogsstyrelsen Rapport 7/2004. 75 pp.

Desai, A.R., Bolstad, P.V., Cook, B.D., Davis, K.J. \& Carey, E.V. (2005): Comparing net ecosystem exchange of carbon dioxide between an old-growth and mature forest in the upper Midwest, USA. Agricultural and Forest Meteorology 128: 33-55.

De Vries, W., Reinds, G.J., Gundersen, P. \& Sterba, H. (2006): The impact of nitrogen deposition on carbon sequestration in European forests and forest soils. Global Change Biology 12: 1151-1173

De Wit, H.A. \& Kvindesland, S. (1999): Carbon stocks in Norwegian forest soils and effects of forest management on carbon storage. Rapport fra skogforskningen, Supplement $14.52 \mathrm{pp}$.

De Wit, H.A., Palosuo, T., Hylen, G. \& Liski, J. (2006): A carbon budget of forest biomass and soils in southeast Norway calculated using a widely applicable method. Forest Ecology and Management 225: 15-26.

DN (2007): Kartlegging av naturtyper - verdisetting av biologisk mangfold. DNhåndbok 13-2007.

Emborg, J., Christensen, M. \& Heilmann-Clausen, J. (2000): The structural dynamics of Suserup Skov, a near-natural temperate deciduous forest in Denmark. Forest Ecology and Management 126: 173-189.

Ericsson, E. (2003): Carbon accumulation and fossil fuel substitution during different rotation scenarios. Scandinavian Journal of Forest Research 18: 269-278.

Esseen, P.-A., Ehnström, B., Ericson, L. \& Sjöberg, K. (1997): Boreal forests. Ecological Bulletins 46: 16-47.

Fang, J., Brown, S., Tang, Y., Nabuurs, G.-J., Wang, X. \& Shen, H. (2006): Overestimated biomass carbon pools of the northern mid- and high latitude forests. Climate Change 74: 355-368.

Framstad, E., Blindheim, T., Erikstad, L., Thingstad, P.G. \& Sloreid, S.-E. (2010): Naturfaglig evaluering av norske verneområder. NINA Rapport 535. 214 pp.

Framstad, E., Økland, B., Bendiksen, E., Bakkestuen, V., Blom, H. \& Brandrud, T.E. (2002): Evaluering av skogvernet i Norge. NINA Fagrapport 54.146 pp.

Framstad, E., Stokland, J.N. \& Hylen, G. (2011): Skogvern som klimatiltak. Verdifulle skogtyper for biologisk mangfold og karbonlagring. NINA Rapport 752. 38 pp.

Freibauer, A. (2009): Old-growth forests in the context of international environmental agreements. pp 451-461 in Wirth, C., Gleixner, G. \& Heimann, M. (eds) OldGrowth Forests - function, fate and value. Heidelberg, Springer-Verlag.

Fremstad, E. (1997): Vegetasjonstyper i Norge. NINA Temahefte 12. 279 pp.

Gärdenfors, U. et al. (2010): Rödlistade arter i Sverige 2010. ArtDatabanken, SLU 
Ge, Z.-M., Kellomäki, S., Peltola, H., Zhou, X., Wang, K.-Y. \& Väisänen, H. (2011): Impacts of changing climate on the productivity of Norway spruce dominant stands with a mixture of Scots pine and birch in relation to water availability in southern and northern Finland. Tree Physiology 31: 323-338.

Georgiadis, P. (2011): Accumulation of carbon and nitrogen in Swedish forest soils over stand age. M.Sc. thesis in Environmental Science. Environmental Science in Europe - Master's Programme. Swedish Univ. of Agric. Sciences. 42 pp.

Giesecke, T. \& Bennett, K.D. (2004): The Holocene spread of Picea abies (L.) Karst. in Fennoscandia and adjacent areas. Journal of Biogeography 31: 1523-1548.

Gjerde, I. \& Baumann, C. (eds) (2002): Miljøregistreringer i skog. Biologisk mangfold. Hovedrapport. Norsk institutt for skogforskning, Ås. 224 pp.

Gjerde, I., Brandrud, T.E., Ohlson, M. \& Ødegaard, F. (2010): Skog. pp: 67-78 in Kålås, J.A., Henriksen, S., Skjelseth, S. \& Viken, Å. (eds) Miljøforhold og påvirkninger for rødlistearter. Artsdatabanken, Trondheim. 136 pp.

Gjerde, I., Sætersdal, M. \& Blom, H.H. (2007): Complementary Hotspot Inventory - a method for identification of important areas for biodiversity at the forest stand level. Biological Conservation 137: 549-557.

Gjerde, I., Sætersdal, M., Rolstad, J., Storaunet, K.O., Blom, H.H., Gundersen, V. \& Heegaard, E. (2005): Productivity-diversity relationships for plants, bryophytes, lichens, and polypore fungi in six northern forest landscapes. Ecography 28: 705-720.

Gleixner, G., Tefs, C., Jordan, A., Hammer, M., Wirth, C., Nueske, A., Telz, A., Schmidt, U.E. \& Glatzel, S. (2009): Soil C accumulation in old-growth forests. pp: 231-266 in Wirth, C., Gleixner, G. \& Heimann, M. (eds) Old-Growth forests - function, fate and value. Heidelberg, Springer-Verlag.

Goodale, C.L., Apps, M.J., Birdsey, R.A. et al. (2002): Forest carbon sinks in the Northern Hemisphere. Ecological Applications 12: 891-899.

Gower, S.T., Mcmurtrie, R.E. \& Murty, D. (1996): Aboveground net primary production decline with stand age: Potential causes. Trends in Ecology \& Evolution 11: 378-382.

Granström, A. (2001): Fire management for biodiversity in the European boreal forest. Scandinavian Journal of Forest Research Supplement 3: 62-69.

Hahn, K., Emborg, J., Vesterdal, L., Christensen, S., Bradshaw, R.H.W., RaulundRasmussen, K. \& Larsen, J.B. (2007): Natural forest stand dynamics in time and space - synthesis of research in Suserup Skov, Denmark and perspectives for forest management. In Hahn, K. \& Emborg, J. (eds) Suserup Skov: structure and processes in a temperate, deciduous forest reserve. Ecological Bulletins 52: 183-194.

Häkkinen, M., Heikkinen, J. \& Mäkipää, R. (2011): Soil carbon stock increases in the organic layer of boreal middle-aged stands. Biogeoscience 8: 1279-1289.

Hanski, I. \& Walsh, M. (2004): How much, how to? Practical tools for forest conservation. BirdLife International. $48 \mathrm{pp}$.

Harmon, M.E. (2009): Woody detritus mass and its contribution to carbon dynamics of old-growth forest: the temporal context. pp: 159-190 in Wirth, C., Gleixner, G. \& Heimann, M. (eds) Old-Growth forests - function, fate and value. Heidelberg, Springer-Verlag.

Harmon, M.E., Ferrell, W.K. \& Franklin, J.F. (1990): Effects on carbon storage of conversion of old-growth forests to young forests. Science 247: 699-701.

Harmon, M.E., Moreno, A. \& Domingo, J.B. (2009): Effects of partial harvest on the carbon stores in Douglas-fir/western hemlock forests: a simulation study. Ecosystems 12: 777-791.

Hart, S.A. \& Chen, H.Y.H. (2006): Understory vegetation dynamics of North American boreal forests. Critical Reviews in Plant Sciences 25: 381-397.

Haugland, H., Økstad. E., Gulbrandsen, M.U., Strømme, I., Fjeldal, P. \& Leffertstra, H. (2011): Skog som biomasseressurs. Klima- og forurensningsdirektoratet TA2762/2011. $100 \mathrm{~s}$. 
Heikkinen, J. \& Mäkipää, R. (2010): Testing hypotheses on shape and distribution of ecological response curves. Ecological Modelling 221: 388-399.

Hellberg, E., Josefsson, T. \& Östlund, L. (2009): The transformation of a Norway spruce dominated landscape since pre-industrial times in northern Sweden: the influence of modern forest management on forest structure. Silva Fennica 43: 783-797.

Helmisaari, H.-S., Hanssen, K.H., Jacobson, S., Kukkola, M., Luiro, J., Saarsalmi, A., Tamminen, P. \& Tveite, B. (2011): Logging residue removal after thinning in Nordic boreal forests: Long-term impact on tree growth. Forest Ecology and Management 261: 1919-1927.

Hobbie, S. (2005): Contrasting effects of substrate and fertilizer nitrogen on the early stages of litter decomposition. Ecosystems 8: 644.

Holtsmark, B. (2012): Harvesting in boreal forests and the biofuel carbon debt. Climate Change 112: 415-428.

Hoover, C.M., Leak, W.B. \& Keel, B.G. (2012): Benchmark carbon stocks from oldgrowth forests in northern New England, USA. Forest Ecology and Management 266: 108-114.

Hörnberg, G., Zackrisson, O., Segerström, U., Svensson, B.W., Ohlson, M. \& Bradshaw, R.H.W. (1998): Boreal swamp forests. BioScience 48: 795-802.

Hotanen, J.-P., Nousiainen, H., Mäkipää, R., Reinikainen, A. \& Tonteri, T. (2008): Metsätyypit - opas kasvupaikkojen luokitteluun. Metsäkustannus. 190 p.

Huston, M.A. \& Marland, G. (2003): Carbon management and biodiversity. Journal of Environmental Management 67: 77-86.

Hynynen, J., Repola, J., \& Mielikäinen, K. (2011): The effect of species mixture on the growth and yield of mid-rotation mixed stands of Scots pine and silver birch. Forest Ecology and Management 262: 1174-1183.

Ilvessalo, Y. \& Ilvessalo, M. (1975): The forest types of Finland in the light of natural development and yield capacity of forest stands. Acta Forestalia Fennica 144.

Isomäki, A., Niemistö, P. \& Varmola, M. (1998): Luonnontilaisten metsien rakenne seurantakoealoilla. Metsäntutkimuslaitoksen Tiedonantoja 705: 75-86.

Jacobson, S., Kukkola, M., Mälkönen, E.\& Tveite, B. (2000): Impact of whole-tree harvesting and compensatory fertilization on growth of coniferous thinning stands. Forest Ecology and Management 129: 41.

Jandl, R., Lindner, M., Vesterdal, L., Bauwens, B., Baritz, R., Hagedorn, F., Johnson, D.W., Minkkinen, K. \& Byrne, K.A. (2007): How strongly can forest management influence soil carbon sequestration? Geoderma 137: 253-268.

Janisch, J.E. \& Harmon, M.E. (2002): Successional changes in live and dead wood carbon stores: implications for net ecosystem productivity. Tree Physiology 22: 77-89.

Janssens, I.A., Kowalski, A.S., Longdoz, B. \& Ceulemans, R. (2000): Assessing forest soil $\mathrm{CO}_{2}$ efflux: an in situ comparison of four techniques. Tree Physiology 20: 23-32.

Johnson, D.W. \& Curtis, P.S. (2001): Effects of forest management on soil C and N storage: meta analysis. Forest Ecology and Management 140: 227-238.

Jones, A., Stolbovoy, V., Tarnocai, C., Broll, G., Spaargaren, O. \& Montanarella, L. (eds.) (2010): Soil Atlas of the Northern Circumpolar Region. European Commission, Office for Official Publications of the European Communities, Luxembourg. 142 pp.

Jongiste, K. (1998): Productivity of mixed stands of Norway spruce and birch affected by population dynamics: a model analysis. Ecological Modelling 106: 77-91.

Jonsson, B.G. \& Siitonen, J. (2012): Natural forest dynamics. pp 275-301 in Stokland, J.N., Siitonen, J. \& Jonsson, B.G. (eds) Biodiversity in dead wood. Cambridge University Press.

Kålås, J.A., Henriksen, S., Skjelseth, S. \& Viken, Å. (ed.) (2010): Miljøforhold og påvirkninger for rødlistearter. Artsdatabanken, Trondheim.

Kira, T. \& Shidei, T. (1967): Primary production and turnover of organic matter in different forest ecosystems of the Western Pacific. Japanese Journal of Ecology 17: 70-87. 
Klemedtsson, L., Klemedtsson, Å.K., Moldan, F. \& Weslien, P. (1997): Nitrous oxide emission from Swedish forest soils in relation to liming and simulated increased $\mathrm{N}$ deposition. Biology and Fertility of Soils 25: 290-295.

Knohl, A., Schulze, E.-D. \& Wirth, C. (2009): Biosphere-atmosphere exchange of oldgrowth forests: process and pattern. Pp: 141-158 in Wirth, C., Gleixner, G. \& Heimann, M. (eds) Old-Growth forests - function, fate and value. Heidelberg, Springer-Verlag.

Knorr, M., Frey, S.D. \& Curtis, P.S. (2005): Nitrogen additions and litter decomposition: A meta-analysis. Ecology 86: 3252-3257.

Kolari, P., Pumpanen, J., Rannik, Ü., Ilvesniemi, H., Hari, P. \& Berninger, F. (2004): Carbon balance of different aged Scots pine forests in Southern Finland. Global Change Biology 10: 1106-1119.

Kouki, J., Löfman, S., Martikainen, P., Rouvinen, S. \& Uotila, A. (2001): Forest fragmentation in Fennoscandia: linking habitat requirements of wood-associated threatened species to landscape and habitat changes. Scandinavian Journal of Forest Research Supplement 3: 27-37.

Krogh, L., Nørgaard, A., Hermansen, M., Greve, M.H., Balstrøm, T. \& Breuning-Madsen, H. (2003): Preliminary estimates of contemporary soil organic carbon stocks in Denmark using multiple datasets and four scaling-up methods. Agric. Ecosystems Environ. 96: 19-28.

Kulmala, L. (2011): Photosynthesis of ground vegetation in boreal Scots pine forests. Dissertationes Forestales 132.

Kutsch, W.L., Kolle, O., Rebmann, C., Knohl, A., Ziegler, W. \& Schulze, E.D. (2008): Advection and resulting $\mathrm{CO}_{2}$ exchange uncertainty in a tall forest in central Germany. Ecological Applications 18: 1391-1405.

Kutsch, W.L., Wirth, C., Kattge, J., Nöllert, S., Herbst, M. \& Kappen, L. (2009): Ecophysiological characteristics of mature trees and stands - consequences for old-growth productivity. Pp: 57-79 in Wirth, C., Gleixner, G. \& Heimann, M. (eds) Old-Growth forests - function, fate and value. Heidelberg, Springer-Verlag.

Kuuluvainen, T. (2009): Forest management and biodiversity conservation based on natural ecosystem dynamics in Northern Europe: the complexity challenge. Ambio 38: 309-315.

Kuuluvainen, T. \& Aakala, T. (2011): Natural forest dynamics in boreal Fennoscandia: a review and classification. Silva Fennica 45: 823-841.

Larjavaara, M \& Muller-Landau, H.C. (2012): Temperature explains global variation in biomass among humid old-growth forests. Global Ecology and Biogeography 21: 998-1006.

Larsson, J.Y. \& Hylen, G. (2007): Skogen i Norge. Statistikk over skogforhold og skogressurser i Norge registrert i perioden 2000-2004. Viten fra Skog og landskap 1/07. $91 \mathrm{pp}$.

Larsson, J.Y. \& Søgnen, S.M. (2003): Vegetasjon i norsk skog - vekstvilkår og skogforvaltning. Landbruksforlaget, Oslo. $256 \mathrm{pp}$.

Lasch, P., Badeck, F.-W., Suckow, F., Lindner, M. \& Mohr, P. (2005): Model-based analysis of management alternatives at stand and regional level in Brandenburg (Germany). Forest Ecology and Management 207: 59-74.

Law, B.E., Sun, O.J., Campbell, J., Van Tuyl, S. \& Thornton, P.E. (2003): Changes in carbon storage and fluxes in a chronosequence of ponderosa pine. Global Change Biology 9: 510-524.

Law, B.E., Thornton, P.E., Irvine, J., Anthoni, P.M. \& Van Tuyl, S. (2001): Carbon storage and fluxes in ponderosa pine forests at different developmental stages. Global Change Biology 7: 755-777.

Lee, X., Goulden, M.L., Hollinger, D.Y., et al. (2011): Observed increase in local cooling effect of deforestation at higher latitudes. Nature 479: 384-387. 
Lehtonen, A., Mäkipää, R., Heikkinen, J., Sievänen, R. \& Liski, J. (2004): Biomass expansion factors (BEFs) for Scots pine, Norway spruce and birch according to stand age for boreal forests. Forest Ecology and Management 188: 211-224.

Lie, M.H., Josefsson, T., Storaunet, K.O. \& Ohlson, M. (2011): A refined view on the "Green lie": forest structure and composition succeeding early twentieth century selective logging in SE Norway. Scandinavian Journal of Forest Research 27: 270-284.

Linder, P. \& Östlund, L. (1998): Structural changes in three mid-boreal Swedish forest landscapes, 1885-1996. Biological Conservation 85: 9-19.

Liski, J., Lehtonen, A., Palosuo, T., Peltoniemi, M., Eggers, T., Muukkonen, P. \& Mäkipää, R. (2006): Carbon accumulation in Finland's forests 1922-2004 - an estimate obtained by combination of forest inventory data with modelling of biomass, litter and soil. Annals of Forest Science 63: 687-697.

Liski, J., Palosuo, T., Peltoniemi, M. \& Sievanen, R. (2005): Carbon and decomposition model Yasso for forest soils. Ecological Modelling 189: 168-182.

Liski, J., Pussinen, A., Pingoud, K., Mäkipää, R. \& Karajalainen, T. (2001): Which rotation length is favourable to mitigation of climate change? Canadian Journal of Forest Research 31: 2004-2013.

Lund, C.P., Riley, W.J., Pierce, L.L. \& Field, C.B. (1999): The effects of chamber pressurization on soil-surface $\mathrm{CO}_{2}$ flux and the implications for NEE measurements under elevated $\mathrm{CO}_{2}$. Global Change Biology 5: 269-281.

Lunden, K. (2002): Norges landbrukshistorie II. Det norske samlaget. 455 pp.

Luyssaert, S., Ciais, P., Piao, S.L., Schulze, E.-D., Jung, M., Zaehle, S., Schelhaas, M.J., Reichstein, M., Churkina, G., Papale, D., Abril, G., Beer, C., Grace, J., Loustau, D., Matteucci, G., Magnani, F., Nabuurs, G.J., Verbeeck, H., Sulkava, M., Van der Werf, G.R., \& CARBOEUROPE-IP Synthesis Team (2009): The European Carbon Balance: part 3: Forests. Global Change Biology 16: 1429-1450.

Luyssaert, S., Inglima, I., Jung, M. et al. (2007): $\mathrm{CO}_{2}$ balance of boreal, temperate, and tropical forests derived from a global database. Global Change Biology 13: 2509-2537.

Luyssaert, S., Schulze, E.-D., Borner, A., Knohl, A., Hessenmöller, D., Law, B.E., Ciais, P. \& Grace, J. (2008): Old-growth forests as global carbon sinks. Nature 455: 213-215.

Mäkipää, R., Karjalainen, T., Pussinen, A. \& Kellomäki, S. (1999): Effects of climate change and nitrogen deposition on the carbon sequestration of a forest ecosystem in the boreal zone. Canadian Journal of Forest Research 29: 1490-1501.

Mäkipää, R., Karjalainen, T., Pussinen, A., Kukkola, M., Kellomäki, S. \& Mälkönen, E. (1998): Applicability of a simulation model for estimating effects of nitrogen deposition on a forest ecosystem: test of the validity of a gap-type model. Forest Ecology and Management 108: 239-250.

Mäkipää, R., Linkosalo, T., Niinimäki, S., Komarov, A., Bykhovets, S., Tahvonen, O. \& Mäkelä, A. (2011): How forest management and climate change affect the carbon sequestration of a Norway spruce stand. Journal of Forest Planning 16: 107-120.

Marklund, L.G. (1988): Biomassafunktioner för tall, gran och björk i Sverige. Biomass functions for pine, spruce and birch in Sweden. Sveriges Lantbruksuniversitet, Institutionen för skogstaxering.

Marland, G. \& Marland, S. (1992): Should we store carbon in trees? Water, Air, and Soil Pollution 64: 181-195.

Messier, C., Posada, J., Aubin, I. \& Beaudet, M. (2009): Functional relationships between old-growth forest canopies, understorey light and vegetation dynamics. Pp: 115-139 in Wirth, C., Gleixner, G. \& Heimann, M. (eds) Old-Growth forests - function, fate and value. Heidelberg, Springer-Verlag.

Metla (2011): Finnish statistical yearbook of forestry 2011. Finnish Forest Research Institute. $470 \mathrm{pp}$.

Metzger, M.J., Bunce, R.G.H., Jongman, R.H.G., Mücher, C.A. \& Watkins, J.W. (2005): A climatic stratification of the environment of Europe. Global Ecology and Biogeography $14:$ 549-563. 
Mielikäinen, K. (1980): Manty-koivusekametsikoiden rakenne ja kehitys (In Finnish with English summary: Structure and development of mixed pine and birch stands). Commun. Inst. For. Fennica 99: 1-82.

Mielikäinen, K. (1985): Koivusekoituksen vaikutus kuusikon rakenteeseen ja kehitykseen (In Finnish with English summary: Effect of an admixture of birch on the structure and development of Norway spruce stands). Commun. Inst. For. Fennica 133: 1-79.

Moen, A. (1998): Nasjonalatlas for Norge: Vegetasjon. Statens kartverk, Hønefoss. $199 \mathrm{pp}$

Moren, A.S. \& Lindroth, A. (2000): $\mathrm{CO}_{2}$ exchange at the floor of a boreal forest. Agricultural and Forest Meteorology 101: 1-14.

Müller, J. \& Bütler, R. (2010): A review of habitat thresholds for dead wood: a baseline for management recommendations in European forests. European Journal of Forest Research 129: 981-992.

Muukkonen, P. \& Mäkipää, R. (2006): Empirical biomass models of understorey vegetation in boreal forests according to stand and site attributes. Boreal Environment Research 11: 355-369.

Myhre, B. \& Øye, I. (2002): Norges landbrukshistorie I. Det norske samlaget.495 pp.

Nave, L.E., Vance, E.D., Swanston, C.W. \& Curtis P.S. (2010): Harvest impacts on soil carbon storage in temperate forests. Forest Ecology and Management 259: 857-866.

Nilsen, P., Hobbelstad, K. \& Clarke, N. (2008): Opptak og utslipp av $\mathrm{CO}_{2}$ i skog. Vurdering av omløpstid, hogstmetode og hogstfredning for $\mathrm{CO}_{2}$-binding i jord og trær. Oppdragsrapport fra Skog og landskap 06/2008. $24 \mathrm{~s}$

Nilsson, M.C. \& Wardle, D.A. (2005): Understory vegetation as a forest ecosystem driver: evidence from the northern Swedish boreal forest. Frontiers in Ecology and the Environment 3: 421-428.

Nord-Larsen, T., Johannsen, V.K., Bastrup-Birk, A. \& Jørgensen, B.B. (eds.) (2008): Skove og plantager 2006. Skov og Landskab and Skov- og Naturstyrelsen, Hørsholm. $185 \mathrm{p}$

Nord-Larsen, T., Johannsen, V.K., Riis-Nielsen, T. \& Jørgensen, B.B. (2012): Skove og plantager 2010. Skov \& Landskab, Hørsholm, 46 pp.

Nord-Larsen, T., Johannsen, V.K., Vesterdal, L., Jørgensen, B.B. \& Bastrup-Birk, A. (2009): Skove og plantager 2008. Skov \& Landskab, Hørsholm, 21 pp.

Noss, R.F. (1990): Indicators for monitoring biodiversity: a hierarchical approach. Conservation Biology 4: 355-364.

Öberg, L. \& Kullman, L. (2011): Ancient subalpine clonal spruces (Picea abies): sources of postglacial vegetation history in the Swedish Scandes. Arctic 64: 183-196.

Odum, E.P. (1969): Strategy of ecosystem development. Science 164: 262-270.

Ohlson, M., Brown, K.J., Birks, H.J.B., Grytnes, J.-A., Hörnberg, G., Niklasson, M., Seppä, H. \& Bradshaw, R.H.W. (2011): Invasion of Norway spruce diversifies the fire regime in boreal European forests. Journal of Ecology 99: 395-403.

Ohlson, M., Dahlberg, B., Økland, T., Brown, K.J. \& Halvorsen, R. (2009): The charcoal carbon pool in boreal forest soils. Nature geoscience 2: 692-695.

Olsson, B.A., Staaf, H., Lundkvist, H., Bengtsson, J. \& Rosen, K. (1996): Carbon and nitrogen in coniferous forest soils after clear-felling and harvest of different intensity. Forest Ecology and Management 82: 19-32.

Ortiz, C., Karltun, E., Gärdenäs, A., Stendahl, J. \& Ågren, G. (2011): Modelling soil carbon development in Swedish coniferous forest soils-An uncertainty analysis of parameters and model estimates using the GLUE method. Ecological Modelling 222:3020-3032.

Östlund, L. (2004): Fire, death and disorder in the forest: 150 years of change in critical ecological structures and processes in boreal Scandinavia. pp 55-65 in Honnay, O., Verheyen, K. \& Bossuyt, B. (eds) Forest biodiversity: lessons from history for conservation. CABI Publishing. IUFRO research Series 10. 
Östlund, L., Zackrisson, O. \& Axelsson, A.-L. (1997): The history and transformation of a Scandinavian boreal forest landscape since the 19th century. Canadian Journal of Forest Research 27: 1198-1206.

Palosuo, T., Peltoniemi, M., Mikhailov, A., Komarov, A., Faubert, P., Thürig, E. \& Lindner, M. (2008): Projecting effects of intensified biomass extraction with alternative modelling approaches. Forest Ecology and Management 255: 1423-1433.

Parducci, L., Jørgensen, T., Tollefsrud, M.M., Elverland, E. et al. (2012): Glacial survival of boreal trees in northern Scandinavia. Science 335: 1083-1086.

Peltoniemi, M., Mäkipää, R., Liski, J. \& Tamminen, P. (2004): Changes in soil carbon with stand age - an evaluation of a modeling method with empirical data. Global Change Biology 10: 2078-2091.

Peltoniemi, M., Thürig, E., Ogle, S., Palosuo, T., Shrumpf, M., Wützler, T., ButterbachBahl, K., Chertov, O., Komarov, A., Mikhailov, A., Gärdenäs, A., Perry, C., Liski, J., Smith, P. \& Mäkipää, R. (2007): Models in country scale carbon accounting of forest soils. Silva Fennica 41: 575-602.

Pennanen, J. 2002. Forest age distribution under mixed-severity fire regimes - a simulation-based analysis for middle boreal Fennoscandia. Silva Fennica 36: 213-231.

Penttilä, R., Lindgren, M., Miettinen, O., Rita, H. \& Hanski, I. (2006): Consequences of forest fragmentation for polyporous fungi at two spatial scales. Oikos 114: 225-240.

Peterken, G.F. (1996): Natural woodland. Ecology and conservation in northern temperate regions. Cambridge University Press.

Pohjola, J., Kerkelä, L. \& Mäkipää, R. (2003): Credited forest carbon sinks: how the cost reduction is allocated among countries and sectors. Climate Policy 3: 445-461.

Post, W.M., Izaurralde, R.C., Mann, L.K., \& Bliss, N. (2001): Monitoring and verifying changes of organic carbon in soil. Climatic Change 51: 73-99.

Poudel, B.C., Sathre, R., Bergh, J., Gustavsson, L., Lundström, A. \& Hyvönen, R. (2012): Potential effects of intensive forestry on biomass production and total carbon balance in north-central Sweden. Environmental Science and Policy 15: 106-124.

Pregitzer, K.S. \& Euskirchen, E.S. (2004): Carbon cycling and storage in world forests: biome patterns related to forest age. Global Change Biology 10: 2052-2077.

Prentice, I.C., Farquhar, G.D., Fasham, M.J.R., Goulden, M.L., Heimann, M., Jaramillo, V.J., Kheshgi, H.S., Le Quéré, C., Scholes, R.J. \& Wallace, D.W.R. (2001): The carbon cycle and atmospheric carbon dioxide. pp 183-237 in Houghton, J.T., Ding, Y., Griggs, D.J., Noguer, M., van der Linden, P.J., Dai, X., Maskell, K. \& Johnson, C.A. (eds) Climate change 2001: The scientific basis. Contribution of Working Group I to the Third Assessment Report of the Intergovernmental Panel on Climate Change. Cambridge University Press.

Prescott, C.E. (1995): Does nitrogen availability control rates of litter decomposition in forests? Plant and Soil 168-169: 83-88.

Prescott, C.E., Blevins, L.L. \& Staley, C.L. (2000): Effects of clear-cutting on decomposition rates of litter and forest floor in forests of British Columbia. Canadian Journal of Forest Research 30: 1751-1757.

Pumpanen, J., Kolari, P., Ilvesniemi, H. et al. (2004a): Comparison of different chamber techniques for measuring soil $\mathrm{CO}_{2}$ efflux. Agricultural and Forest Meteorology 123: 159-176.

Pumpanen, J., Westman, C.J. \& Ilvesniemi, H. (2004b): Soil $\mathrm{CO}_{2}$ efflux from a podzolic forest soil before and after forest clear-cutting and site preparation. Boreal Environment Research 9: 199-212.

Pussinen, A., Karjalainen, T., Mäkipää, R., Valsta, L. \& Kellomäki, S. (2002): Forest carbon sequestration and harvests in Scots pine stand under different climate and nitrogen scenarios. Forest Ecology and Management 158: 103-115.

Påhlsson, L. (ed.) (1994): Vegetationstyper i Norden. TemaNord 1994:665. 627 pp.

Randerson, J.T., Chapin, F.S., Harden, J.W., Neff, J.C. \& Harmon, M.E. (2002): Net ecosystem production: A comprehensive measure of net carbon accumulation by ecosystems. Ecological Applications 12: 937-947. 
Rantakari, M., Lehtonen, A., Linkosalo, T., Tuomi, M., Tamminen, P., Heikkinen, J., Liski, J., Mäkipää, R., Ilvesniemi, H. \& Sievänen, R. (2012): Yasso07 soil carbon model - testing against repeated soil carbon inventory. Forest Ecology and Management 286: 137-147.

Rassi, P., Hyvärinen, E., Juslén, A. \& Mannerkoski, I. (eds.) (2010): The 2010 Red List of Finnish Species. Ympäristöministeriö \& Suomen ympäristökeskus, Helsinki. 685 pp.

Reichstein, M., Ågren, G.I. \& Fontain, S. (2009): Is there a theoretical limit to soil carbon storage in old-growth forests? A model analysis with contrasting approaches. Pp 267-281 in Wirth, C., Gleixner, G. \& Heimann, M. (eds) Old-Growth forests function, fate and value. Heidelberg, Springer-Verlag.

Rolstad, J., Framstad, E., Gundersen, V. \& Storaunet, K.O. (2002): Naturskog i Norge. Definisjoner, økologi og bruk i norsk skog- og miljøforvaltning. Aktuelt fra skogforskningen 1/02. 53 pp.

Röser, C., Montagnani, L., Schulze, E.-D., Mollicone, D., Kolle, O., Meroni, M., Papale, D., Marchesini, L.B., Federici, S. \& Valentini, R. 2002. Net $\mathrm{CO}_{2}$ exchange rates in three different successional stages of the "Dark Taiga" of central Siberia. Tellus 54B: 642-654.

Ruuhijärvi, R., Kuusinen, M., Raunio, A. \& Esko, K. (2000): Forest protection in southern Finland and Ostrobothnia. Finnish Environment 437. 284 pp.

Sabine, C.L., Heimann, M., Artaxo, P., Bakker, D.C.E., Chen, C.-T.A., Field, C.B., Gruber, N., Le Quéré, C., Prinn, R.G., Richley, J.E., Lankao, P.R., Sathaye, J.A. \& Valentini, R. (2004): Current status and past trends of the global carbon cycle. pp: 17-44 in Field, C.B. \& Raupach, M.R. (eds) The global carbon cycle: integrating humans, climate, and the natural world. Island Press.

Schimel, D. (2007): Carbon cycle conundrums. Proceedings of the National Academy of Sciences of the United States of America 104: 18353-18354.

Schlamadinger, B. \& Marland, G. (1996): The role of forest and bioenergy strategies in the global carbon cycle. Biomass and Bioenergy 10: 275-300.

Schulze, E.-D., Körner, C., Law, B.E., Habrl, H. \& Luyssaert, S. (2012): Large-scale bioenergy from additional harvest of forest biomass is neither sustainable nor greenhouse gas neutral. Global Change Biology Bionergy 4: 611-616.

Schulze, E.-D., Lloyd, J., Kelliher, F.M., Wirth, C., Rebmann, C., Lühker, B., Mund, M., Knohl, A., Milyukova, I.M., Schulze, W., Ziegler, W., Varlagin, A.B., Sogachev. A.F., Valentini, R., Dore, S., Grigoriev, S., Kolle, O., Panfyorov, M.I., Tchebakova, N. \& Vygodskaya, N.N. (1999): Productivity of forests in the Eurosiberian boreal region and their potential to act as a carbon sink - a synthesis. Global Change Biology 5: 703-722.

Schulze, E.-D., Valentini, R. \& Sanz, M.J. (2002): The long way from Kyoto to Marrakesh: Implications of the Kyoto Protocol negotiations for global ecology. Global Change Biology 8: 505-518.

Seely, B., Welham, C. \& Kimmins, H. (2002): Carbon sequestration in a boreal forest ecosystem: results from the ecosystem simulation model, FORECAST. Forest Ecology and Management 169: 123-135.

SEPA (2011): National Inventory Report 2011. Submitted under the United Nations Framework Convention on Climate Change and the Kyoto Protocol. Swedish Environmental Protection Agency. 367 pp.

Seppä, H., Alenius, T., Bradshaw, R.H.W., Giesecke, T., Heikkilä, M. \& Muukkonen, P. (2009): Invasion of Norway spruce (Picea abies) and the rise of the boreal ecosystem in Fennoscandia. Journal of Ecology 97: 629-640.

Shanin, V.N., Komarov, A., Mikhailov, A.V. \& Bykhovets, S. (2011): Modelling carbon and nitrogen dynamics in forest ecosystems in Central Russia under different climate change scenarios and forest management regimes. Ecological Modelling 222: 2262-2275.

Shorohova, E., Kneeshaw, D., Kuuluvainen, T. \& Gauthier, S. (2011): Variability and dynamics of old-growth forests in the circumboreal zone: implicaitons for conservation, restoration and management. Silva Fennica 45: 785-806. 
Siitonen, J. (2001): Forest management, coarse woody debris and saproxylic organisms: Fennoscandian boreal forests as an example. Ecological Bulletins 49: 11-41.

Siitonen, J., Martikainen, P., Punttila, P. \& Rauh, J. (2000): Coarse woody debris and stand characteristics in mature managed and old-growth boreal mesic forests in southern Finland. Forest Ecology and Management 128: 211-225.

Simard, M., Lecomte, N., Bergeron, Y., Bernier, P.Y. \& Paré, D. (2007): Forest productivity decline caused by successional paludification of boreal soils. Ecological Applications 17: 1619-1637.

Sjöberg, G., Bergkvist, B., Berggren, D. \& Nilsson, S.I. (2003): Long-term N addition effects on the $\mathrm{C}$ mineralization and DOC production in mor humus under spruce. Soil Biology and Biochemistry 35: 1305-1315

Sjöberg, K. \& Ericson, L. (1997): Mosaic boreal landscapes with open and forested wetlands. Ecological Bulletins 46: 48-60.

Skogsstyrelsen (2011): Swedish Statistical Yearbook of Forestry 2011. Official Statistics of Sweden. 384 pp.

Skovsgaard, J.P. \& Nord-Larsen, T. (2012): Biomass, basic density and biomass expansion factor functions for European beech (Fagus sylvatica L.) in Denmark. European Journal of Forest Research 131: 1035-1053.

Skovsgaard, J.P., Bald, C. \& Nord-Larsen, T. (2011): Functions for biomass and basic density of stem, crown and root system of Norway spruce (Picea abies (L.) Karst.) in Denmark. Scandinavian Journal of Forest Rsearch 26, S11: 3-20.

SLU (2011): Skogsdata 2011. Aktuella uppgifter om de svenska skogarna från Riksskogstaxeringen. SLU, Institutionen för skoglig resurshushållning. $122 \mathrm{pp}$.

Sogn, T.A., Stuanes, A. \& Abrahamsen, G. (1999): The capacity of forest soils to adsorb anthropogenic N. Ambio 28: 346-349.

Stendahl, J., Johansson, M.-B., Eriksson, E., Nilsson, Å. \& Langvall, O. (2010): Soil organic carbon in Swedish spruce and pine forests - differences in stock levels and regional patterns. Silva Fennica 44: 5-21.

Stinson, G., Kurz, W.A., Smyth, C.E., Neilson, E.T., Dymond, C.C., Metsaranta, J.M., Boisvenue, C., Rampley, G.J., Li, Q., White, T.M. \& Blains, D. (2011): An inventory-based analysis of Canada's managed forest carbon dynamics, 1990 to 2008. Global Change Biology 17: 2227-2244.

Stokland, J.N., Eriksen, R., Tomter, S.M., Korhonen, K., Tomppo, E., Rajaniemi, S., Söderberg, U., Toet, H. \& Riis-Nielsen, T. (2003): Forest biodiversity indicators on the Nordic countries. Status based on national forest inventories. TemaNord 2003:514, 108 pp.

Stokland, J.N., Siitonen, J. \& Jonsson, B.G. (2012): Biodiversity in dead wood. Cambridge University Press. 524 pp.

Storaunet, K.O., Eriksen, R. \& Rolstad, J. (2011): Mengde og utvikling av død ved i produktiv skog i Norge. Oppdragsrapport fra Skog og landskap 15/2011. 44 pp.

Storaunet, K.O. \& Rolstad, J. (2002): Time since death and fall of Norway spruce logs in old-growth and selectively cut boreal forest. Candian Journal of Forest Research 32: 1801-1812.

Storaunet, K.O., Rolstad, J., Gjerde, I. \& Gundersen, V. (2005): Historical logging, productivity, and structural characteristics of boreal coniferous forests in Norway. Silva Fennica 39: 429-442.

Strömgren, M., Mjöfors, K., Holmström, B. \& Grelle, A. (2012): Soil $\mathrm{CO}_{2}$ flux during the first years after stump harvesting in two Swedish forests. Silva Fennica 46: 67-79.

Sun, O.J., Campbell, J., Law, B.E. \& Wolf, V. (2004): Dynamics of carbon stocks in soils and detritus across chronosequences of different forest types in the Pacific Northwest, USA. Global Change Biology 10: 1470-1481.

Svensson, M., Jansson, P.-E. \& Kleja, D.B. (2008): Modelling soil C sequestration in spruce forest ecosystems along a Swedish transect based on current conditions. Biogeochemistry 89: 95-119. 
Swann, A., Fung, I.Y., Levis, S., Bonan, G.B. \& Doney, S.C. (2010): Changes in Arctic vegetation amplify high-latitude warming through the greenhouse effect. Proceedings of the National Academy of Sciences 107: 1295-1300.

Tamm, C.O. (1991): Nitrogen in terrestrial ecosystems: questions of productivity, vegetational changes, and ecosystem stability. Ecological Studies 81. SpringerVerlag. 128 pp.

Tamminen, P., Saarsalmi, A., Smolander, A., Kukkola, M. \& Helmisaari, H.-S. (2012): Effects of logging residue harvest in thinnings on amounts of soil carbon and nutrients in Scots pine and Norway spruce stands. Forest Ecology and Management 263: 31-38.

Tanninen, T., Storrank, B., Haugen, I., Friis Møller, P., Löfgren, R., Thorsteinsson, I. \& Ragnarsson, H. (1994): Naturskogar i Norden. Nord 1994:7. 109 pp.

Taylor, A.R., Wang, J.R. \& Kurz, W.A. (2008): Effects of harvesting intensity on carbon stocks in eastern Canadian red spruce (Picea rubens) forests: An exploratory analysis using the CBM-CFS3 simulation model. Forest Ecology and Management 255: 3632-3641.

Tefs, C. \& Gleixner, G. (2012): Importance of root derived carbon for soil organic matter storage in a temperate old-growth beech forest - Evidence from $\mathrm{C}, \mathrm{N}$ and (14)C content. Forest Ecology and Management 263: 131-137.

Thomas, S.C. \& Martin, A.R. (2012): Carbon content of tree tissues: a synthesis. Forests 3: 332-352.

Thornley, J.H.M. \& Cannell, M.G.R. (2000): Managing forests for wood yield and carbon storage: a theoretical study. Tree Physiology 20: 477-484.

Turetsky, M.R. (2003): The role of bryophytes in carbon and nitrogen cycling. Bryologist 106: 395-409.

Turner, D.P., Ritts, W.D., Yang, Z.Q., Kennedy, R.E., Cohen, W.B., Duane, M.V., Thornton, P.E. \& Law, B.E. (2011): Decadal trends in net ecosystem production and net ecosystem carbon balance for a regional socioecological system. Forest Ecology and Management 262: 1318-1325.

U, K.T.P., Falk, M., Suchanek, T.H., Ustin, S.L., Chen, J., Park, Y.-S., Winner, W.E., Thomas, S.C., Hsiao, T.C., Shaw, R.H., King, T.S., Pyles, R.D., Schroeder, M. \& Matista, A.A. (2004): Carbon dioxide exchange between an old-growth forest and the atmosphere. Ecosystems 7: 513-524.

UNFCCC (2001): Matters relating to land use, land-use change and forestry. FCCC/CP/2001/L.11/Rev.1.

http://unfccc.int/resource/docs/cop6secpart/111r01.pdf.

UNFCCC (2006): Report of the Conference of the Parties serving as the meeting of the Parties to the Kyoto Protocol on its first session, held at Montreal from 28 November to 10 December 2005. Addendum. Part Two: Action taken by the Conference of the Parties serving as the meeting of the Parties to the Kyoto Protocol at its first session. Annex. Definitions, modalities, rules and guidelines relating to land use, land-use change and forestry activities under the Kyoto Protocol. FCCC/KP/CMP/2005/8/Add.3. 103 pp.

Vesterdal, L. \& Christensen, M. (2007): The carbon pools in a Danish semi-natural forest. In Hahn, K. \& Emborg, J. (eds) Suserup Skov: structure and processes in a temperate, deciduous forest reserve. Ecological Bulletins 52: 113-121.

Vesterdal, L., Dalsgaard, M., Felby, C., Raulund-Rasmussen, K. \& Jørgensen, B.B. (1995): Effects of thinning and soil properties on accumulation of carbon, nitrogen and phosphorus in the forest floor of Norway spruce stands. Forest Ecology and Management 77: 1-10.

Vesterdal, L. \& Raulund-Rasmussen, K. (1998): Forest floor chemistry under seven tree species along a soil fertility gradient. Canadian Journal of Forest Research 28 : 1636-1647. 
Vesterdal, L., Schmidt, I.K., Callesen, I., Nilsson, L.O. \& Gundersen, P. (2008): Carbon and nitrogen in forest floor and mineral soil under six common European tree species. Forest Ecology and Management 255: 35-48.

Vucetich, J.A., Reed, D.D., Breymeyer, A., Degórski, M., Mroz, G.D., Solon, J., RooZielinska, E. \& Noble, R. (2000): Carbon pools and ecosystem properties along a latitudinal gradient in northern Scots pine (Pinus sylvestris) forests. Forest Ecology and Management 136: 135-145.

Walker, L.R., Wardle, D.A., Bardgett, R.D. \& Clarkson, B.D. (2010): The use of chronosequences in studies of ecological succession and soil development. Journal of Ecology 98: 725-736.

Wallenius, T. (2011): Major decline in fires in coniferous forests - reconstructing the phenomenon and seeking for the cause. Silva Fennica 45: 139-155.

Wardle, D.A. (2009): Aboveground and belowground consequences of long-term forest retrogression in the timeframe of millennia and beyond. Pp 193-209 in Wirth, C., Gleixner, G. \& Heimann, M. (eds) Old-Growth Forests - function, fate and value. Heidelberg, Springer-Verlag.

Wardle, D.A., Jonsson, M., Bansal, S., Bardgett, R.D., Gundale, M.J. \& Metcalfe, D.B. (2012): Linking vegetation change, carbon sequestration and biodiversity: insights from island ecosystems in a long-term natural experiment. Journal of Ecology 100: 16-30.

Wardle, D.A., Hörnberg, G., Zackrisson, O., Kalela-Brundin, M. \& Coomes, D.A. (2003): Long-term effects of wildfire on ecosystem properties across an island area gradient. Science 300: 972-975.

Wirth, C. \& Lichstein, J.W. (2009): The imprint of species turnover on old-growth forest carbon balances - insights from a trait-based model of forest dynamics. pp 81-113 in Wirth, C., Gleixner, G. \& Heimann, M. (eds) Old-Growth Forests - function, fate and value. Heidelberg, Springer-Verlag.

Wirth, C., Messier, C., Bergeron, Y., Frank, D. \& Fankhanel, A. (2009): Old-growth forest definitions: a pragmatic view. Pp: 11-33 in Wirth, C., Gleixner, G. \& Heimann, M. (eds) Old-Growth forests - function, fate and value. Heidelberg, Springer-Verlag.

Wirth, C., Schulze, E.-D., Lühker, B., Grigoriev, S., Siry, M., Hardes, G., Ziegler, W., Backor, M., Bauer, G. \& Vygodskaya, N.N. (2002): Fire and site type effects on the long-term carbon and nitrogen balance in pristine Siberian Scots pine forests. Plant and Soil 242: 41-63.

Xu, C.Y., Turnbull, M.H., Tissue, D.T., Lewis, J.D., Carson, R., Schuster, W.S.F., Whitehead, D., Walcroft, A.S., Li, J. \& Griffin, K.L. (2012): Age-related decline of stand biomass accumulation is primarily due to mortality and not to reduction in NPP associated with individual tree physiology, tree growth or stand structure in a Quercusdominated forest. Journal of Ecology 100: 428-440.

Yanai, R.D., Arthur, M.A., Siccama, T.G. \& Federer, C.A. (2000): Challenges of measuring forest floor organic matter dynamics: Repeated measures from a chronosequence. Forest Ecology and Management 138: 273-283.

Yanai, R.D., Currie, W.S. \& Goodale, C.L. (2003): Soil carbon dynamics after forest harvest: an ecosystem paradigm reconsidered. Ecosystems 6: 197-212.

Yatskov, M., Harmon, M.E. \& Krankina, O.N. (2003): A chronosequence of wood decomposition in the boreal forests of Russia. Canadian Journal of Forest Research 33: 1211-1226.

Zackrisson, O. (1977): Influence of forest fires on the North Swedish boreal forest. Oikos 29: 22-32.

Zhou, G.Y., Liu, S.G., Li, Z. et al. (2006): Old-growth forests can accumulate carbon in soils. Science 314: 1417-1417. 


\section{Sammendrag}

Skogene er viktige terrestriske økosystemer i det globale klimasystemet og representerer store deler av karbonkretsløpet. De nordiske landene har store skogarealer med stort og økende volum av trær som fanger betydelige mengder av klimagassen karbondioksid $\left(\mathrm{CO}_{2}\right)$. Nordiske skoger er også viktige for det biologiske mangfoldet. De inneholder et bredt spekter av komplekse økosystemer og leveområder for over halvparten av alle kjente stedegne arter og nesten halvparten av alle truete arter i Finland, Norge og Sverige. Skogarealene byr også på viktige rekreasjonsmuligheter for folk i Norden og leverer ressurser til den økonomisk viktige skognæringen.

\section{Målet med rapporten}

I denne rapporten gir vi en vitenskapelig basert oversikt over rollen til gammel skog i karbonkretsløpet og hvordan karbonopptaket i gammel skog kan sammenfalle med den veldokumenterte verdien av gammel skog for biologisk mangfold. Rollen til gammel skog som del av karbonkretsløpet er mye mindre studert enn dens rolle for biologisk mangfold. Her sammenfatter vi dagens kunnskap om karbonbalansen i gammel skog i Norden. Med «gammel skog» forstår vi her skog som er betydelig eldre enn hogstmoden alder og som inneholder mange trær nær sin naturlige levealder.

\section{Skogens utvikling og menneskelig påvirkning}

Nordiske skoger har utviklet seg etter siste istid, etter hvert som klimaet ble varmere og nye arter innvandret. Menneskene har utnyttet et bredt spekter av skogenes ressurser opp gjennom tidene og har dermed påvirket skogenes struktur og økosystemfunksjoner. Menneskenes endring av skogene i Norden har vært spesielt sterk i lavlandet i takt med befolkningsøkning og økonomisk utvikling i løpet av særlig de siste 300 årene, og i innlandet og i nord der moderne industriell skogsdrift har utbredt seg fra slutten av 1800-tallet. Siden 1950-tallet har bestandsskogbruket, med flatehogst, planting, og intensiv skogkultur, blitt vidt utbredt. Denne driftsmodellen har vært svært vellykket ved å produsere store mengder tømmer til avvirkning, samtidig som volumet av skog har $\varnothing \mathrm{kt}$ betydelig. Bestandsskogbruket har også medført betydelige endringer i skoglandskapet. 


\section{Naturskogens dynamikk og biologisk mangfold}

I de senere årene har vi utviklet bedre forståelse av den naturlige dynamikken i boreale og tempererte skoger, særlig knyttet til viktigheten av naturlige forstyrrelser for skogstruktur og økosystemfunksjoner. Naturlig skogdynamikk produserer nøkkelressurser og prosesser som er viktige for bevaring av skogens stedegne biologiske mangfold, spesielt en rik tilførsel av død ved og gamle trær, samt et variert landskapsmønster av slike ressurser, noe som er avgjørende for langsiktig overlevelse av mange skogsarter. I tillegg til død ved og gamle trær som følge av naturlig skogdynamikk, vil skogens biomangfold også være begunstiget av rik skog med høyt innhold av edelløvtrær eller osp, selje og rogn, samt av spesielle skogtyper som sumpskog, kalkskog, eller nylig brent skog. Flere skogegenskaper av stor betydning for biologisk mangfold registreres $\mathrm{i}$ de ulike landsskogtakseringene, f.eks. treslag og alder, død ved, og markas produksjonsevne. Det er imidlertid vanskelig å knytte miljøgradienter og lokale miljøfaktorer direkte til verdier for biomangfoldet, og spesielle undersøkelser av habitater og naturtyper er ofte nødvendig for å identifisere et områdes biomangfoldverdier. Det er få studier som eksplisitt knytter skogens egenskaper av verdi for biologisk mangfold til de som bestemmer høye karbonlagre eller opptaksrater. Generelt vil høy verdi for både biologisk mangfold og karbonopptak være knyttet til gammel skog og produktive voksesteder.

\section{Gammel skog og karbonkretsløpet}

Verdens skoger spiller en stor rolle i det globale karbonkretsløpet og tar opp 30-40 \% (2.1 til 2.6 Pg C år-1) av årlige utslipp fra fossile energikilder. Biomasse tar opp mer karbon enn jord og død ved. I boreale og tempererte skoger representerer karbonlageret i jord $60-85 \%$ av skogens totale karbonlager. Estimater av skogens totale årlige karbonbinding i Finland og Norge i de siste to tiårene er henholdsvis 8 og 5,6 Tg C år-1, eller 39 og $46 \mathrm{~g} \mathrm{C} \mathrm{m}^{-2} \mathrm{a}^{-1}$. For Sverige ble akkumulasjonen av karbon i skog anslått til 7,1 Tg C år-1, eller $31 \mathrm{~g} \mathrm{C} \mathrm{m}^{-2} a^{-1}$ mellom 1920 og 2000. Jordsmonnets karbonopptak ble estimert til ca 19-28 \% av det totale karbonopptaket. Foreløpige vurderinger for Danmark tyder også på en økning i skogens karbonlager i løpet av de siste tiårene. Skogene i Fennoskandia representerer om lag $1 \%$ av det globale karbonlageret i skog. Det finnes ikke tilstrekkelige data for å anslå bidraget fra gammel skog til det totale karbonopptaket i Fennoskandia.

Gammel skog ble tidligere antatt å være karbonnøytralt fordi vedlikehold (tap av karbon) vil tilsvare produksjon (opptak av karbon), og karbonlageret vil dermed utvikle seg mot likevekt med atmosfæren med økende alder på skogen. Det har også vært antatt at gammel skog ville bli en kilde til karbon i atmosfæren på grunn av økt dødelighet hos gamle trær som skades av forstyrrelser som brann, storm eller insekter. Flere studier viser imidlertid at skog fungerer som karbonlager langt utover normal alder for avvirkning. Noen mikrometeorologiske (eddy co- 
variance) studier av gamle ( $>200$ år) tempererte skoger i Nord-Amerika tyder på at karbon akkumuleres i økosystemene med ca $150-500 \mathrm{~g} \mathrm{C} \mathrm{m}^{-2}$ $a^{\circ}{ }^{-1}$. Gjentatt prøvetaking av jordkarbon i temperert bøkeskog (250 år) og boreal granskog ( 90 år), begge drevet skog, viser akkumuleringsrater for karbon i jord på 60-160 g C m-2 år-1. Resultater fra flere tidssekvens (chronosequence) studier indikerer at karbon akkumuleres i økosystemene med rater på fra 4,5 til $170 \mathrm{~g} \mathrm{C} \mathrm{m}^{-2}$ år-1 $^{-1}$ for skog som er fra 120 til $>200$ år gammel, med laveste verdier for de eldste skogene. Sammenligninger av skogbestand med ulike aldre tyder også på at eldre skog har høyere karbonlagre enn yngre skog. Selv om endringer i karbonlagre i jord eller i hele økosystemet er vanskelig å overvåke, og de ulike metodene har sine problemer, gir de samlete resultatene av de ulike studiene tydelig indikasjon på at gammel skog fungerer som karbonlager i lang tid. Karbonlageret i biomassen i gammel skog fortsetter å øke med alderen, muligens i flere hundre år, selv om økning i biomasse og dermed karbonopptaket vil avta med økende alder. Også karbonlageret i skogsjord og dødt organisk materiale (spesielt grov død ved) ser ut til å øke med bestandsalderen.

Endringer i karbonlageret i biomassen i boreale og nordlige tempererte skoger er i stor grad bestemt av treslag og bestandsalder, markas produktivitet og de forstyrrelsene området har gjennomgått. Karbonlageret i skogsjord drives av markas produktivitet og jordtype (primært ved produksjon av strø, men også nedbryting), kvalitet på strøet, og lokal topografi og tidligere forstyrrelser. Sammenhengene mellom eksterne drivere og karbonlageret i skogsjord er komplekse, og det er derfor vanskelig å beskrive klare mønstre i responsen til jordas karbonlager på slike drivere. Generelt er variasjonen i jordas karbonlager med ulike miljøforhold mest uttalt for det organiske laget, i mindre grad for mineraljord og det totale karbonlageret $\mathrm{i}$ jord.

\section{Effekter av høsting på karbonlagre}

Moderne skogbruk omfatter ulike driftstiltak som påvirker biomasse, karbonlagre og karbonflukser. Den grunnleggende påvirkningen er fjerning av mye biomasse fra skogen, noe som direkte reduserer karbonlageret i biomassen. Hogst produserer betydelige mengder hogstavfall av ulike størrelser. Det meste vil være av små dimensjoner og nedbrytes ganske raskt over et tiår eller så, men stubber representerer grov død ved med langsom nedbrytingshastighet (som varer opp til hundre år). Karbon fra hogstavfall og naturlig strøproduksjon vil delvis bli innlemmet i det organiske materialet $\mathrm{i}$ jorda, og dels bli sluppet ut $\mathrm{i}$ atmosfæren som $\mathrm{CO}_{2}$. Det er mindre klart hvordan jordas karbonlager vil svare på selve hogstbegivenheten. Etter den første tilførselen av hogstavfall vil lite ekstra strø bli produsert i et flatehogd bestand i noen tiår. I løpet av de første tiårene vil nedbrytingen av strø og organisk materiale i jorda være større enn produksjonen av biomasse, og det samlede karbonlageret vil avta. Noen studier tyder på at mengden av karbon i jordsmonnet 
kan bli redusert etter høsting i flere tiår. Slike effekter av høsting på karbonlageret i jord påvirkes mest av redusert produksjon og tilførsel av strø og død ved, snarere enn av økt nedbrytingshastighet. Totalt karbonlager i drevet skog vil øke med lengre omløpstid, mindre tynning og høsting av hogstavfall og stubber, og mer intensiv skjøtsel etter avvirkning for å sikre rask gjenvekst av bestandet, ved markberedning, planting med produktive arter eller provenienser, og gjødsling.

\section{Kunnskapshull}

Mange studier på karbon i skog og skogens rolle i det globale karbonkretsløpet er publisert de siste 10-15 årene, men det er fortsatt viktige hull i vår kunnskap. Selv om dynamikken i trærnes vekst og i karbonlageret i biomassen er rimelig godt forstått for hogstmoden skog, er slik dynamikk i gammel skog, med trær som nærmer seg sin naturlige levealder, dårlig kjent. Spesielt har vi mangelfull kunnskap om trærnes dødelighet i gammel skog under naturlige dynamikk, og om glenneforyngelse vil kompensere biomassetapet ved naturlig dødelighet. Et annet viktig område vi trenger bedre kunnskap om, er variasjonen i jordas karbonlager med bestandsalder, markas produktivitet og andre miljøfaktorer, samt responsen til karbon i jord på forstyrrelser som hogst og annen biomassehøsting. En sentral problemstilling er om jordas karbonlager vil øke i svært lang tid eller nå en likevekt i løpet av noen tiår eller århundrer, avhengig av skogtype og klimaforhold. Vi trenger også å forbedre vår forståelse av sammenhengene mellom biomangfoldets struktur og økosystemfunksjoner, spesielt hvordan disse samvirker med karbon- og nitrogenkretsløpene og forholdene mellom disse biogeokjemiske kretsløpene. En utfordring som går utover realfagene, er om og hvordan de ulike godene ved biomangfold, karbonbinding, tømmerproduksjon, rekreasjon og andre miljøverdier i skog kan bli behandlet og veid mot hverandre innenfor et felles rammeverk for økosystemtjenester.

\section{Implikasjoner for skogpolitikk og forvaltning}

Selv om klimaeffektene av skogbruk er utfordrende å vurdere realistisk på grunn av komplekse sammenhenger ved endringer i karbonkretsløpet og biofysiske klimapådriv i skog, samt dårlig forståtte substitusjonseffekter ved høsting av biomasse fra skog, kan vi likevel gi noen anbefalinger om skogforvaltning i et klimaperspektiv. Siden skogøkosystemer fortsetter å akkumulere karbon i lang tid, er bevaring av skogens karbonlager ved å øke mengden av gammel skog et troverdig politikkalternativ som også vil fremme bevaring av det biologiske mangfoldet. I skjøttet skog vil forlenget omløpstid også øke skogens karbonlager. Tynning av produksjonsskog og høsting av hogstavfall og stubber vil redusere skogens karbonlager, mens intensiv skogskjøtsel for å sikre rask gjenvekst vil øke det. Det gjenstår imidlertid fortsatt å utvikle mer komplette livsløpsanalyser for å vurdere omfanget på karbonopptaket i gammel skog eller ved skogsdrift med lang omløpstid, sett i forhold til 
alternative driftsformer. Slike livsløpsanalyser kan da fungere som innspill til kombinerte analyser av økosystemtjenester i gammel skog knyttet til karbonbinding, biologisk mangfold og andre miljøverdier.

Vår forståelse av effekten av skogbruk på biologisk mangfold er rimelig god, selv om det er noe uenighet om hvor følsomme arter og økosystemfunksjoner er for ulike skogbrukstiltak. Samlet vil skogens biomangfold bli mest begunstiget av store områder med gammel skog under naturlig dynamikk, med mange gamle og store trær, en rik og variert tilførsel av død ved, og langvarig stabilitet i substrater og mikroklima. I skog under aktiv drift vil både lengre omløpstid, lukkete hogster og bevaring av gamle trær, død ved og buffersoner mot våtmark være gunstig for store deler av skogenes opprinnelige biologiske mangfold.

I den virkelige verden, hvor skogen skal oppfylle flere, delvis motstridende målsettinger, er utfordringen hvordan skogforvaltningen kan differensieres for områder med ulike egenskaper av verdi for biologisk mangfold, karbonbinding eller tømmerproduksjon, og å balansere slike forvaltningsmål best mulig. For å få fram mer realistiske analyser og modeller for å underbygge slike politikkalternativer vil vi trenge bedre kunnskap om endringer i både karbonlagre og biologisk mangfold og hvordan de varierer med miljøegenskaper som klima, terreng, markas produktivitet, og nåværende og tidligere arealbruk. 


\section{Yhteenveto}

Metsät vaikuttavat globaaliin ilmastoon ja muodostavat tärkeän osan hiilen kiertoa. Pohjoismaissa on paljon metsiä ja niihin on varastoitunut suuri määrä hiiltä. Koska metsien biomassa on kasvussa, niihin sitoutuu ilmakehästä hiilidioksidia, joka on tärkeä kasvihuonekaasu. Pohjoismaissa metsät ovat tärkeitä myös biodiversiteetin kannalta, sillä yli puolet kaikista Norjan, Ruotsin ja Suomen alkuperäisistä eliölajeista ja melkein puolet uhanalaisista lajeista elää metsäympäristöissä. Pohjoismaissa metsät tarjoavat myös vapaa-ajanviettomahdollisuuksia ja luovat pohjan taloudellisesti tärkeälle metsäsektorille.

\section{Raportin tavoitteet}

Tarkastelemme tutkimustietoon perustuen vanhojen metsien merkitystä hiilen kierrossa. Vertaamme hiilensidontakykyä metsien tarjoamiin muihin ekosysteemipalveluihin $\mathrm{mm}$. biodiversiteetin suojeluun. Vanhojen metsien merkitys hiilen kierrossa on paljon vähemmän tutkittu aihe kuin niiden rooli biodiversiteetin suojelussa. Määrittelimme vanhojen metsien olevan huomattavasti päätehakkuuikäistä vanhempia metsiä, joissa monien puuyksilöiden ikä lähenee lajin luontaista maksimi-ikää.

\section{Metsien kehitys ja ihmisvaikutus}

Pohjoismaiden metsät ovat kehittyneet viime jääkauden jälkeen ilmaston lämmettyä ja lajien vaellettua pohjoiseen. Ihmiset ovat hyödyntäneet metsiä monipuolisesti koko jääkauden jälkeisen ajan ja täten vaikuttaneet metsien rakenteeseen ja dynamiikkaan. Ihmisten vaikutus Pohjoismaiden metsiin on ollut voimakasta eteläisillä alankoalueilla väentiheyden lisäännyttyä nopeasti viimeisen kolmensadan vuoden aikana ja pohjoisempana 1800-luvun loppupuolelta lähtien metsäteollisuuden kehityksen seurauksena. 1950-luvulta lähtien metsikkömetsätalous avohakkuineen, istutuksineen ja intensiivisine metsänhoitoineen on ollut vallitsevaa ja sen avulla on menestyksellisesti onnistuttu turvaamaan puutavaran saanti samanaikaisesti lisäten metsien puuston kokonaistilavuutta. Tämänkaltainen metsien käsittely on voimakkaasti muuttanut myös metsämaisemaa.

\section{Metsien luontainen dynamiikka ja biodiversiteetti}

Viimeaikaisten tutkimusten myötä on opittu ymmärtämään boreaalisten ja temperaattisen metsien dynamiikkaa - erityisesti luonnonhäiriöiden merkitys metsien rakenteen ja ekosysteemien toiminnan selittäjänä. Luonnollinen dynamiikka tuottaa elinympäristöjä ja prosesseja, jotka ovat tärkeitä alkuperäiselle metsien biodiversiteetille. Monille lajeille merkityksellistä on runsas lahopuun määrä, vanhojen puuyksilöiden esiintymi- 
sellä ja näiden resurssien vaihtelulla laajassa mittakaavassa. Metsien luonnondynamiikan lisäksi metsien biodiversiteetille on hyötyä metsien jaloista lehtipuista, haavoista, pajuista ja pihlajista kuten myös erilaisista metsäympäristöistä kuten suometsistä, kalkkikivimetsistä tai äskettäin palaneista metsistä. Monia metsien biodiversiteetin kannalta keskeisiä asioita, kuten puulajeja, metsiköiden ikiä, lahopuun määrää ja kasvupaikkan ominaisuuksia, mitataan kansallisissa metsävarojen inventaarioissa. Valittavasti kuitenkin tavanomaisissa inventaariossa mitattuja muuttujia on vaikea liittää suoraan biodiversiteettiin ja usein tarvitaan lisäinventointeja alueen arvon määrittämiseksi biodiversiteetin suojelun kannalta. Muutamissa tutkimuksissa on kuitenkin arvioitu metsien arvoa sekä biodiversiteetin suojelun että hiilivaraston tai sen kasvunopeuden kannalta. Tyypillisesti sekä biodiversiteettiarvon että hiilivaraston kannalta arvokkaimmat metsät ovat vanhoja ja viljavalla maaperällä.

\section{Vanhat metsät ja hiilen kierto}

Metsien merkitys globaalissa hiilen kierrossa on suuri sillä ne sitovat 30-40 \% (2.1-2.6 Pg hiiltä vuodessa) vuosittaisista fossiilisten polttoaineiden käytön hiilipäästöistä. Puuston biomassa on suurempi hiilinielu (eli hiilivaraston kasvu on nopeampaa) kuin maaperä ja lahopuusto. Kuitenkin boreaalisessa ja temperaattisessa metsässä maaperän hiilivarasto on suurempi eli 60-85 \% koko metsän hiilivarastosta. Suomen ja Norjan metsien hiilivaraston kasvun on arvioitu olleen kahtena viime vuosikymmenenä 8,0 ja 5,6 Tg vuodessa tai 39 ja 46 g hiiltä neliömetrille vuodessa. Ruotsissa keskimääräinen hiilivaraston kasvu oli 7,1 Tg hiiltä vuodessa eli 31 g hiiltä neliömetrille vuodessa vuosien 1920 ja 2000 välillä. Metsien maaperän nielun on arvioitu olleen 19-28 \% metsien kokonaisnielusta. Alustavat arviot viittaavat metsien hiilivaraston kasvuun myös Tanskassa. Fennoskandian metsien osuus koko maailman metsien hiilinielusta on noin $1 \%$. Valitettavasti aineiston puutteen takia vanhojen metsien osuutta Fennoskandian metsien koko hiilinielusta ei pystytä arvioimaan.

Vanhojen metsien uskottiin aiemmin olevan tasapainossa siten että hiilivaraston koko ei muuttuisi. Toisinaan on myös oletettu että vanhat metsät muuttuvat hiilen lähteiksi lisääntyneen myrskyistä ja hyönteisistä johtuneiden tuhojen takia. Uudempien tutkimustulosten perusteella vanhat metsät ovat kuitenkin hiilinieluja. Muutamat kaasutasemittaukset pohjoisamerikkalaisista lauhkean vyöhykkeen yli 200 vuotiaista metsistä viittaavat hiilivaraston kasvuun 150-500 g vuosivauhdilla neliömetrillä. Toistettujen maaperän hiilivarastomittausten perusteella 250-vuotiaan lauhkean vyöhykkeen pyökkimetsän ja 90 -vuotiaan boreaalisen kuusikon maan hiilivarastot näyttäisivät kasvavan 60-160 g vuosivauhdilla neliömetrille. Lukuisten kronosekvenssi tutkimusten (joissa oletetaan kaikkien tutkittavien metsiköiden erojen johtuvan iästä) perusteella hiilivarastonkasvunopeus olisi noin 4,5-170 g vuodessa neliömetrille metsien iän vaihdellessa 120 ja yli 200 vuoden välillä. Kasvunopeus oli alhaisempaa 
vanhemmissa metsissä. Myös eri-ikäisten metsiköiden vertailut osoittavat että vanhoissa metsissä on enemmän hiiltä kuin nuorissa. Vanhojen metsien hiilivaraston suuruutta on vaikea tutkia ja jokaiseen menetelmään liittyy heikkouksia, mutta kaikki menetelmät viittaavat selvästi vanhojen metsien toimivan pitkään hiilinieluina. Biomassan hiilivaraston kasvu jatkuu pitkään - kenties satoja vuosia - vaikkakin kasvunopeus heikkenee metsän ikääntyessä. Myös maaperän ja lahopuuston hiilivarastot näyttäisivät kasvavan metsän ikääntyessä.

Biomassan hiilivarastojen muutokset johtuvat lähinnä puulajista, metsikön iästä, maaperän viljavuudesta, ilmastosta ja häiriöhistorista. Metsämaan hiilivarasto riippuu metsän tuotoskyvystä ja maaperätyypistä - jotka vaikuttavat lähinnä kariketuotantoon mutta myös hajoamiseen - sekä karikkeen laadusta, paikallistopografiasta ja häiriöhistoriasta. Näiden eri tekijöiden vaikutuksia maaperän hiilivaraston suuruuteen on kuitenkin vaikea erotella. Tyypillisesti kyseisten tekijöiden vaikutus on selkeämpi orgaaniseen kerrokseen kuin kivennäismaahan.

\section{Hakkuiden vaikutus hiilivarastoon}

Monet nykyaikaisen metsänhoidon toimenpiteistä vaikuttavat metsien hiilivarastoihin ja -virtoihin. Kaikkein voimakkaimmin vaikuttaa hakkuu, jossa biomassaa poistetaan ja siten pienennetään suoraan metsän hiilivarastoa. Hakkuissa syntyy suuri määrä hakkutähdettä, joka hajoaa suhteellisen nopeasti suurin piirtein vuosikymmenessä, jos tätä biomassaa ei korjata bioenergian tuottamiseksi. Kannot toisaalta hajoavat paljon hitaammin säilyen jopa vuosisadan. Hakkuutähteistä tai elävistä puista syntyvän karikkeen hajotessa hiili vapautuu pääosin ilmakehään osan päätyessä maan hiilivarastoon. Avohakkuussa syntyvän valtavan karikemäärän jälkeen karikesadanta on pieni muutaman vuosikymmenen. Ensimmäisten avohakkuuta seuraavien vuosikymmenten aikana karikkeen ja maan hiilivaraston hajoamisen aiheuttamat hiilipäästöt ylittävät kasvavien puiden nielemän hiilen ja metsän hiilivarasto pienenee. Joidenkin tutkimuksien mukaan maaperän hiilivarasto olisi pieni vuosikymmeniä hakkuun jälkeen. Tämä johtuu ennen kaikkea pienentyneestä karikkeen ja lahopuuston tuotannosta eikä nopeutuneesta hajoamisesta. Talousmetsissä kiertoajan keskimääräistä hiilivarastoa voidaan suurentaa pidentämällä kiertoaikaa, vähentämällä harvennuksia ja hakkutähteen ja kantojen korjuuta sekä varmistamalla nopea taimikon kehitys maanmuokkauksella, nopeakasvuisten taimien istutuksella ja lannoituksella.

\section{Tutkimustarve}

Metsien hiilestä ja sen merkityksestä globaalin hiilen kiertoon on julkaistu paljon tutkimuksia viimeisten $10-15$ vuoden aikana, mutta vieläkin tiedoissamme on monia merkittäviä aukkoja. Puiden kasvun ja biomassan hiilivaraston kehitys ymmärretään suhteellisen hyvin normaalin talousmetsien päätehakkuuikään saakka, mutta paljon huonommin metsille, joiden puiden ikä lähenee biologista maksimi-ikää. Emme tiedä 
korvaako aukkoihin syntyneiden puiden kasvu kuolevien puiden hajoamisesta seuraavat päästöt. Toinen keskeinen kysymys liittyy maan hiilivarastoon ja sen potentiaaliseen vaihteluun metsikön iän, kasvupaikan puuntuotoskyvyn ja muiden tekijöiden vaikutuksesta. Myöskään hakkuiden ja hakkuutähteiden ja kantojen korjuun vaikutuksia maaperän hiilen ei ymmärretä riittävän hyvin. Ratkaisematta on myös kysymys kasvaako maaperän hiilivarasto seuraavaan metsäpaloon saakka vai pysähtyykö varaston kasvu vuosikymmenten tai -satojen kuluttua riippuen metsätyypistä ja ilmastosta. Meidän pitäisi myös ymmärtää paremmin biodiversiteetin ja ekosysteemin toiminnan suhde, erityisesti miten nämä linkittyvät hiilen ja typen kiertoihin ja miten nämä kierrot liittyvät toisiinsa. Biodiversiteetin, hiilen varastoinnin, puun tuotannon, virkistyskäytön ja muiden hyötyjen yhteensovittaminen on haastava yhteiskuntatieteellinen kysymys.

\section{Metsäpoliittiset johtopäätökset}

Metsienkäsittelyn ilmastovaikutusten arviointi on haastavaa, koska ne eivät rajaudu ainoastaan tässä kuvattuihin hiilivaikutuksiin vaan metsät myös vaikuttavat suoremmin ilmastoon esimerkiksi säteilyn heijastumisen (albedo) ja huonosti tunnettujen substituutiovaikutusten kautta. Voimme silti tehdä alustavia suosituksia metsien käsittelystä ilmaston näkökulmasta. Koska metsäekosysteemien hiilivarasto kasvaa pitkään metsien ikääntyessäkin, on vanhojen metsien suojelu hyödyllistä biodiversiteettivaikutusten lisäksi myös hiilitaseiden kannalta. Talousmetsissä pidennetty kiertoaika lisää keskimääräisen hiilivaraston suuruutta. Harvennukset sekä hakkuutähteiden ja kantojen korjuu pienentävät metsien hiilivarastoa kun taas intensiivinen taimikonhoito nuoren metsän kehityksen nopeuttamiseksi kasvattaa hiilivarastoa. Valitettavasti kattavat elinkaarianalyysit vanhojen metsien tai pidennettyjen kiertoaikojen hiilensidonnan vertaamiseksi tavanomaisiin käsittelyketjuihin vielä puuttuvat.

Metsätalouden vaikutukset biodiversiteetille tunnetaan suhteellisen hyvin, vaikkakin lajien ja ekosysteemin herkkyys monille toimenpiteille on epäselvä. Metsien biodiversiteetin suojelun kannalta arvokkaimpia ovat laajat vanhojen metsien alueet, joissa vallitsee luonnollinen häiriödynamiikka, joissa on paljon vanhoja ja suuria puita sekä monen laatuista lahopuuta ja stabiiliutta kasvualustoissa ja mikroilmastoissa. Talousmetsissä pidennetyt kiertoajat, jatkuva kasvatus, vanhojen puiden, lahopuun ja vesistöjen suojavyöhykkeiden suojelu hyödyttävät merkittävää osaa alkuperäisestä biodiversiteetistä.

Koska metsäpoliittiset tavoitteet ovat moninaisia ja ristiriitaisia, on suuri haaste optimoida metsänhoito parhaalla mahdollisella tavalla palvelemaan biodiversiteetin suojelua, hiilen varastointia ja puun tuotosta. Jotta pystyttäisiin realistisempiin metsäpolitiikkaa palveleviin analyyseihin ja malleihin tarvitaan enemmän ymmärrystä ilmaston, maastonmuotojen, puuntuotospotentiaalin sekä menneen ja nykyisen maankäytön vaikutuksista hiilivarastoon, biodiversiteettiin ja niiden vaihteluun. 


\section{Appendix}

\subsection{Abbreviations and acronyms}

\begin{tabular}{|c|c|}
\hline Abbreviation & Explanation \\
\hline AGB & AboveGround Biomass \\
\hline ANPP & Aboveground Net Primary Productivity \\
\hline GPP & $\begin{array}{l}\text { Gross Primary Productivity: production of organic matter from atmospheric or aquatic } \mathrm{CO}_{2} \text { by } \\
\text { plant photosynthesis }\end{array}$ \\
\hline LAl & Leaf Area Index: a measure of the photosynthetically active leaf surface per unit ground area \\
\hline NBP & $\begin{array}{l}\text { Net Biome Productivity: net rate of } \mathrm{C} \text { accumulation across different ecosystems on longer time } \\
\text { scales, including effects of natural disturbances or management }\end{array}$ \\
\hline NECB & Net Ecosystem Carbon Balance: total rate of organic $\mathrm{C}$ accumulation (or loss) from ecosystems \\
\hline NEE & $\begin{array}{l}\text { Net Ecosystem Exchange: net exchange of carbon of an ecosystem with its surroundings; } \\
\text { equivalent to NEP but most often used when measuring gas exchange rates by eddy covariance } \\
\text { methods }\end{array}$ \\
\hline NEP & Net Ecosystem Productivity: GPP - Ra - Rh; or the rate of change in C stocks within an ecosystem \\
\hline NPP & Net Primary Productivity: GPP - Ra; \\
\hline Ra & $\begin{array}{l}\text { Autotrophic respiration: the metabolic work by plants for maintenance, construction and ion } \\
\text { uptake }\end{array}$ \\
\hline $\mathrm{Rh}$ & $\begin{array}{l}\text { Heterotrophic respiration: the } \mathrm{CO}_{2} \text { produced by decomposition of plant material by organisms } \\
\text { using plant material as an energy source, mainly microorganisms and herbivores }\end{array}$ \\
\hline FWD & $\begin{array}{l}\text { Fine woody debris, i.e., fine dead woody (generally }<10 \mathrm{~cm} \text { in diameter), often includes logging } \\
\text { residues }\end{array}$ \\
\hline CWD & Coarse woody debris, i.e., coarse dead wood, typically logs or snags $>10 \mathrm{~cm}$ in diameter \\
\hline
\end{tabular}

\subsection{Tree species and their scientific names}

Some common native trees in the Nordic countries, mentioned in the text by their full or short names (e.g. spruce, birches).

\begin{tabular}{lll}
\hline Main vegetation zone & English common name & Scientific name \\
\hline Boreal & Norway spruce & Picea abies \\
Boreal & Scots pine & Pinus sylvestris \\
Boreal & Silver birch & Betula pendula \\
Boreal & Downy birch & Betula pubescens \\
Boreal & Mountain birch & Betula pubescens ssp. czerepanovii \\
Boreal & Grey alder & Alnus incana \\
Boreal & Aspen & Populus tremula \\
Boreal & Rowan & Sorbus aucuparia \\
Boreal & Goat willow & Salix caprea \\
Boreal & Willows & Salix spp. \\
Temperate & Common ash & Fraxinus excelsior \\
Temperate & Common beech & Fagus sylvatica \\
Temperate & Common hazel & Corylus avellana \\
Temperate & Hornbeam & Carpinus betulus \\
Temperate & Small-leafed lime & Tilia cordata \\
Temperate & Norway maple & Acer platanoides \\
Temperate & English oak & Quercus robur \\
Temperate & Sessile oak & Quercus petrea \\
Temperate & Common alder & Alnus glutinosa \\
\hline
\end{tabular}


Other tree species mention in the text

\begin{tabular}{llll}
\hline Continent & Main vegetation region & English common name & Scientific name \\
\hline N America & Rocky Mountains & Ponderosa pine & Pinus ponderosa \\
N America & Pacific NW, Rocky Mts & Lodgepole pine & Pinus contorta \\
N America & Pacific NW & Western larch & Larix occidentalis \\
N America & Pacific NW & Douglas fir & Pseudotsuga menziesii \\
N America & Pacific NW & Sitka spruce & Picea sitchensis \\
N America & Pacific NW & Grand fir & Abies grandis \\
\hline
\end{tabular}


Nordic Council of Ministers

Ved Stranden 18

DK-1061 Copenhagen K

www.norden.org

\section{Biodiversity, carbon storage and dynamics of old northern forests}

Forests play a key role in the global climate system. The Nordic countries have extensive forests with large and growing tree biomass that captures substantial amounts of the greenhouse gas carbon dioxide. Nordic forests are also important for biodiversity, with complex ecosystems providing habitats for about half of all known native species and threatened species in Finland, Norway, and Sweden. Forests also supply the basis for the economically important forest sector. In this report we review current knowledge on the role of old forests in the carbon cycle, their natural dynamics and importance for biodiversity. Based on evidence in the literature, it is clear that old forests continue to accumulate carbon for a long time, well past the normal logging age. The carbon uptake of old forests represents an important co-benefit for the well-documented value of old forests for biodiversity.

TemaNord 2013:507

ISBN 978-92-893-2510-3

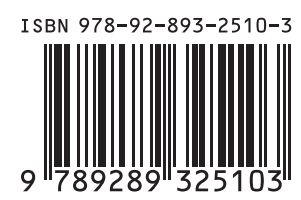

